ISABELA MARTINS ANGELO

\title{
RECOMENDAÇÕES PARA O DESENVOLVIMENTO DE AMBIENTES DE PROGRAMAÇÃO INCLUSIVOS PARA CRIANÇAS CEGAS
}


ISABELA MARTINS ANGELO

\title{
RECOMENDAÇÕES PARA O DESENVOLVIMENTO DE AMBIENTES DE PROGRAMAÇÃO INCLUSIVOS PARA CRIANÇAS CEGAS
}

\author{
Dissertação apresentada à Escola Po- \\ litécnica da Universidade de São Paulo para \\ obtenção do Título de Mestre em Ciências.
}


ISABELA MARTINS ANGELO

\section{RECOMENDAÇÕES PARA O DESENVOLVIMENTO DE AMBIENTES DE PROGRAMAÇÃO INCLUSIVOS PARA CRIANÇAS CEGAS}

Dissertação apresentada à Escola Po-
litécnica da Universidade de São Paulo para
obtenção do Título de Mestre em Ciências.

Área de Concentração:

Sistemas Eletrônicos

Orientadora:

Profa. Dra. Roseli de Deus Lopes 
Este exemplar foi revisado e alterado em relação à versão original, sob responsabilidade única do autor e com a anuência de seu orientador.

São Paulo, de de 20

Assinatura do autor

Assinatura do orientador

Angelo, Isabela Martins

Recomendaçōes para o Desenvolvimento de Ambientes de Programação Inclusivos para Crianças Cegas / I. M. Angelo - versão corr. - São Paulo, 2018. $125 \mathrm{p}$.

Dissertação (Mestrado) - Escola Politécnica da Universidade de São Paulo. Departamento de Engenharia de Sistemas Eletrônicos.

1.Deficiência Visual 2.Inclusão escolar (Deficiência) 3.Interface humano computador I.Universidade de São Paulo. Escola Politécnica. Departamento de Engenharia de Sistemas Eletrônicos II.t. 


\section{AGRADECIMENTOS}

Começo agradecendo a Deus por todas as pessoas que colocou em meu caminho e todas as coisas que me providenciou.

Agradeço à meus pais e irmã pelo amor e apoio incondicional. Ao meu namorado pelo carinho, companheirismo e pela paciência. E também meu cunhado pela ajuda com a escrita e troca de ideias.

Agradeço à minha orientadora, Roseli, pela confiança em me deixar navegar pelo mundo do conhecimento científico escolhendo meus caminhos e pela inspiração em seu empenho pela melhoria na educação e pela maior acessibilidade para pessoas com deficiência.

Agradeço ao pessoal do CITI-USP, começando pelo Marcelo Archanjo pela paciência em ouvir minhas ideias e me auxiliar durante meu trabalho. À Irene, Alexandre, Leandro, Cassia, Yohan, Erich, Raphael, Marcos, Jade, Marcia, Adriana, Luma e Rodrigo pela ótima companhia e ambiente de trabalho incrível.

Agradeço à Rosabelli, pessoa incrível, por todo auxílio durante minha viagem ao MIT. Ao Leo Burd, outra pessoa incrível, que ainda não descobri como agradecer por todo auxílio, paciência e atenção. Ao Matt Taylor e John Maloney por acreditarem em minha ideia de projeto e pela disposição em me auxiliar no desenvolvimento. Ao Eric Rosenbaum, Tim e toda equipe do Scratch por me ajudarem no desenvolvimento do meu código. Ao Mitchel Resnick por criar esta equipe incrível e pela sua capacidade de inspirar a todos.

Por fim, agradeço à Olga por acreditar em meu projeto e me auxiliar com testes além de me surpreender com seu jeito atencioso e prestativo. E a todos da equipe da escola onde alguns testes foram realizados e cujo trabalho que desenvolvem com crianças, adolescentes e adultos é incrível. 
"Humans are allergic to change. They love to say, "We've always done it this way. "I try to fight that. That's why I have a clock on my wall that runs counter-clockwise."

--Rear Admiral Grace Murray Hopper 


\section{RESUMO}

A inclusão de crianças com deficiência em escolas regulares, ocorrida seguindo a Lei 13.146 de 06 de julho de 2015, que institui a Lei Brasileira de Inclusão da Pessoa com Deficiência, exige que as atividades escolares sejam acessíveis a todas as crianças. Entre as atividades escolares, as atividades de programação têm se espalhado nas escolas devido aos benefícios gerados nas habilidades dos alunos, como criatividade e pensamento lógico. Atualmente, essas atividades utilizam principalmente ambientes de programação em blocos, como o Scratch, que focam em aspectos visuais para interação, contando com cores, formatos e utilização do mouse. Nesse contexto, é de grande importância o estudo de interfaces de programação para que crianças com deficiência visual possam ser incluídas e participem em conjunto com as outras crianças. Este projeto busca investigar este tema, bem como propor e avaliar um sistema para atividades de introdução à programação para crianças cegas e videntes. Foi proposto um sistema formado por peças tangíveis, em que os blocos digitais foram substituídos por peças físicas com formas para reconhecimento tátil e respostas auditivas. Foi adotado um modelo cíclico para o desenvolvimento do protótipo que garantiu duas etapas de testes com usuários. Na primeira etapa foram 4 participantes videntes, sendo que três participaram vendados, e a partir das observações foram gerados novos requisitos e modificações no protótipo. Na segunda etapa participaram 2 crianças cegas e os resultados destes testes geraram requisitos específicos para a utilização do sistema por crianças cegas. Este trabalho traz como contribuição final um conjunto de recomendações para o desenvolvimento de sistemas que permitam a crianças cegas e videntes brincarem juntas em atividades de programação.

Palavras-Chave - Acessibilidade. Desenho Universal. Interface de Usuário Tangível. Deficiência visual. Introdução à programação. Scratch. 


\section{ABSTRACT}

The inclusion of children with disabilities in regular schools, following Law 13,146 of July 6, 2015, which establishes the Brazilian Law on the Inclusion of Persons with Disabilities, requires that school activities be accessible to all children. Among school activities, programming activities have spread in schools because of the benefits generated in students' skills such as creativity and logical thinking. Currently, these activities mainly use blocks programming environments, such as Scratch, that focus on visual aspects for interaction, counting on colors, shapes and mouse usage. In this context, it is of great importance to study programming interfaces so that children with visual impairment can be included and participate together with other children. This project seeks to investigate this theme as well as to propose and evaluate a system for introductory programming activities for blind and sighted children. It was proposed a system formed by tangible pieces in which the digital blocks were replaced by physical pieces with forms for tactile recognition and auditory responses. It was adopted a cyclical model for the development of the prototype that guaranteed two stages of testing with users. In the first stage, four sighted participants, three were blindfolded among them, and and from the first observations were generated new requirements and modifications in the prototype. The second stage involved 2 blind children and the results of these tests generated specific requirements for the use of the system by blind children. This work brings as final contribution a set of recommendations for the development of systems that allow blind and sighted children to play together in programming activities.

Keywords - Accessibility. Universal Design. Tangible User Interface. Visual disability. Introduction to programming. Scratch 


\section{LISTA DE FIGURAS}

$1 \quad$ Ambiente de programação do Scratch 2.0 . . . . . . . . . . . . . . . . . . . 14

2 Ambiente de programação do Scratch 2.0 e suas partes principais . . . . . 19

3 Uma pilha de blocos com o primeiro bloco sendo o bloco de evento quando a bandeira verde for pressionada . . . . . . . . . . . . . . . . . . 20

$4 \quad$ Botões de bandeira verde e de parar a execução do código . . . . . . . . . . . 20

5 Exemplo de duas tentativas de encaixe de parâmetros . . . . . . . . . . . . 21

6 Exemplo de bloco de repetição à esquerda e este bloco com uma sequência de blocos em sua abertura à direita . . . . . . . . . . . . . . . . . . . . 22

$7 \quad$ Exemplo de Micromundo Scratch com o tema casa interativa . . . . . . . . 23

$8 \quad$ Representação de elementos gráficos em interface tangível . . . . . . . . . . . . 24

$9 \quad$ AlgoBlock criado por Suzuki e Kato[(1993)] . . . . . . . . . . . . . . . . 25

10 Figuras dos ambientes de linguagem de programação tangível . . . . . . . . 27

11 Relação entre desenhos acessível, universal, adaptável e transgeracional . 29

12 Sistema desenvolvido por Howard, Park e Remy $[(2012)]$. . . . . . . . . . . 34

13 Exemplos tirados do artigo para montagem dos problemas a serem resolvidos nos testes com usuários . . . . . . . . . . . . . . . . . . . . . . . 35

14 Impressão 3D de um mapa gerado a partir de análises de mensagens no Twitter . . . . . . . . . . . . . . . . . . . 37

15 Figuras retiradas do artigo de Kakehashi et al. [2013) mostrando os blocos de programação, o espaço em madeira para colocação dos blocos e o robô . 39

$16 \quad$ Figuras retiradas do artigo de Barros et al. $[2017)$. . . . . . . . . . . . . . 40

17 Figuras retiradas do artigo de Thieme et al. $(2017)$ demonstrando o sistema e exemplos de interações entre as crianças enquanto brincam com o sistema 42

18 Etapas do desenvolvimento do protótipo seguindo Metodologia PDCA . . . 52

19 Arquitetura do protótipo do sistema $\ldots \ldots \ldots$. . . . . . . . . . 57 
20 Protótipo do sistema e suas partes principais . . . . . . . . . . . . . 58

21 Imagem da estrutura de Lego à esquerda e webcam à direita $\ldots . . . .58$

22 Peça tangível da esquerda é criada no Scratch como um bloco . . . . . . . 59

23 Fluxograma do código desenvolvido . . . . . . . . . . . . . . . . 61

$24 \quad$ Fluxograma do código para criação de blocos no Scratch . . . . . . . . . . 62

25 Exemplos das peças de comando e parâmetros . . . . . . . . . . . 66

26 Triângulos em relevo identificam peças de comando de som e seus parâmetros 67

27 Círculos em relevo identificam peças de comando de controle e seus parâmetros 68

28 Encaixe entre peças de comandos $\ldots \ldots \ldots$. . . . . . . . . . . . . 69

29 Encaixe dos parâmetros f . . . . . . . . . . . . . . 70

30 Indentação gerada pelas peças de início e fim de repetição . . . . . . . . . 71

31 Gráfico dos desempenhos dos participantes no teste inicial . . . . . . . . . 76

32 Exemplo de utilização da condição se uma tecla for pressionada e sua representação em blocos no Scratch 3.0 . . . . . . . . . . . . . . . . . . . . . 79

33 Velcro colocado no encaixe das peças de comando $\ldots . . . . . .79$

34 Braille presente nas peças de parâmetro . . . . . . . . . . . . . . . 80

35 Exemplo de código com peças tangíveis à esquerda e uma versão mais nova do Scratch VM Playground com o código à direita . . . . . . . . . . . . . . 80

$36 \quad$ Gráfico dos desempenhos dos participantes no teste de usabilidade . . . . . 83

37 Fluxograma do código do protótipo do sistema com checagem do reconhecimento de marcadores em verde . . . . . . . . . . . . . . . . . . . 86

38 Conjunto de peças testadas no teste do reconhecimento de marcadores. . . 88 


\section{LISTA DE TABELAS}

1 Tabela com os principais aspectos dos trabalhos correlatos. . . . . . . . . . 44

$2 \quad$ Perfil dos participantes do teste inicial $\ldots \ldots \ldots \ldots$. . . . . . . . 74

3 Tabela explicativa da observação de desempenho dos participantes no teste inicial . . . . . . . . . . . . . . . . . . . . . . 74

$4 \quad$ Respostas dos participantes ao questionário do teste inicial . . . . . . . . . 75

$5 \quad$ Perfil dos participantes do teste de usabilidade . . . . . . . . . . . . . . 82

6 Tabela explicativa da observação de desempenho dos participantes no teste de usabilidade . . . . . . . . . . . . . . . . . . . . . 83

1 Tabela de avaliação pelo observador do desempenho na realização das atividades pelo usuário no teste inicial . . . . . . . . . . . . . . . . . . . . . . 98

2 Tabela de avaliação pelo observador do desempenho na realização das atividades pelo usuário no teste de usabilidade . . . . . . . . . . . . . . . . . 99 


\section{SUMÁRIO}

\begin{tabular}{lll}
\hline 1 & Introdução & 13
\end{tabular}

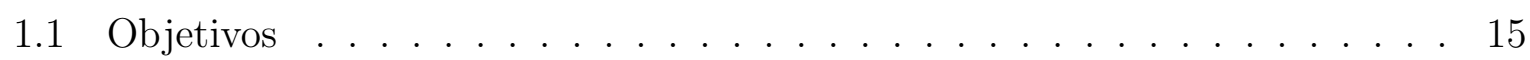

1.2 Hipótese $\ldots \ldots \ldots \ldots \ldots \ldots$

1.3 Organização do Documento . . . . . . . . . . . . . . . . . . . . . 15

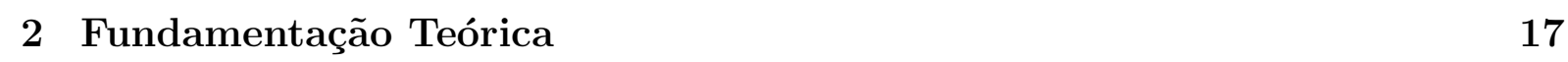

2.1 Introdução à Programação $\ldots$. . . . . . . . . . . . . . . . . . . . . 17

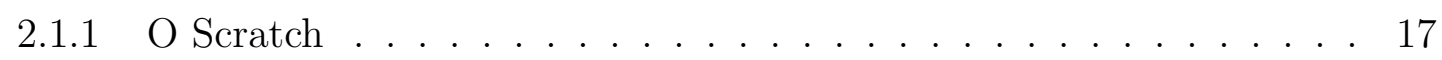

2.1.1.1 O ambiente de programação . . . . . . . . . . . . . . . 19

2.1.1.2 Conceitos de programação . . . . . . . . . . . . . 21

2.1 .1 .3 Micromundos Scratch . . . . . . . . . . . . 23

2.2 Interface de Usuário Tangível $\ldots \ldots$. . . . . . . . . . . . . . . . . . . . . 24

2.3 Deficiência Visual . . . . . . . . . . . . . . . . . . . . . . . . . . . . . . . . . . 28

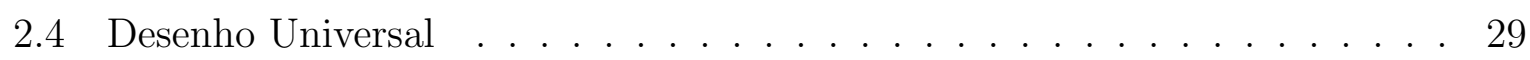

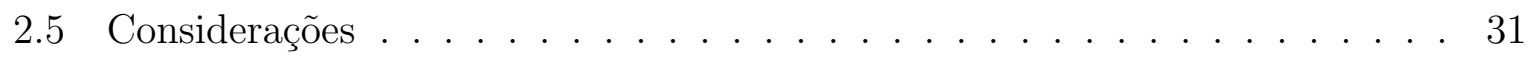

3 Introdução à programação para crianças com deficiência visual 32

3.1 Robótica . . . . . . . . . . . . . . . . . . . . . . . . . . . 32

$3.2 \quad$ Ensino de pensamento algorítmico usando modelos hápticos . . . . . . . . 35

3.3 Impressão, gerenciamento de crises e Twitter . . . . . . . . . . . . . . . 35

3.4 Programação em blocos . . . . . . . . . . . . . . . . . . . . 36

3.5 Interface tangível e aprendizado colaborativo . . . . . . . . . . . . . . . 41

3.6 Síntese dos trabalhos correlatos . . . . . . . . . . . . . . . . . . 43

3.7 Considerações $\ldots \ldots \ldots \ldots \ldots \ldots$. . . . . . . . . . . . . . . . . . . 50 
$\begin{array}{lll}4 & \text { Materiais e Métodos } & 51\end{array}$

$\begin{array}{lll}5 & \text { Proposta de sistema } & 54\end{array}$

5.1 Requisitos . . . . . . . . . . . . . . . . . . . 54

5.1 .1 Requisitos funcionais . . . . . . . . . . . . . . . . . . 54

5.1 .2 Requisitos não funcionais . . . . . . . . . . . . . . . . . . . 55

$5.2 \quad$ Arquitetura do protótipo do sistema $\ldots \ldots \ldots \ldots$. . . . . . . 56

5.3 Primeiros protótipos e testes $\ldots \ldots \ldots \ldots$

5.3 .1 Pré-testes e teste inicial . . . . . . . . . . . . . . . . . 72

5.3 .1 .1 Pré-teste . . . . . . . . . . . . . . . . 73

$5.3 .1 .2 \quad$ Aplicação do teste inicial . . . . . . . . . . . . . . 73

5.3 .2 Considerações . . . . . . . . . . . . . . . . . . . . . 77

$5.4 \quad$ Protótipo final e testes de usabilidade . . . . . . . . . . . . . . . . 78

5.4 .1 Teste de usabilidade . . . . . . . . . . . . . . . . . . . . . 81

$5.4 .1 .1 \quad$ Aplicação do teste . . . . . . . . . . . . . . . . . 82

$5.4 .1 .2 \quad$ Considerações . . . . . . . . . . . . . . . . . . . . . . . 84

5.4 .2 Teste de reconhecimento de marcadores do sistema . . . . . . . . . 85

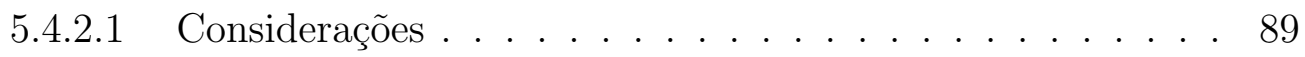

\begin{tabular}{lll}
\hline & Conclusões & 90
\end{tabular}

6.1 Discussão dos principais resultados . . . . . . . . . . . . . . . . . . 90

6.2 Recomendações para desenvolvimento de sistema $\ldots . . . . . .91$

6.3 Dificuldades enfrentadas e limitações da pesquisa $\ldots . . . . . . .92$

6.4 Trabalhos Futuros . . . . . . . . . . . . . . . . . . . . . 93

\begin{tabular}{ll}
\hline Referências & 95
\end{tabular}

\begin{tabular}{|ll}
\hline Apêndice A - Guia para coleta de dados do teste inicial & 98
\end{tabular} 


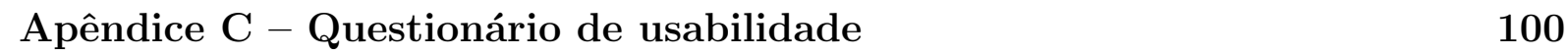

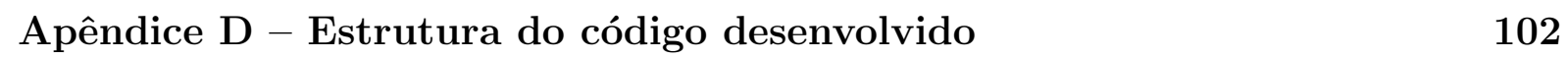

\begin{tabular}{|ll}
\hline Apêndice E - Código desenvolvido & 103
\end{tabular}

\begin{tabular}{|ll}
\hline Anexo A - Parecer Consubstanciado do CEP & 117
\end{tabular}

A.1 Parecer inicial . . . . . . . . . . . . . . . . . . . . . 117

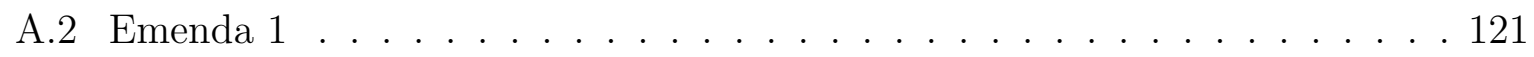

A.3 Emenda 2 . . . . . . . . . . . . . . . . . . . . . . 124 


\section{INTRODUÇÃO}

Segundo Resnick et al. (2009), atividades de programação e compartilhamento de projetos no ambiente Scratch propiciam a aprendizagem de conceitos matemáticos e de computação bem como contribuem para pensar criativamente, raciocinar sistematicamente e trabalhar colaborativamente, que são habilidades essenciais para o século XXI. A fim de desenvolver estas habilidades, muitas escolas de Educação Básica ao redor do mundo e no Brasil têm adotado o uso do ambiente Scratch (Maloney et al., 2004, 2010) em atividades inseridas em sua grade curricular ou em atividades extra-curriculares. A autora desta dissertação foi coautora de artigo de revisão sistemática sobre o uso educacional do Scratch no Brasil (Eloy, Lopes e Angelo, 2017). O ambiente Scratch é utilizado tanto com crianças como com adolescentes e não exige conhecimento de sintaxe para criação de códigos. Outros ambientes de programação de blocos são Alice Đe Snap! 2 .

O Scratch, que é o foco do presente trabalho, foi criado pelo grupo Lifelong Kindergarten do Media Lab, MIT. Como já mencionado, é um ambiente de programação baseado em blocos, ou seja, não há escrita de código de programação na forma textual, mas sim junção de peças, chamadas de blocos, na tela como pode ser visto na figura 1 . A saída como resultado desta programação pode ser vista ao lado do código e é constituída de personagens, planos de fundo e sons. Assim, pode-se criar músicas, histórias e jogos sem a necessidade de entender sintaxe, pois os blocos só precisam ser selecionados e unidos, sendo que não é possível unir blocos que causem erros de sintaxe no programa.

Como o ambiente Scratch possui uma interface visual de programação, baseia-se na manipulação do mouse para criação do código de programação e produz saída predominantemente visual, atualmente pessoas com deficiência visual dependem de assistência de outras pessoas para que possam explorar e entender os recursos e produções compartilhadas no ambiente Scratch. Assim, é essencial o desenvolvimento de novas formas de interação com o ambiente Scratch a fim de possibilitar a participação ativa e inclusiva

\footnotetext{
${ }^{1}$ Disponível em: $\langle$ https://www.alice.org/

${ }^{2}$ Disponível em: $\langle\langle$ http://snap.berkeley.edu/ $\rangle$
} 
de crianças e jovens com deficiência visual em atividades educacionais envolvendo o uso deste ambiente.

A necessidade desta inclusão se torna ainda mais óbvia com a Lei 13.146 de 06 de julho de 2015, que institui a Lei Brasileira de Inclusão da Pessoa com Deficiência, que exige acessibilidade nas atividades escolares, uma vez que crianças com e sem deficiência estão juntas nas escolas. Segundo a Secretaria de Direitos Humanos da Presidência da República (SDH-PR, 2017), 528.624 pessoas são incapazes de enxergar, ou seja, cegas, e 6.056.654 de pessoas possuem baixa visão ou visão subnormal, ou seja, grande e permanente dificuldade de enxergar. Não há dados exatos em relação ao número de crianças com deficiência visual nas escolas, mas, segundo a mesma Secretaria (SDH-PR, 2012), 5,3\% das pessoas entre 0 e 14 anos possuem deficiência visual.

Considerando este contexto de inclusão de crianças em escolares regulares, é importante também pensar em atividades que não somente incluam, mas que também possibilitem que crianças com ou sem deficiência possam interagir (Thieme et al., 2017). Desta forma, o presente trabalho teve por objetivo investigar o tema e propor recomendações para o desenvolvimento de um sistema inclusivo para atividades de programação. Para isso foi desenvolvido um protótipo que foi testado em atividades de introdução à programação com crianças cegas e videntes.

Figura 1: Ambiente de programação do Scratch 2.0

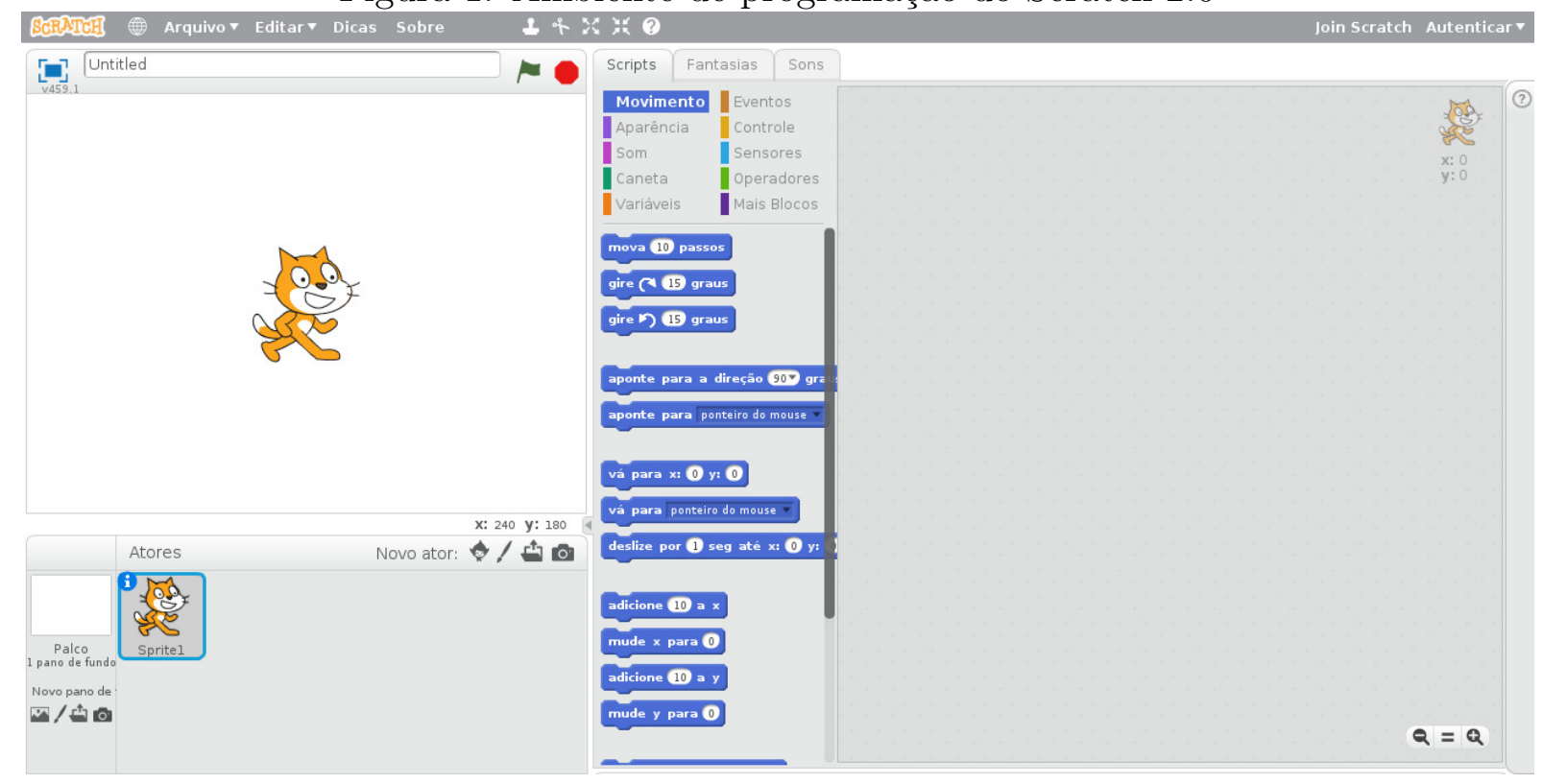

Fonte: Disponível em: $\langle$ scratch.mit.edu/projects/editor/ $\rangle$ 


\subsection{Objetivos}

O objetivo principal desta pesquisa foi investigar o tema ambientes de programação para crianças e jovens cegos e, a partir dos resultados da pesquisa, propor recomendações para a implementação de novas formas de interação com ambientes como o Scratch para que possam ser usados por crianças e jovens cegos. Para atingir este objetivo principal, foi necessário atingir os seguintes objetivos secundários:

- realizar levantamento sobre estudos e ambientes de programação para crianças;

- realizar levantamento sobre estudos e tecnologias voltadas a introdução à programação para crianças e jovens com deficiência visual;

- analisar criticamente os estudos, ambientes e tecnologias encontrados;

- desenvolver um protótipo de ambiente inclusivo para programação integrado à plataforma Scratch;

- testar o protótipo com crianças videntes e crianças cegas;

- avaliar os resultados dos testes;

- propor recomendações para desenvolvimento de ambientes de programação inclusivos para crianças cegas.

\section{$1.2 \quad$ Hipótese}

Este trabalho teve como hipótese que era possível, seguindo a abordagem de Desenho Universal, propor e implementar novas formas de interação com ambientes como o Scratch para que estes possam ser usados por crianças cegas ou videntes sozinhas ou em conjunto.

\subsection{Organização do Documento}

Este documento está organizado em seis capítulos. O primeiro capítulo apresenta uma breve introdução com a descrição do problema, motivação e objetivos da pesquisa. O segundo, de fundamentação teórica, apresenta os principais conceitos relevantes para a compreensão do texto da dissertação relacionados a: introdução à programação com Scratch, interfaces tangíveis, deficiência visual e desenho universal. O terceiro capítulo 
apresenta o estado da arte em ambientes voltados a introduzir a programação para crianças com deficiência visual. O quarto capítulo trata dos materiais e métodos utilizados para a realização desta pesquisa. O quinto capítulo apresenta uma proposta de sistema inclusivo para introdução à programação integrado à plataforma Scratch. Este capítulo apresenta também detalhes sobre os protótipos implementados e testes realizados. O sexto capítulo apresenta a discussão dos resultados, as recomendações para futuras implementações, as principais contribuições e limitações da pesquisa, bem como sugestões de trabalhos futuros. 


\section{FUNDAMENTAÇÃO TEÓRICA}

Este capítulo apresenta os conceitos relevantes para a compreensão do texto da dissertação. A primeira seção discute sobre Introdução à programação para crianças, expondo as principais características do Scratch e apresentando seu ambiente de programação. A segunda seção explica o conceito de Interface de Usuário Tangível, referida neste trabalho também por Interface Tangível. Nesta seção, também é explicado o conceito de linguagem de programação tangível e é apresentada a primeira linguagem deste tipo denominada AlgoBlock. A penúltima seção trata do termo deficiência visual e os números de pessoas com deficiência no Brasil. Por fim, a última seção apresenta a definição e princípios do Desenho Universal.

\subsection{Introdução à Programação}

Alguns autores defendem que se explore não apenas a introdução à programação com crianças, mas o conceito de computação criativa. Segundo Brennan, Balch e Chung (2014), Computação Criativa envolve: criatividade, empoderamento e computação. Este conceito tem como base as muitas possibilidades da programação, explorando aquelas que mais alcancem os interesses e valores dos alunos. A partir desta abordagem mais significativa para o aluno, ele torna-se não apenas um consumidor de tecnologia, mas um criador com empoderamento sobre os conceitos de programação. E este empoderamento não é útil apenas para áreas de computação, também pode ser aproveitado em várias áreas do conhecimento como facilitador na realização de tarefas. Várias ferramentas são de computação criativa e uma delas, o Scratch, é a ferramenta base para este projeto.

\subsubsection{O Scratch}

O Scratch é um ambiente de programação que inclui uma comunidade online de compartilhamento de projetos muito popular entre crianças e adolescentes. Ele foi criado pelo grupo Lifelong Kindergarten, Media Lab - MIT e oferece uma interface de programação 
baseada em blocos, que representam conceitos de programação e quando encaixados formam músicas, animações e jogos. Com o aumento da popularidade do Scratch, cresceu também o interesse no ensino de programação nas escolas com o objetivo de aprimorar habilidades como: pensamento lógico, criatividade e trabalho em equipe.

Os princípios de desenho do Scratch buscam desenvolver estas habilidades. Estes princípios são englobados em três principais: mais tinkerable, mais significativo e mais social (Resnick et al., 2009). O primeiro princípio refere-se à forma como as crianças brincam com o Scratch, que foi inspirado no Lego. Com poucas instruções, alguns bloquinhos são unidos e, no fim, a montagem é feita a partir de várias descobertas e novas ideias que vão surgindo durante a brincadeira. Ou seja, não há instruções do que ou como deve ser montado, a montagem flui naturalmente, e isso é ser tinkerable. Ao longo do texto, a palavra tinkerable é utilizada sem tradução e em itálico pela falta de uma tradução padrão para o português. O segundo demonstra a importância do aprendizado a partir de práticas que sejam significativas para o aprendiz. No Scratch, esta aprendizagem está baseada em uma diversidade de projetos que podem ser criados, como músicas, histórias e jogos, e também na possibilidade de personalização de imagens e sons. Por fim, como o time do Scratch prefere dizer, o Scratch não é somente um ambiente de programação, mas sim uma comunidade online. E esta comunidade é a grande característica social: lá as pessoas ajudam umas às outras, compartilham e constroem projetos juntas. 


\subsubsection{O ambiente de programação}

O ambiente de programação do Scratch, de forma geral, possui uma área de código, paleta com blocos de programação e área da saída da execução do código. Estas partes podem ser vistas na figura 2. Os blocos são movidos e unidos na área de código utilizando o mouse e formando, com isso, o código de programação. Estes blocos são separados na paleta por diferentes tipos: movimento, aparência, som, caneta, variáveis, eventos, controles, sensores, operadores e mais blocos. Depois de um código ser criado, ele pode ser executado clicando-se sobre o início dele ou causando seu evento inicial se o início for um bloco de vento, como, por exemplo, quando clicar na bandeira verde. Um exemplo de pilha de blocos está na figura 3 e os botões de bandeira verde e parar execução do código na figura 4. Também se pode executar um bloco de comando sozinho clicando sobre ele.

Figura 2: Ambiente de programação do Scratch 2.0 e suas partes principais

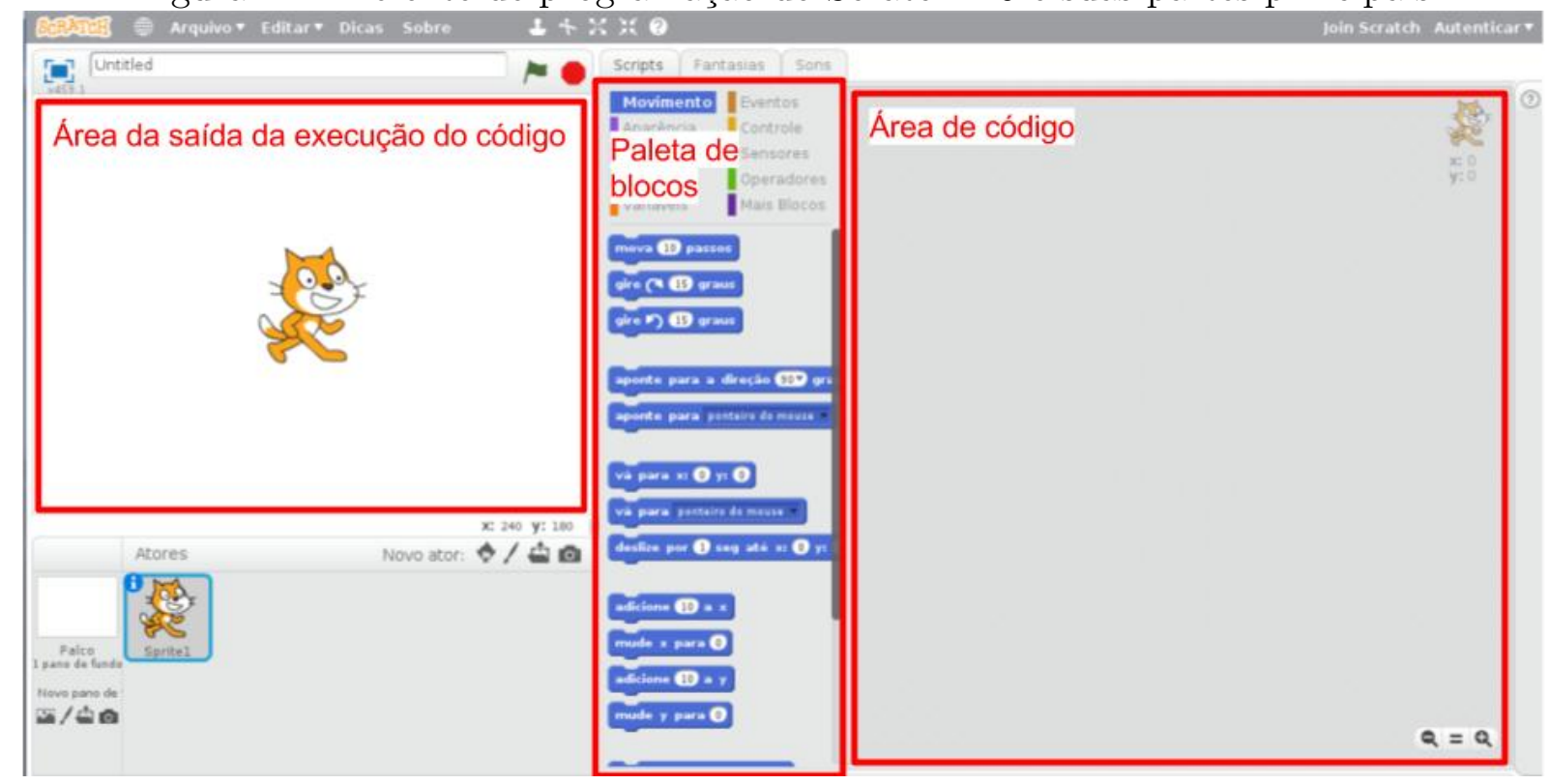

Fonte: Imagem modificada pela autora proveniente de:

$\langle$ scratch.mit.edu/projects/editor/ $\rangle$ 
Figura 3: Uma pilha de blocos com o primeiro bloco sendo o bloco de evento quando a bandeira verde for pressionada

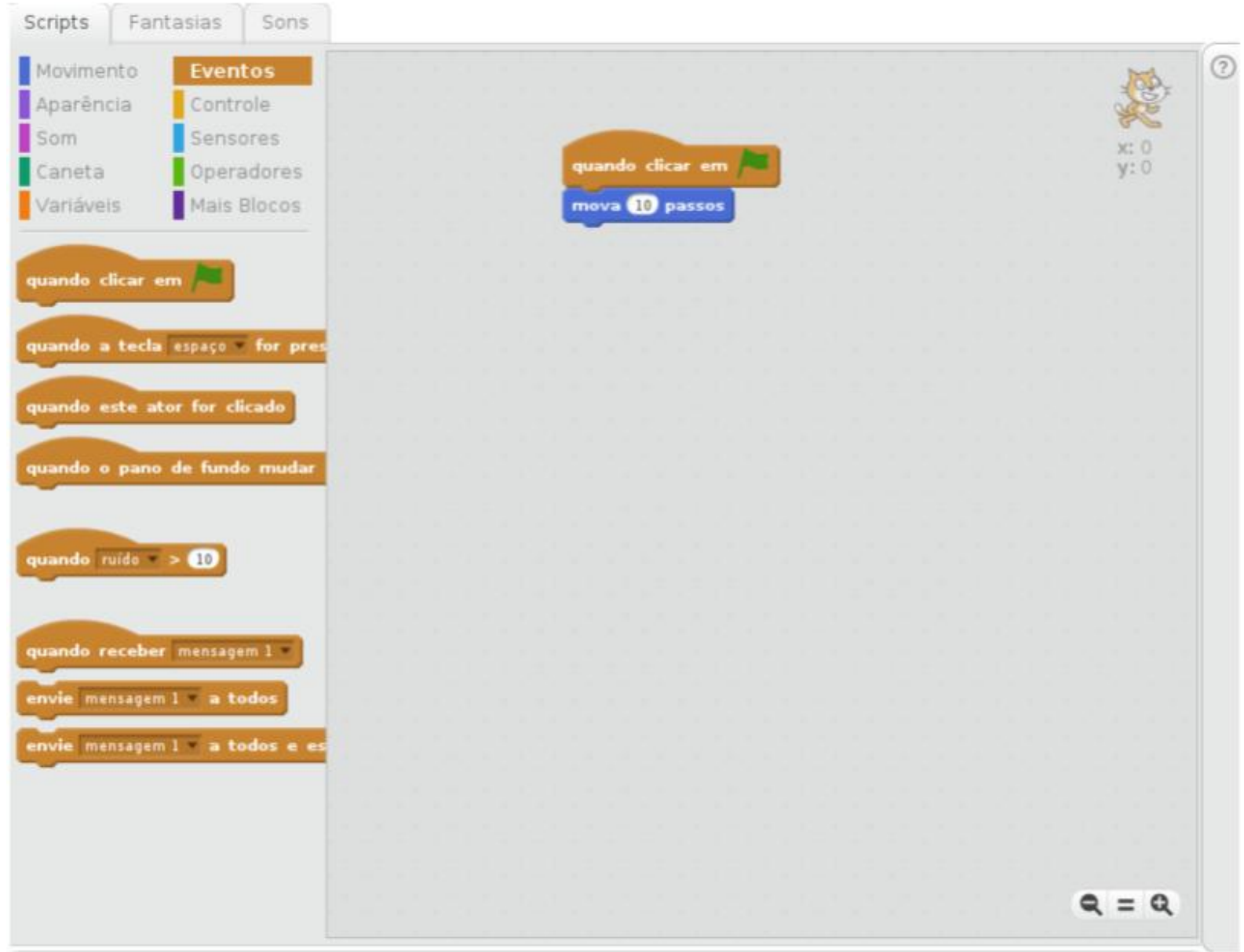

Fonte: Imagem modificada pela autora proveniente de: $\langle$ scratch.mit.edu/projects/editor/

Figura 4: Botões de bandeira verde e de parar a execução do código

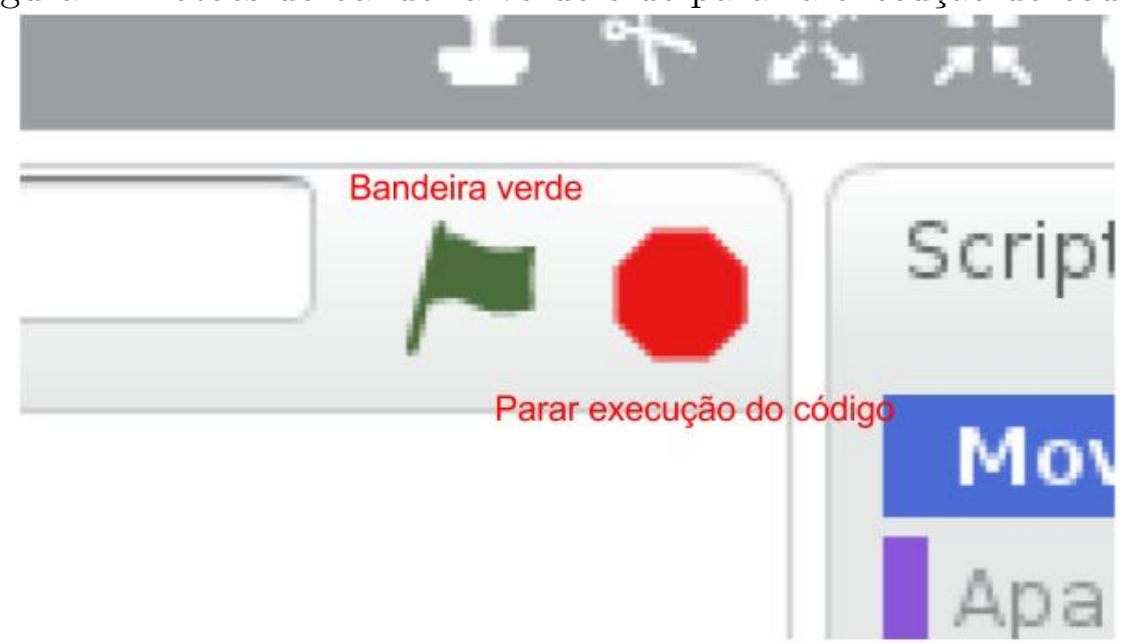

Fonte: Imagem modificada pela autora proveniente de: $\langle$ scratch.mit.edu/projects/editor/ 


\subsubsection{Conceitos de programação}

Há vários conceitos de programação presentes no Scratch. Entre eles pode-se citar: sequência, condição, repetição, variáveis, listas, funções, multi-threading, entre outros (Maloney et al., 2010). Para facilitar a programação e também o aprendizado destes conceitos, não há erros de sintaxe. Estes erros não acontecem porque os blocos possuem encaixes específicos e se uma tentativa de encaixe sem significado é feita pelo usuário, esta tentativa é desconsiderada. Quando o encaixe pode ser feito, surge um brilho para destacar o encaixe, como pode ser visto na figura 5. Nesta figura, à esquerda, é um parâmetro do tipo booleano que pode ser encaixado então há o brilho ao redor do encaixe. À direita, há a tentativa de encaixe de um parâmetro que não faz sentido na programação então não há o brilho para destacar o encaixe e ele será desconsiderado

Outra facilidade do Scratch é a simplificação da abertura e fechamento de estruturas como condições e repetições. Um bloco de repetição é um único bloco com abertura para encaixe de um bloco ou uma sequência deles. Estes blocos já possuem início e fim, evitando erros da falta de finalização destas estruturas. A figura 6 mostra um exemplo do bloco de repetição e ao lado o bloco com uma sequência de outros blocos em sua abertura. Pode-se perceber que estes blocos com abertura são extensíveis e aumentam conforme o número de blocos colocados na abertura.

Figura 5: Exemplo de duas tentativas de encaixe de parâmetros

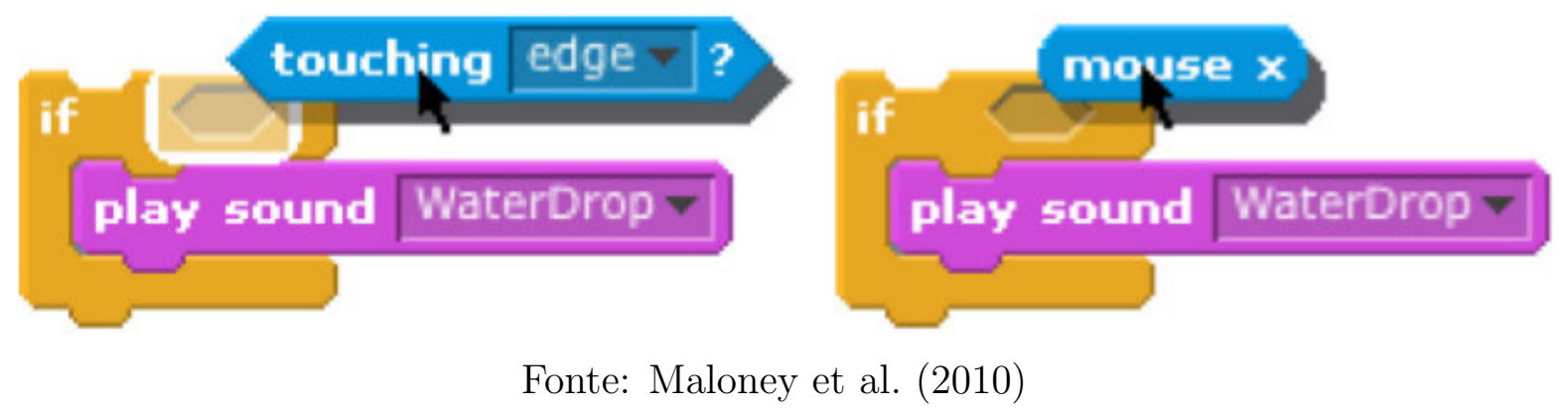


Figura 6: Exemplo de bloco de repetição à esquerda e este bloco com uma sequência de blocos em sua abertura à direita
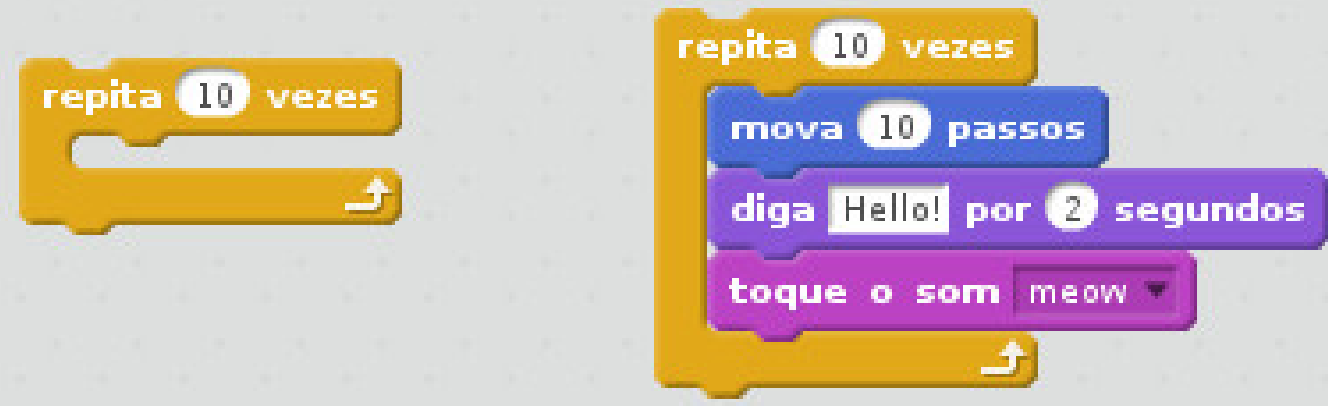

Fonte: Elaborada pela autora 


\subsubsection{Micromundos Scratch}

Um Micromundo do Scratch, segundo Tsur (2017), é o ambiente de programação do Scratch com um pequeno conjunto de blocos do Scratch para criação de projeto com temas específicos, como dança, futebol ou música. Ele facilita a aprendizagem para iniciantes que à vezes se perdem com a grande quantidade de possibilidades do Scratch, mas não deixam de instigar a criatividade apesar do número reduzido de blocos. Exemplos de micromundos podem ser vistos em 〈https://scratch.mit.edu/microworlds/go . Na figura 7 há um exemplo com o tema casa interativa.

Figura 7: Exemplo de Micromundo Scratch com o tema casa interativa

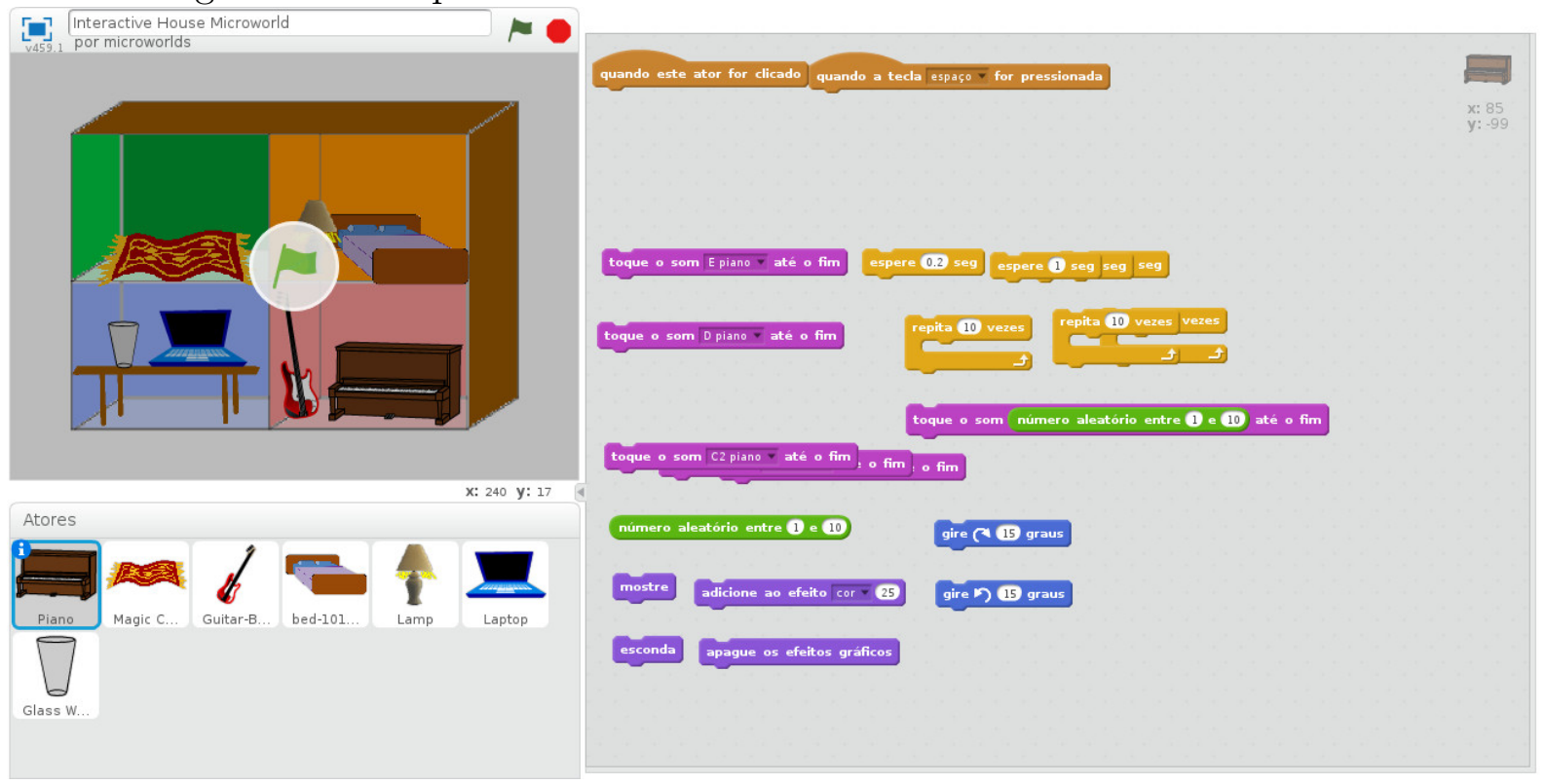

Fonte: Disponível em

$\langle$ https://scratch.mit.edu/projects/embed-editor/133835490/?isMicroworld=true 


\subsection{Interface de Usuário Tangível}

O termo Interface de Usuário Tangível (TUI) foi definido por Brygg Anders Ullmer em 1997 (Ullmer, 1997). Segundo o autor, uma Interface de Usuário Tangível utiliza, em tradução livre, "objetos físicos, instrumentos, superfícies e espaços como interfaces físicas para informações digitais". Estes objetos físicos incorporam a informação digital e as funcionalidades de objetos digitais. Um exemplo é um objeto físico que possui as informações digitais de um botão digital e sua manipulação tem funcionalidades iguais, ou seja, se pressionado, a função é ativada. Não se pode considerar, neste sentido, mouses, teclados, controles remotos e outros objetos físicos como TUIs, pois estes objetos não incorporam informações e funcionalidades de objetos digitais, apenas são formas de interação com estes objetos.

Figura 8: Representação de elementos gráficos em interface tangível

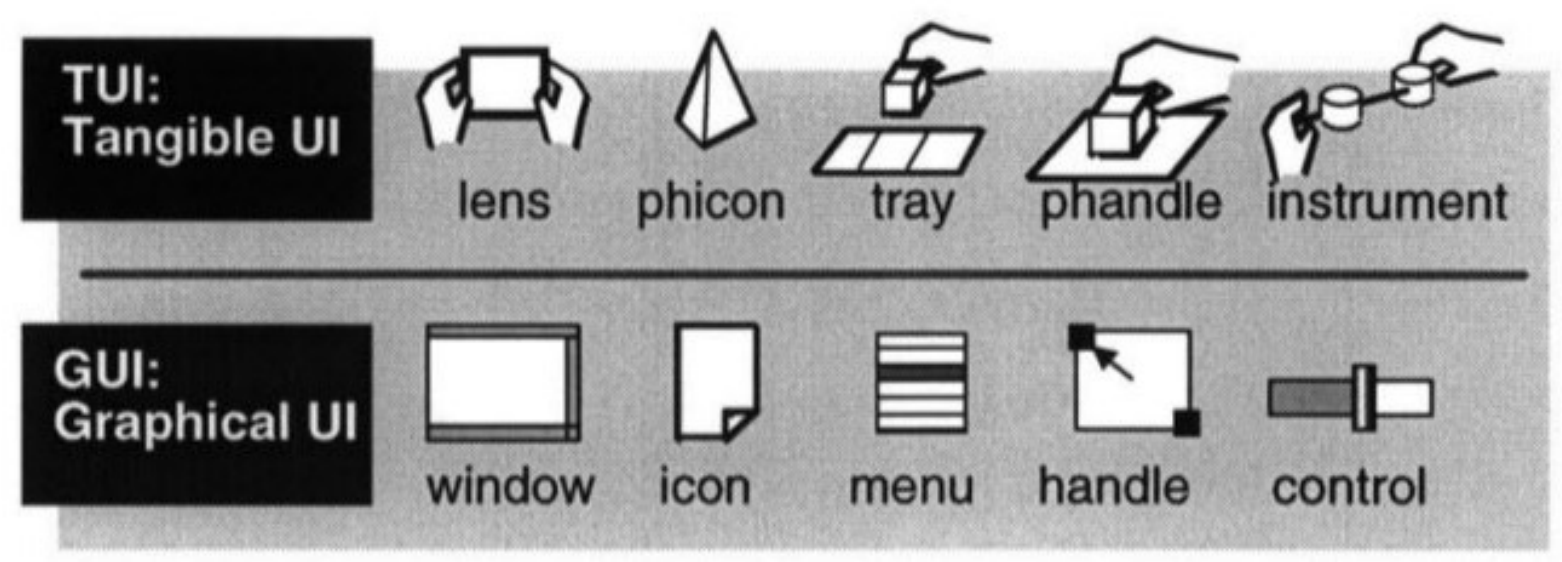

$$
\text { Fonte: Ullmer (1997) }
$$

De modo mais específico para programação, alguns anos antes, Suzuki e Kato (1993) definiram o termo Linguagem de Programação Tangível como uma linguagem onde o escrever o código é manipular objetos físicos que se comunicam com o computador. Segundo os autores, a linguagem de programação tangível proporciona os requisitos para uma aprendizagem colaborativa, sendo eles: fácil operação, acesso simultâneo, monitoramento mútuo e controle natural de quem é a vez de modificar a programação.

O primeiro requisito, fácil operação, refere-se à facilidade em manipular objetos físicos, sendo mais direto do que manipular objetos digitais utilizando o mouse e teclado. Esta facilidade de manipulação contribui para exame do código de forma coletiva, promovendo discussões para correção de erros e melhorias. A capacidade de acesso simultâneo, segundo requisito, provém do fato de que os objetos físicos estão ao acesso de todos a todo momento, também promovendo a atividade em grupo. 
O segundo requisito anteriormente citado leva ao terceiro requisito: o monitoramento mútuo. Por estar em um espaço coletivo, onde todos podem acessar a programação sendo codificada, o grupo consegue monitorar as ações de cada um, entendendo e discutindo cada passo. O controle natural de quem é a vez de modificar a programação, último requisito, é o que mais diferencia uma Linguagem de Programação Tangível de uma gráfica. Nesta última, há a necessidade de passar o dispositivo que está auxiliando na codificação da programação para o "programador da vez", enquanto na primeira, para modificar a programação e ser o "programador da vez" pode-se levantar a mão ou falar algo, gestos mais naturais, e simplesmente começar a mexer na área coletiva onde está a programação.

Suzuki e Kato (1993) não só definiram, mas também desenvolveram uma linguagem de programação tangível chamada AlgoBlock, apresentada na figura 9. Os blocos físicos são representações de comandos para controlar um submarino. Há blocos de movimentos, condição e repetição.

Figura 9: AlgoBlock criado por Suzuki e Kato (1993)

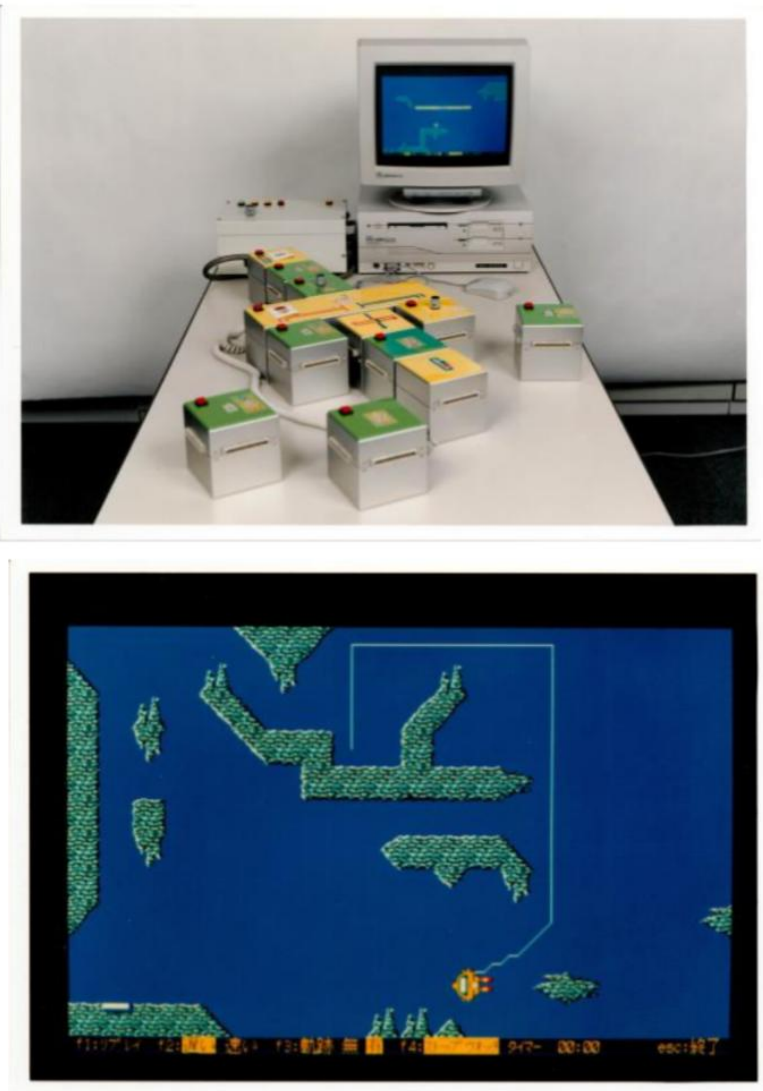

Fonte: Suzuki e Kato (1993)

Na literatura, encontram-se outras Linguagens de Programação Tangíveis. Uma delas é o Tern (Horn e Jacob 2007, 2007), que possui objetos físicos de programação com 
marcadores para reconhecimento de cada um por processamento de imagens a partir de um computador. Outra linguagem também utiliza processamento de imagens (Gordon, Ackermann e Breazeal 2015, 2015 para programar um robô por meio de etiquetas que são reconhecidas por uma câmera do próprio robô. Em outros casos, outras tenologias são utilizadas para executar a programação, como comunicação sem fio e infravermelho (Wang et al. 2012, 2012), identificadores de microcontroladores (Chawla et al. 2013, 2013 ) e microcontrolador para executar tarefas e se comunicar com microcontroladores de objetos de programação vizinhos (McNerney 1999, 1999).

Além da literatura, encontram-se produtos com linguagem de programação tangível para crianças. O Cubetto ${ }^{1}$ ensina programação por meio de peças de madeira de diferentes formatos encaixadas em um paralelepípedo também de madeira que contém um sistema de reconhecimento das peças. A brincadeira é mover um robô que pode ser personalizado pela criança. Também há o Osmo $2^{2}$ para produtos Apple. Por meio da câmera presente em um tablet ou smartphone, há o reconhecimento das peças que se conectam por imãs. A programação é feita para solucionar desafios, como mover um personagem para pegar frutas no cenário.

\footnotetext{
${ }^{1}$ Disponível em: $\langle$ https://www.primotoys.com/

${ }^{2}$ Disponível em: $\langle$ https://www.playosmo.com/〉
} 
Figura 10: Figuras dos ambientes de linguagem de programação tangível com destaque para o trabalho de McNerney 1999 (1999) que se preocupou com a inclusão de pessoas cegas em seu trabalho incluindo o sistema Braille nos blocos de programação

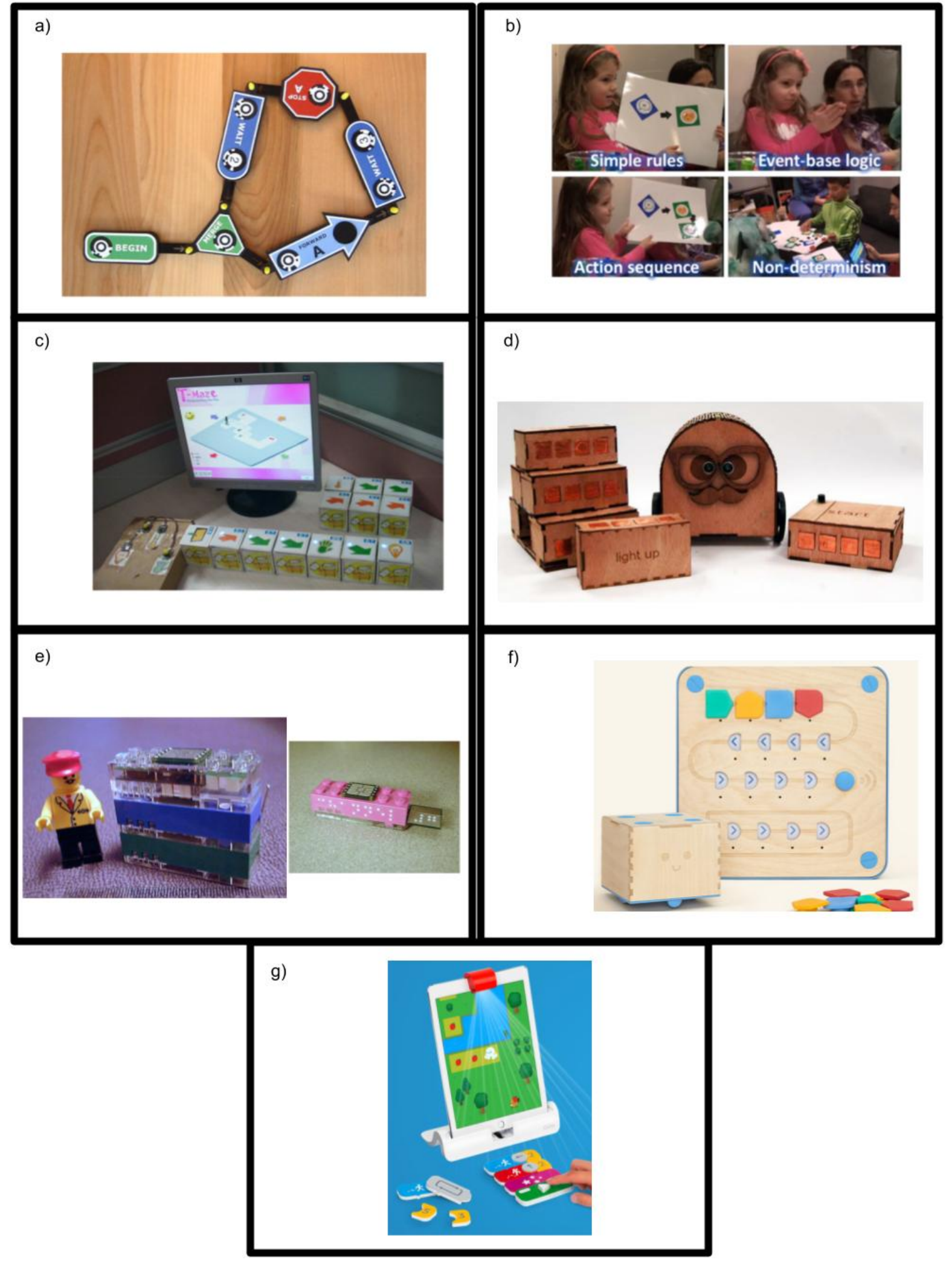

Fonte: a) Horn e Jacob 2007 (2007) b) Gordon, Ackermann e Breazeal 2015 (2015) c) Wang et al. 2012 (2012) d) Chawla et al. 2013 (2013) e) McNerney 1999 (1999) f) Disponível em: 〈https://www.primotoys.com/ $/$ g) Disponível em: $\langle$ https://www.playosmo.com/ 


\subsection{Deficiência Visual}

Segundo a Classificação Internacional de Deficiências, Incapacidades e Desvantagens (CIDID), reimpressa em 1993, "uma deficiência é qualquer perda ou anormalidade da estrutura ou função psicológica, fisiológica ou anatômica. Representa a exteriorização de um estado patológico e, em princípio, reflete distúrbios no nível do órgão" Fundação Dorina Nowill para Cegos, 2017). A deficiência visual, foco do presente trabalho, refere-se à perda total ou parcial, congênita ou adquirida, da visão. De acordo com o nível de acuidade visual, tem-se a cegueira e a baixa visão ou visão subnormal.

No caso da cegueira, a perda é total ou o nível de acuidade da visão é muito baixo. Neste caso, a pessoa com cegueira utiliza o sistema Braille $3^{3}$ para ler e escrever em meios não eletrônicos. Nos outros casos, há perda da funcionalidade visual dos olhos mesmo após tratamento, mas a acuidade visual é suficiente para leitura de textos com ampliadores, como, por exemplo, lupas.

Segundo a Secretaria de Direitos Humanos da Presidência da República (SDH-PR, 2017), falando um pouco de números no Brasil, do total da população em 2010, 45,6 milhões $(23,9 \%)$ de pessoas declararam ter algum tipo de deficiência, sendo a visual a mais comum com 3,5\% da população. Desta porcentagem, 528.624 pessoas são cegas e 6.056.654 pessoas possuem baixa visão ou visão subnormal.

"Glaucoma, retinopatia diabética, atrofia do nervo ótico, retinose pigmentar e degeneração macular relacionada à idade (DMRI) são as principais causas da cegueira na população adulta. Entre as crianças, as principais causas são glaucoma congênito, retinopatia da prematuridade e toxoplasmose ocular congênita." (Fundação Dorina Nowill para Cegos 2017)

Por fim, é importante considerar que o termo correto a ser utilizado é "Pessoa com Deficiência", que faz parte do texto aprovado pela Convenção Internacional para Proteção e Promoção dos Direitos e Dignidades das Pessoas com Deficiência, aprovado pela Assembleia Geral da ONU, em 2006, e ratificada, no Brasil, em julho de 2008.

\footnotetext{
${ }^{3}$ Disponível em: $\langle$ https://pt.wikipedia.org/wiki/Braille $\rangle$
} 


\subsection{Desenho Universal}

Story (1998), em seu artigo sobre os princípios do Desenho Universal, inicia explicando a relação entre desenho acessível, universal, adaptável e transgeracional.

Figura 11: Relação entre desenhos acessível, universal, adaptável e transgeracional

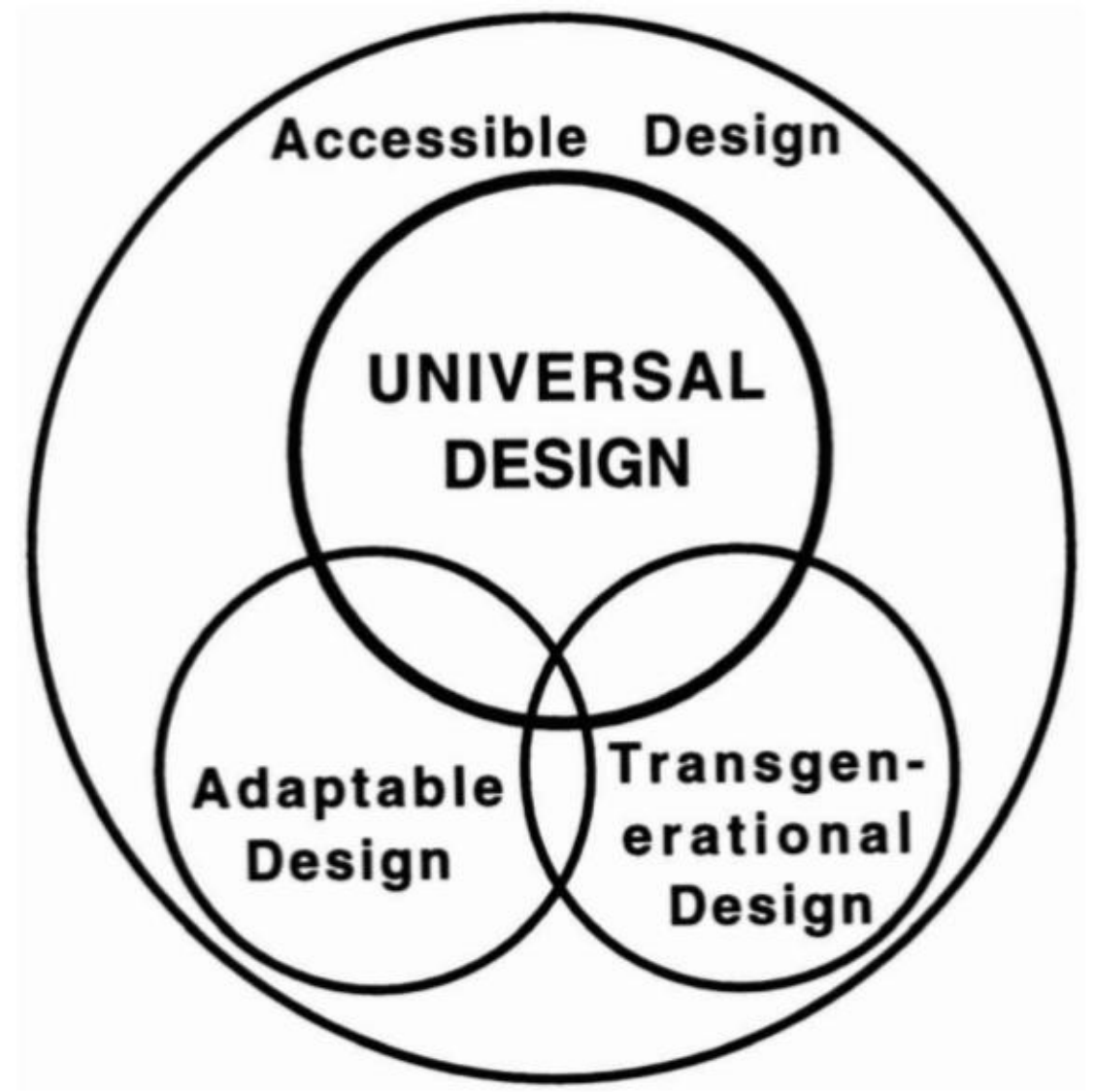

Fonte: Story (1998)

Um sistema com desenho acessível atende aos requisitos para uso por pessoas com deficiência (Center for Accessible Housing, 1991, apud Story, 1998). Como pode ser visto na figura 11, desenhos universal, transgeracional e adaptável atendem a este conceito. Porém, para um sistema possuir desenho adaptável, deve-se ter modificações em um desenho padrão para tornar o desenho utilizável por um indivíduo conforme necessário (Center for Accessible Housing, 1991, apud Story, 1998). E para possuir desenho transgeracional, deve-se considerar as mudanças conforme a pessoa envelhece (Center for Accessible Housing, 1991, apud Story, 1998). Por fim, a autora define desenho universal, em tradução livre para o português:

O desenho universal pode ser definido como o desenho de produtos e ambientes que podem ser utilizados e experimentados por pessoas de todas as idades e habilidades, 
na medida do possível, sem adaptação (Centro de Habitação Acessível, 1995). Nos melhores exemplos, as características de desenho universal passam despercebidas porque foram completamente integradas em profundas soluções de desenho que são usadas por um espectro completo da população. Soluções universais bem desenvolvidas não chamam a atenção para si mesmas por serem nada mais do que mais fácil para todos usarem, o que é exatamente o que são. Projetos que foram desenvolvidos com consideração pelas necessidades da população diversificada funcionam para homens e mulheres, crianças e idosos, pessoas pequenas e grandes, e pessoas com deficiência temporária ou de longo prazo. Eles trabalham quando está escuro, ruidoso, molhado ou quando estamos cansados. Todos se beneficiam. (Story, 1998, p. 4)

Assim, um sistema de desenho universal pode ser adaptável e transgeracional ou um dos dois ou nenhum deles. Mas sempre será um desenho acessível. E este sistema, como sendo de desenho universal, possui princípios que estão enumerados a seguir.

1. Uso equitativo: possibilita o uso por pessoas com diferentes habilidades, providenciando as mesmas funcionalidades, segurança e atratividade.

2. Flexibilidade no uso: há mais de uma forma na interação com o sistema, providenciando adaptabilidade ao ritmo do usuário, fidelidade e precisão.

3. Uso simples e intuitivo: elimina complexidade na interação, atende à usuários de vários níveis de linguagem, dispõe as informações de acordo com sua importância e há respostas durante e depois de uma tarefa ser completada.

4. Informação perceptível: passa as informações ao usuário de diferentes formas e as mais relevantes possuem maior legibilidade, diferencia elementos para serem descritos com facilidade e há compatibilidade com tecnologias utilizadas por pessoas com limitações sensoriais.

5. Tolerância ao erro: sinaliza e organiza as informações para minimizar perigos e ações indesejadas.

6. Baixo esforço físico: permite uma interação com posição confortável ao usuário e força razoável e minimiza ações repetitivas.

7. Tamanho e espaço para acesso e uso: permite que os usuários tenham acesso à componentes importantes e providencia espaço adequado para usuários que utilizam algum dispositivo de Tecnologia Assistiva. 


\subsection{Considerações}

Este trabalho parte dos princípios de desenho do Scratch para o desenvolvimento de um sistema que inclua crianças cegas em atividades de programação. Além destes princípios, a autora deste trabalho focou em criar um sistema para atividades de programação em grupo e, a partir disto, segue-se o conceito de Interface de Usuário Tangível, ou somente Interface Tangível, para atingir de forma natural os requisitos para a cooperação em grupo das crianças. Por último neste capítulo, há a apresentação do conceito de Desenho Universal que é o conceito que une as ideias deste trabalho no sentido da inclusão. Tem-se um sistema com princípios do Scratch e Interface Tangível para que as crianças trabalhem juntas em programação e com Desenho Universal para que estas crianças possam utilizar este sistema mesmo possuindo níveis de acuidade visual diferentes, mais especificamente crianças videntes e cegas. 


\title{
3 INTRODUÇÃO À PROGRAMAÇÃO PARA CRIANÇAS COM DEFICIÊNCIA VISUAL
}

As interfaces dos ambientes de programação existentes para crianças não são fáceis de serem utilizadas pelas que têm deficiência visual. O sistema de "arrastar e soltar" e as cores e formas apresentadas na tela do computador, que ajudam a memorizar as ações dos blocos para quem enxerga, tornam-se empecilhos para crianças com deficiência visual.

O levantamento apresentado a seguir foi focado em interfaces para engajar crianças e jovens com deficiência visual em atividades de programação. Portanto, as interfaces que somente auxiliam na leitura de uma programação textual não foram levadas em consideração. As bibliotecas digitais da IEEE Xplore Library e da Biblioteca Digital ACM foram usadas com o seguinte comando de consulta:

\author{
(pupil OR children OR kid OR student) \\ AND (blind OR disabilities OR impairment OR impaired) \\ AND (programming OR robot OR algorithm)
}

Foram filtrados os resultados correspondentes ao início do ano de 2012 até o ano de 2017 (dia 21, mês de julho). Destes, foram selecionadas as dez referências que apresentavam interfaces focadas em crianças ou adolescentes com deficiência visual e que possuíam alguma característica para engajamento dos participantes. A seguir, apresentase e discute-se a síntese deste levantamento, tendo em conta as seguintes características de engajamento consideradas relevantes pela autora deste trabalho: robótica, modelos hápticos, impressão 3D, programação em blocos e aprendizagem colaborativa.

\subsection{Robótica}

Com o foco em robótica e estudantes adolescentes de ensino médio e fundamental, os autores Ludi, Ellis e Jordan (2014) desenvolveram o JBrick, um ambiente de programação 
para robôs acessível do Lego Mindstorms \. Este ambiente é compatível com leitor de tela, display braille e ampliador de tela e também possui uma interface de fácil entendimento tanto para usuários videntes quanto para usuários com baixa visão. Adicionalmente, o usuário pode executar comandos por meio do teclado e do mouse, localizar códigos pela número da linha e receber respostas auditivas durante a compilação, o carregamento do programa e o estado da conexão com o robô.

Para os testes, foram feitas atividades em grupos de 2 a 3 participantes durante 4 dias, entre 3 a 4 horas por dia. Os 10 participantes possuem diferentes níveis de deficiência visual, incluindo cegos, e apenas 3 possuem alguma experiência prévia em programação. As atividades eram formadas por desafios e cada grupo trabalhou sozinho obtendo ajuda se necessário. Ao fim, uma entrevista foi realizada com perguntas em relação à numeração de linhas para auxílio na localização de erros de compilação, realce das linhas e posicionamento do cursor para auxílio na localização do código, à confiança em seguir a estrutura do código criado, à experiência com programação, à satisfação na utilização do JBrick para programar um robô e ao nível de recomendação do JBrick a amigos com deficiência visual. Para trabalhos futuros, de acordo com os resultados dos testes, há necessidade de recursos adicionais para navegação no código e depuração.

Em outro trabalho, Howard, Park e Remy (2012) têm o objetivo de utilizar mecanismos de respostas adicionais para facilitar a programação de robôs por estudantes com deficiência visual. A interface desenvolvida para alcançar este objetivo é baseada na programação do kit robô Lego Mindstorms NXT, chamada Bricx Command Center (BricxCC), e integrada ao leitor de tela JAWS e ao ampliador de tela MAGIC. Assim, os estudantes cegos e aqueles com baixa visão poderiam acessar este ambiente de programação. Durante a execução do programa, um controle remoto Wii foi usado como interface háptica entre o robô e o usuário e diferentes notas de piano como a interface sonora. Ambas as interfaces representam as seguintes ações do robô: mover-se para a frente, atingir o objetivo, girar para a esquerda, virar à direita, detectar um objeto e colisão de objetos. Após a execução do programa, um agente inteligente chamado Robbie fornece realimentação sonora ao estudante sobre o que o estudante programou e o que o robô executou. O recurso Robbie permite que estudantes com deficiência visual avaliem seus próprios progressos.

A avaliação das interfaces acessíveis foi feita por nove estudantes com deficiência visual do ensino médio durante duas semanas. Eles possuíam níveis de experiência com computadores variados, a maioria possuía experiência prévia com computadores e poucos

\footnotetext{
${ }^{1}$ Disponível em: 〈https://www.lego.com/en-us/mindstorms
} 
com programação. Dados subjetivos e objetivos foram coletados no teste. O objetivo é o número de tentativas para finalizar cada tarefa e o subjetivo, uma avaliação ao fim do teste. O resultado deste teste foi que é factível a utilização de um sistema multimodal de interação que permite que os estudantes com deficiência visual participem em processos de programação de robô tradicionais.

A figura (Howard, Park e Remy 2012) mostra os aspetos principais do sistema, sendo:

a) o robô Lego Mindstorms NXT;

b) os gráficos de amplitude versus tempo da vibração do Wiimote em relação à cada ação do robô;

c) os sons associados às ações do robô;

d) um exemplo de resposta do agente inteligente Robbie à uma programação feita pelo usuário.

Figura 12: Sistema desenvolvido por Howard, Park e Remy (2012)

a)

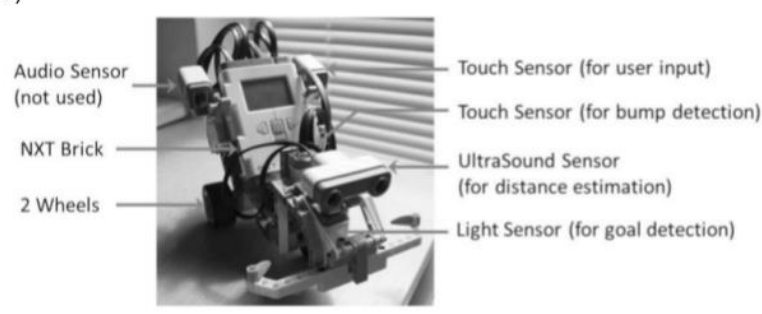

b)

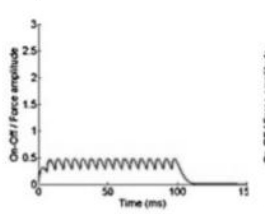

Travel Forward

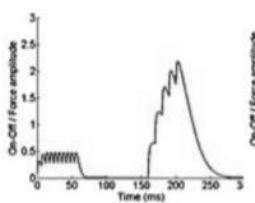

Turning Right

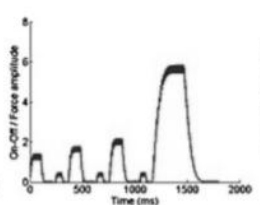

Goal Achieved

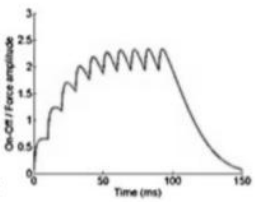

Object Detected

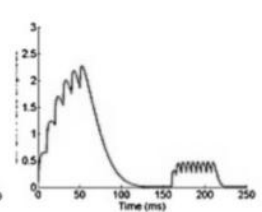

Turning Left

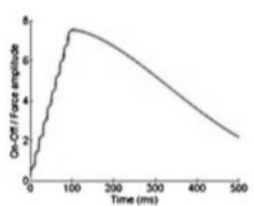

Object Collision

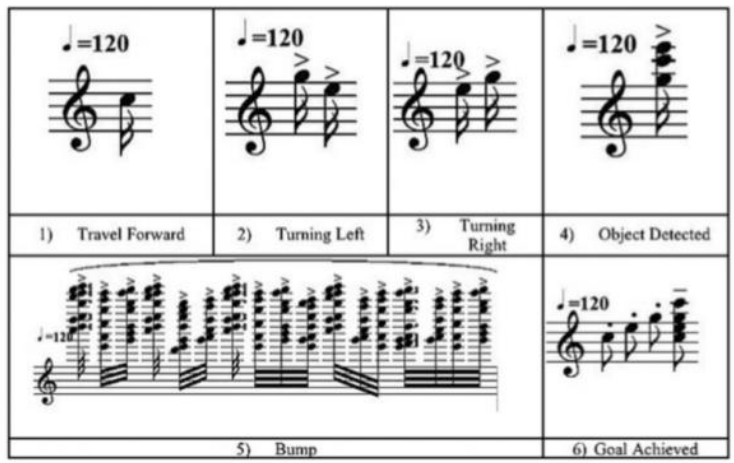

d)

I think your robot tumed left, 41 degrees. Which is not the correct action. it then, moved up, 4 centimeters. it then, stopped doing anything Do you know how to fix your program?

Fonte: Howard, Park e Remy (2012) 


\subsection{Ensino de pensamento algorítmico usando mode- los hápticos}

A proposta dos autores Capovilla, Krugel e Hubwieser (2013) é utilizar legos, números táteis vermelhos em legos brancos, para alto contraste, e placas para ajudar os estudantes a resolver algoritmos básicos de busca. O experimento foi feito com 5 participantes cegos com idade entre 17 e 29 anos e sem experiência prévia com programação. Eles foram convidados a resolver problemas sobre busca linear na lista ordenada e em uma árvore binária. Todos esses problemas exigem o uso de princípios fundamentais de programação, como repetições, recursões, etc. As tarefas foram resolvidas com êxito pelos participantes que também conseguiram entender e descrever sua própria programação. Portanto, os pesquisadores concluíram que o método de ensino proposto mostrou-se adequado para ensinar o pensamento algorítmico.

Figura 13: Exemplos tirados do artigo para montagem dos problemas a serem resolvidos nos testes com usuários
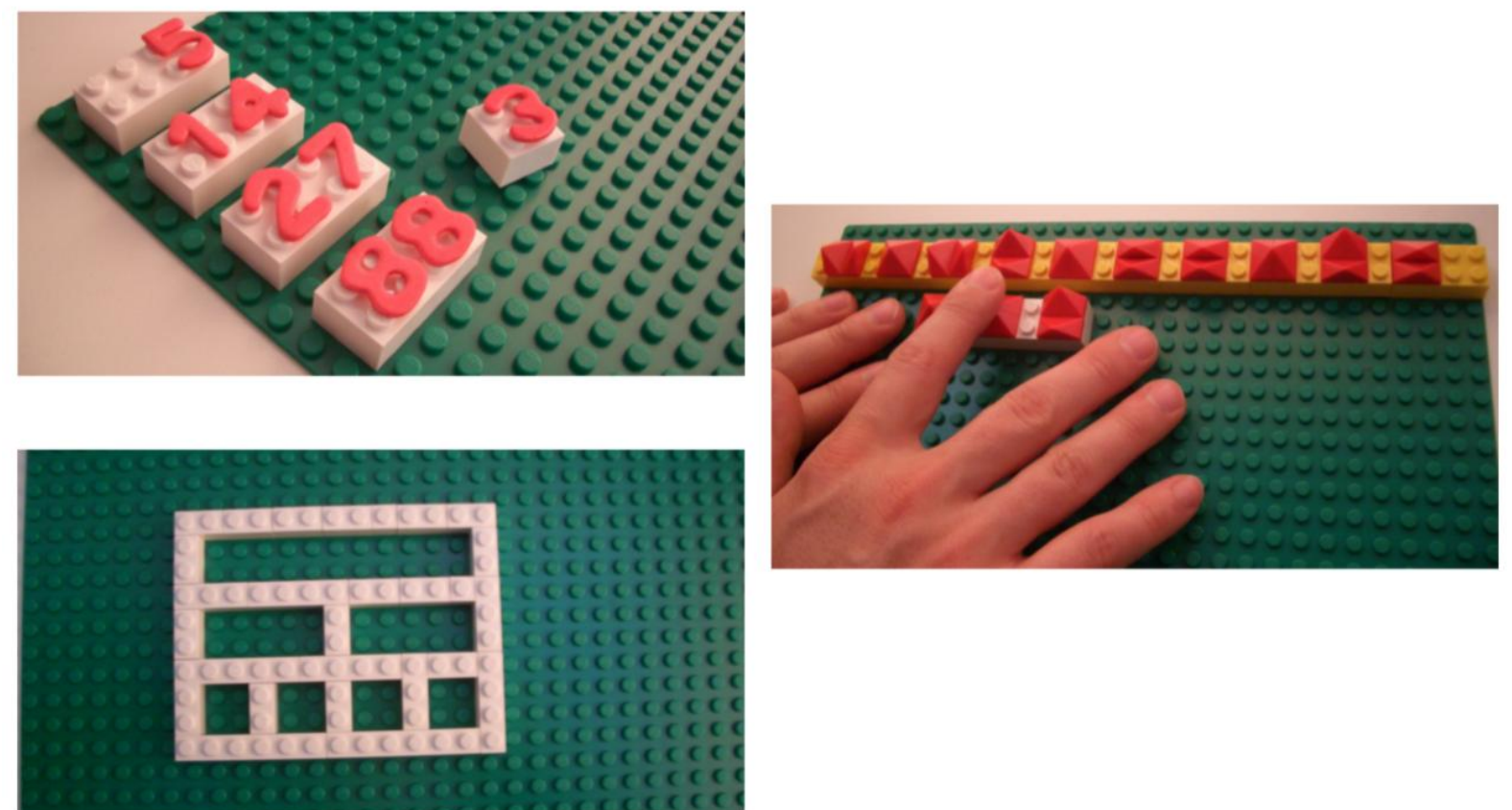

Fonte: Capovilla, Krugel e Hubwieser (2013)

\subsection{Impressão, gerenciamento de crises e Twitter}

Neste artigo, Kane e Bigham (2014) descrevem o planejamento e execução de um workshop para estudantes do ensino médio cegos e com baixa visão cujo objetivo é escrever programas em Ruby para analisar dados do Twitter relacionados à crises ecológicas 
fictícias. O workshop tem duração de 4 dias e foram cinquenta estudantes participantes divididos nas áreas aeroespacial, química, robótica e informática. No último grupo, nove estudantes foram desafiados a escrever programas que imprimissem em 3D os lugares das mensagens monitoradas no Twitter, formando um mapa tátil. Estes estudantes possuem níveis de experiência em computador em programação variados além de acuidade visual e dispositivos de Tecnologia Assistiva preferenciais diferentes. A linguagem de programação selecionada para o workshop foi Ruby devido aos benefícios para os programadores cegos. Alguns destes benefícios são os símbolos de texto para expressar a sintaxe, alguns símbolos não alfanuméricos e o intérprete interativo. Todos esses aspectos ajudam os usuários cegos a entender o código usando o leitor de tela.

Os pesquisadores concluíram que o workshop foi bem sucedido. Embora nem todos os alunos tenham concluído toda a tarefa, eles estavam engajados nos desafios de programação. Um resultado que não foi planejado foi o interesse dos participantes em fazer o leitor de tela como uma saída musical e esse resultado possivelmente foi preferido porque pode ser produzido em tempo real enquanto a impressão 3D demora alguns minutos.

\subsection{Programação em blocos}

Com o objetivo de inclusão de estudantes com deficiência visual na criação de programas, Kakehashi et al. (2013) desenvolveram o P-Cube, um sistema com interface tangível para programação em blocos de um robô. Imagens do P-Cube podem ser vistas na figura 15. Esta programação é feita utilizando um espaço de madeira com leitores RFID e blocos com etiqueta RFID. Estes blocos podem ser de movimento ou controle, como o "se" e "repetição". A programação montada é passada para o robô por meio de um cartão microSD gerado por um computador ligado ao espaço de madeira com leitores RFID.

Dois testes diferentes foram feitos com o primeiro protótipo. O primeiro é um teste de reconhecimento dos blocos. Os catorze participantes deste teste são videntes, têm entre 20 e 38 anos e foram vendados. A análise foi feita de acordo com o tempo para reconhecimento dos blocos, que em média foi entre 80 e 100 segundos, e foi utilizada como base para modificações para o protótipo dois. O segundo teste com o primeiro protótipo envolveu a avaliação da utilização do P-Cube em relação à outro ambiente de programação por meio da criação de uma programação sequencial. Foram dez participantes videntes novamente vendados e, no fim, houve um questionário. Concluiu-se que houve pequenas variações nas respostas ao questionário, principalmente em relação ao tempo para conclusão da tarefa utilizando cada um dos ambientes. Por fim, um teste com o segundo protótipo 
Figura 14: Impressão 3D de um mapa gerado a partir de análises de mensagens no Twitter

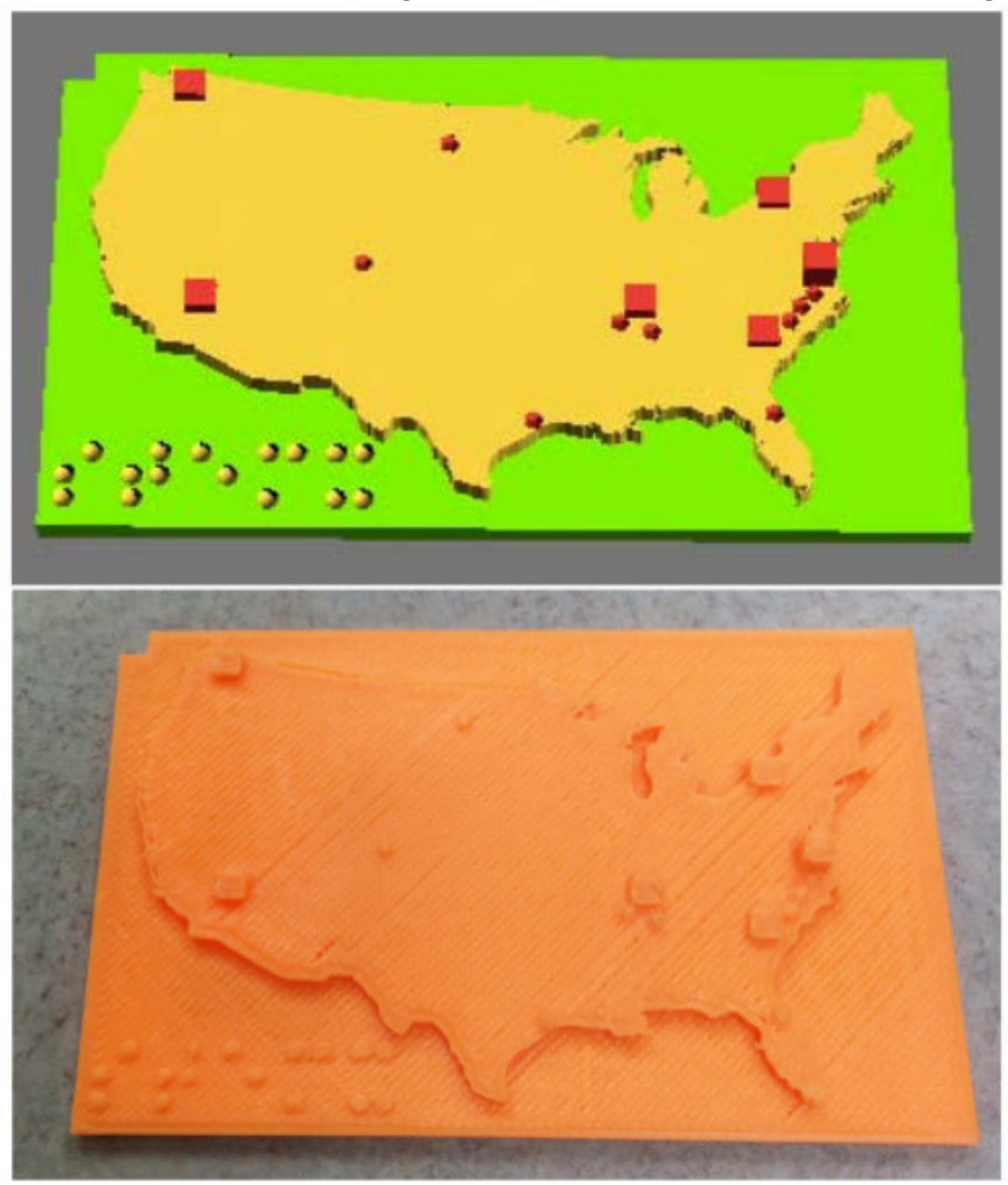

Fonte: Kane e Bigham (2014)

foi feito para comprovar sua funcionalidade, ou seja, que o sistema é capaz de criar um código para que o robô siga uma linha no chão. Com o sucesso do último teste, os autores concluíram que o P-Cube é um sistema robusto e relativamente barato.

Em outro trabalho, Barros et al. (2017) desenvolveram o CardBot, que utiliza cartões de papel com QR Code reconhecidos por um aplicativo de celular que envia por Bluetooth os comandos para um robô, e pode ser visto na figura 16. O objetivo é prover acesso à atividades de robótica educacionais para estudantes de baixa visão. A linguagem formada por estes cartões e também os cartões em si são criados pelo professor por meio de um ambiente desenvolvido pelos autores. Assim, criam-se os cartões com formatos, tamanhos e texturas para cada comando de acordo com a necessidade da atividade que o professor queira desenvolver com os alunos. Também foi desenvolvido pelos autores um aplicativo que identifica o QR Code dos cartões e envia comandos para o robô. Este aplicativo possui dois modos de funcionamento: um de controle, em que cada cartão lido é executado 
pelo robô, e outro de programação, em que o robô somente executa os comandos após o último cartão ser lido. A utilização deste aplicativo envolve a utilização da câmera para reconhecimento dos cartões e viração como resposta para o usuário de que um cartão foi lido.

Para testes, uma linguagem simples foi criada no ambiente desenvolvido pelos autores. Foram feitos quatro experimentos: em um clube de robótica, sem nenhuma pessoa com deficiência; com uma pessoa de 28 anos que é cega e sem conhecimento de programação; com uma criança de 11 anos também cega e sem conhecimento de programação; e, por último, foram realizados 15 encontros com crianças entre 5 e 7 anos, três com baixa visão e duas são cegas. Para análise foram selecionadas as oficinas mais significativas segundo observações e foram dadas notas empiricamente de um a cinco nas categorias: colaboração, autonomia, interatividade e versatilidade. Com os resultados, os autores confirmaram que é possível desenvolver atividade de robótica com crianças com deficiência visual de forma interativa e com objetivos educacionais.

Foram encontrados outros três trabalhos (Milne, 2017; Ludi, 2015; Koushik e Lewis, 2016), porém sem protótipos. Estes três trabalhos discutem requisitos para que ambientes de programação em blocos sejam acessíveis para pessoas cegas. Pode-se citar entre os requisitos:

- desenho universal, desenho para crianças pequenas, interface com tela sensível ao toque, construção e exploração não-visual, suporte para áudio (Milne, 2017));

- possibilidade de mudança das cores dos objetos da interface para facilitar o discernimento, possibilidade de leitura dos blocos no menu e na área de código, movimentação e conexão de blocos por teclado ou mouse, resposta visual e auditiva para blocos que podem se conectar, possibilidade de navegação pelo código usando o teclado (Ludi, 2015);

- blocos baseados em movimentos do teclado, chamados pelos autores de pseudoblocos, pois são blocos não visuais (Koushik e Lewis, 2016). 
Figura 15: Figuras retiradas do artigo de Kakehashi et al. (2013) mostrando os blocos de programação, o espaço em madeira para colocação dos blocos e o robô
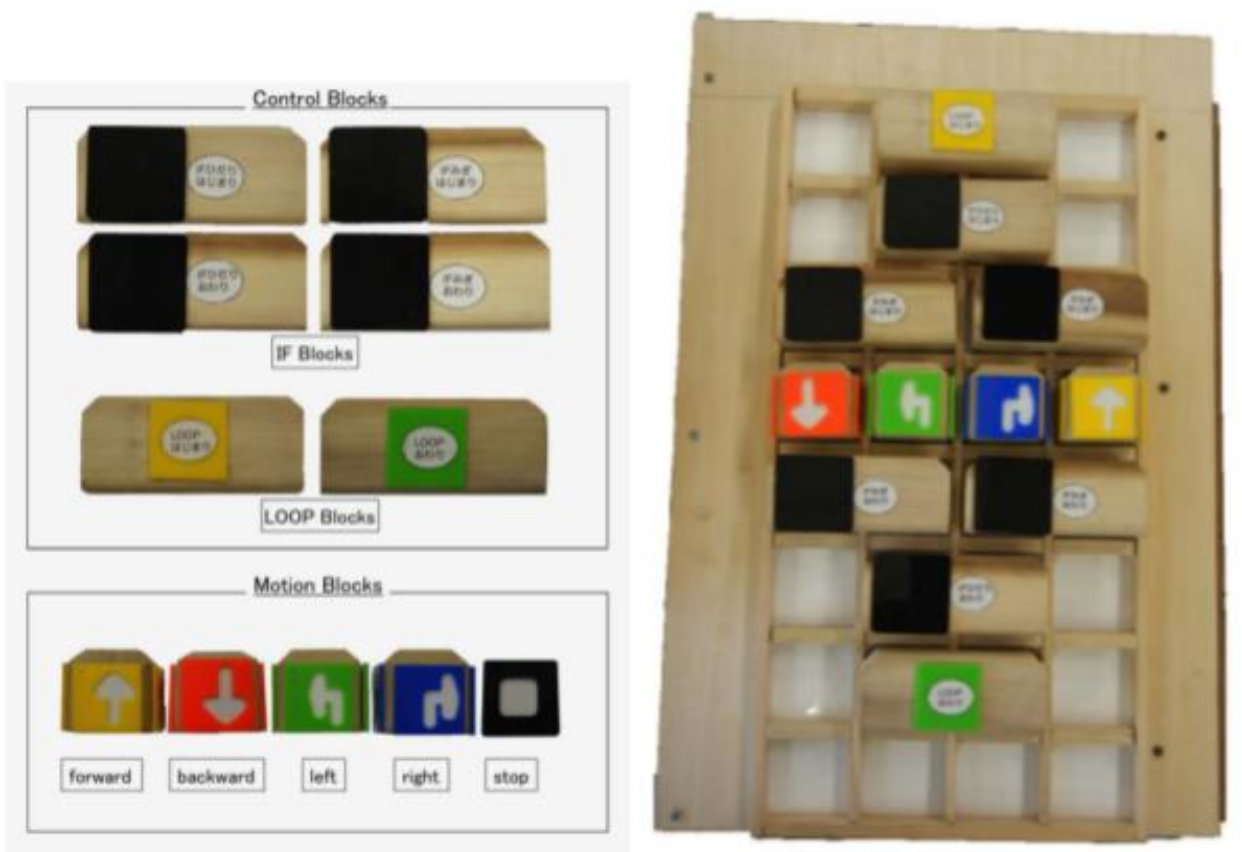

Line Trace Program

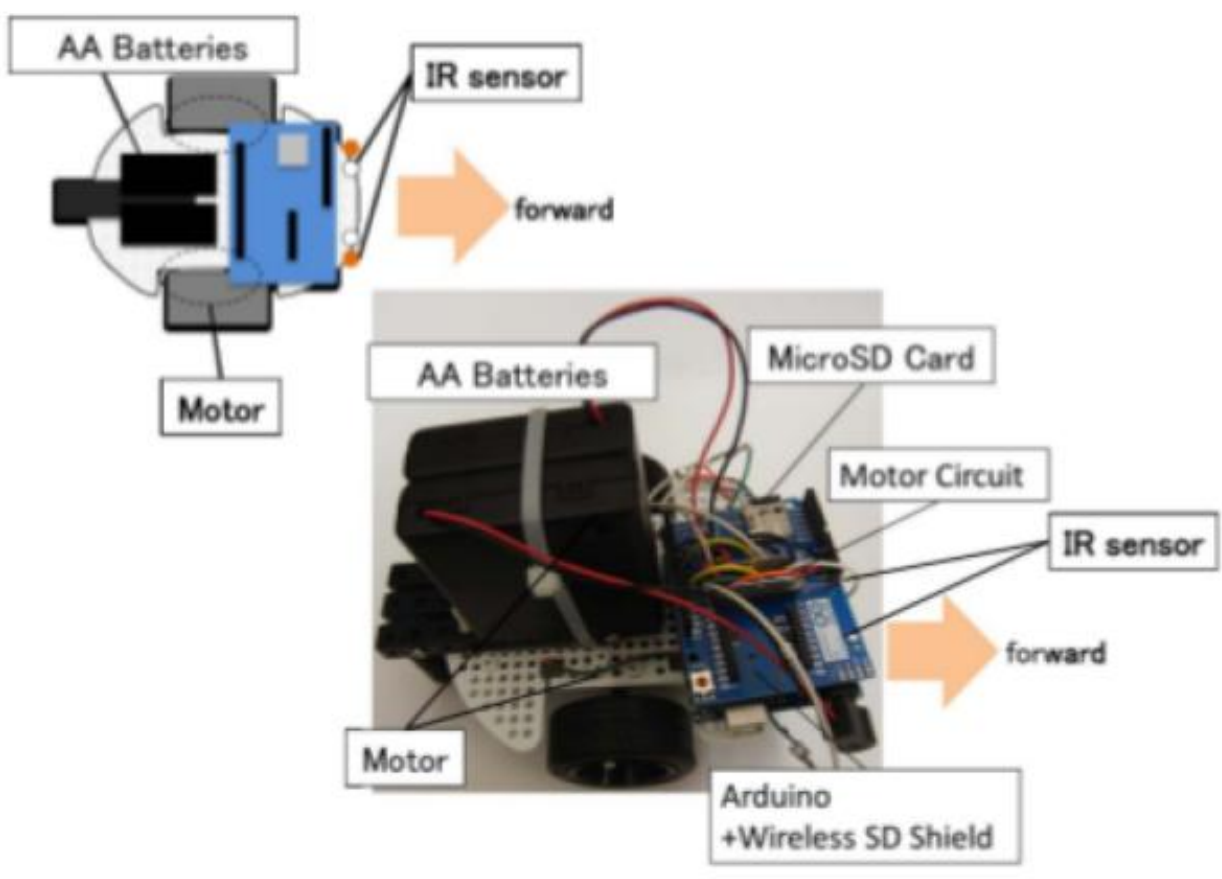

Fonte: Kakehashi et al. (2013) 
Figura 16: Figuras retiradas do artigo de Barros et al. (2017) mostrando o sistema de forma geral, com o robô, ambiente de criação de linguagem um exemplo de linguagem e um smartphone com o aplicativo, e o ambiente de criação de linguagem de forma mais detalhada
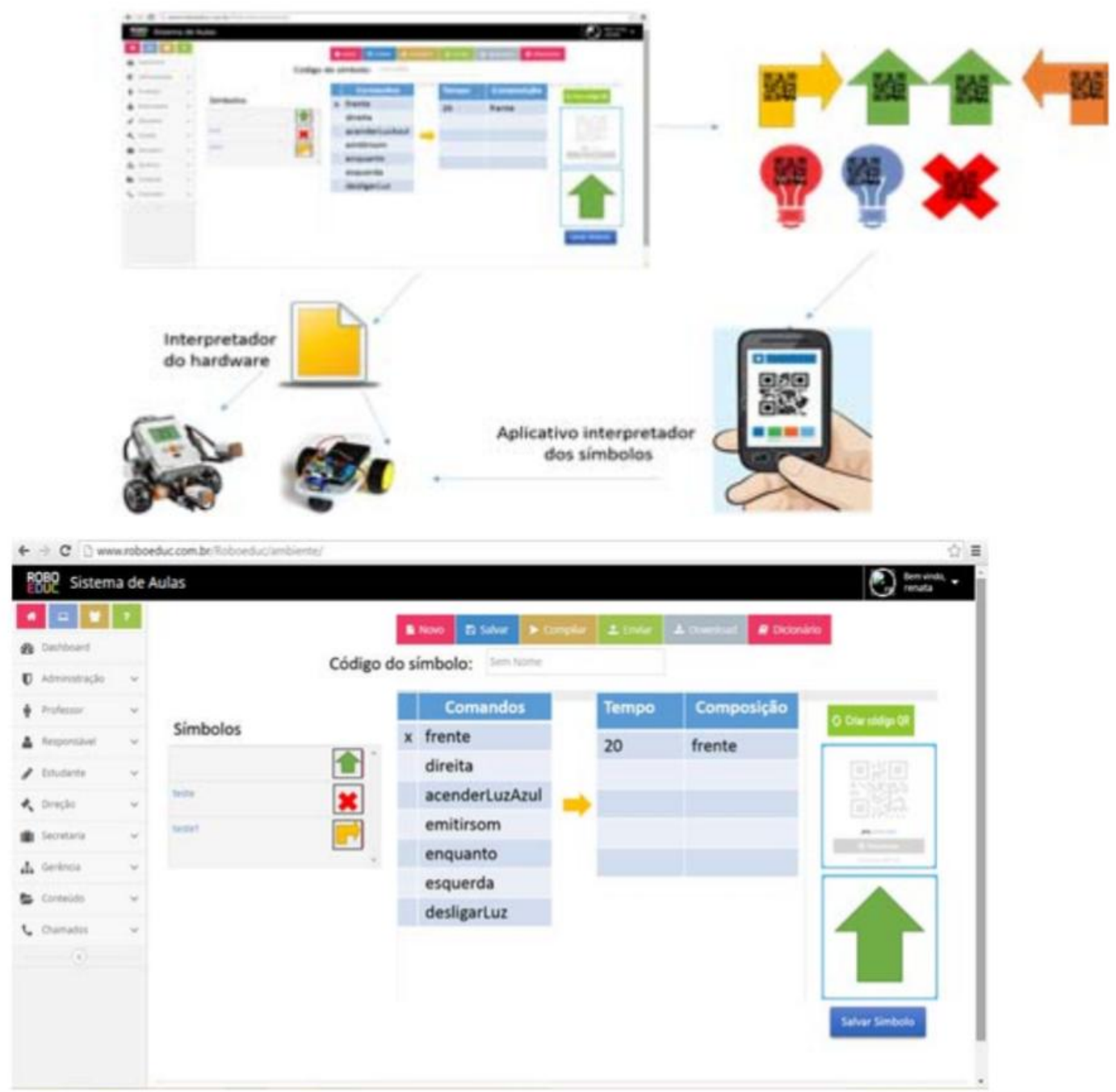

Fonte: Barros et al. (2017) 


\subsection{Interface tangível e aprendizado colaborativo}

O projeto Torino (Thieme et al., 2017) oferece uma linguagem de programação tangível para crianças entre 7 e 11 anos. As atividades com esta linguagem são colaborativas e inclusivas para crianças com deficiência visual. O código é feito utilizando módulos que são diferenciados pelas formas, tamanhos e com cores de alto contraste. Estes módulos podem ser ligados entre si e depois a um hub, onde ocorre o processamento de código e a execução. A saída desta linguagem é uma música ou uma história e os comandos utilizados para o código são: tocar, pausar e repetição. O sistema desenvolvido pode ser visto na figura 17.

O teste deste projeto foi feito com 10 crianças com diferentes níveis de deficiência visual, incluindo crianças videntes. As atividades eram feitas em pares e depois cada criança deveria explicar o que desenvolveu para o seu respectivo responsável, que estava presente no teste. Os autores relatam grandes achados em relação à dinâmica de colaboração entre crianças videntes e as com deficiência visual, como, por exemplo, as explicações das montagens de código que cada uma fazia. Também relatam a grande necessidade de resposta auditiva sobre o que está sendo feito no código, se algum módulo foi retirado ou está com mal contato. Por fim, para trabalhos futuros, testes em larga escala serão feitos. 
Figura 17: Figuras retiradas do artigo de Thieme et al. (2017) demonstrando o sistema e exemplos de interações entre as crianças enquanto brincam com o sistema
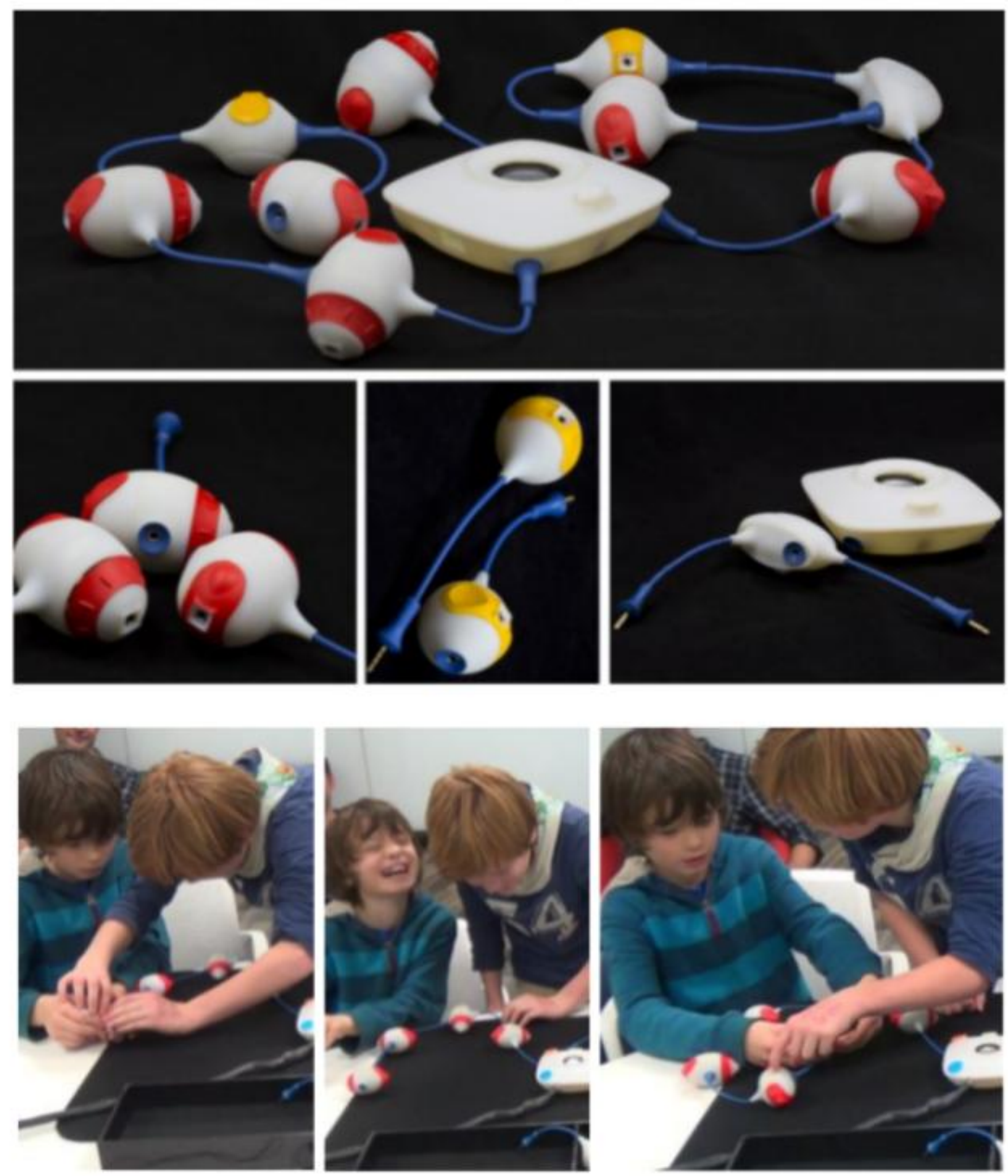

Fonte: Thieme et al. (2017) 


\subsection{Síntese dos trabalhos correlatos}

A tabela 1 mostra um resumo dos principais aspectos dos trabalhos descritos nos artigos selecionados. 


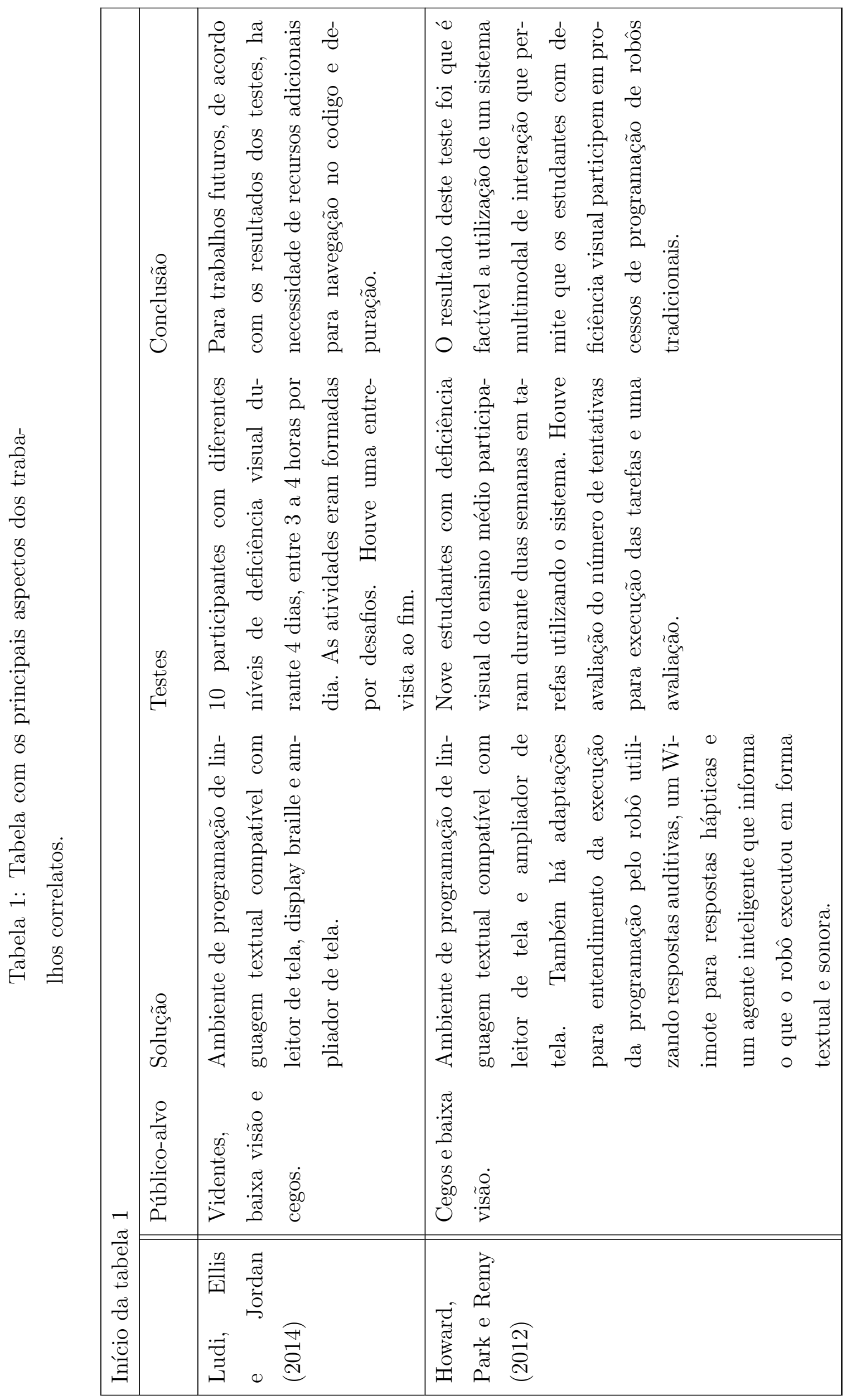




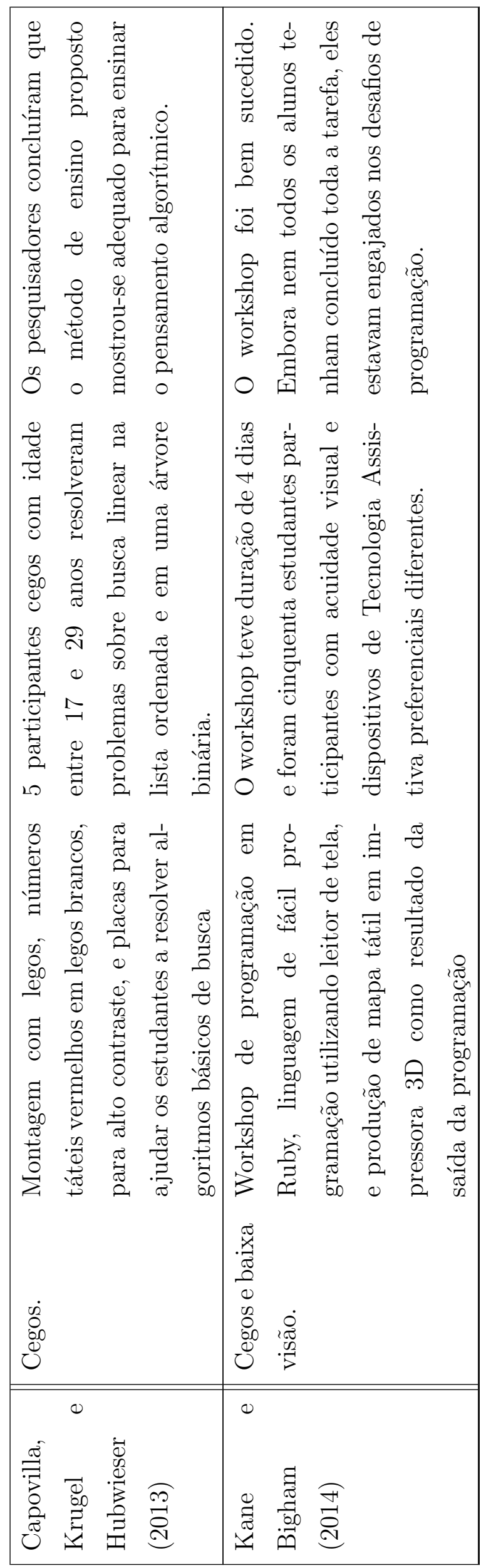




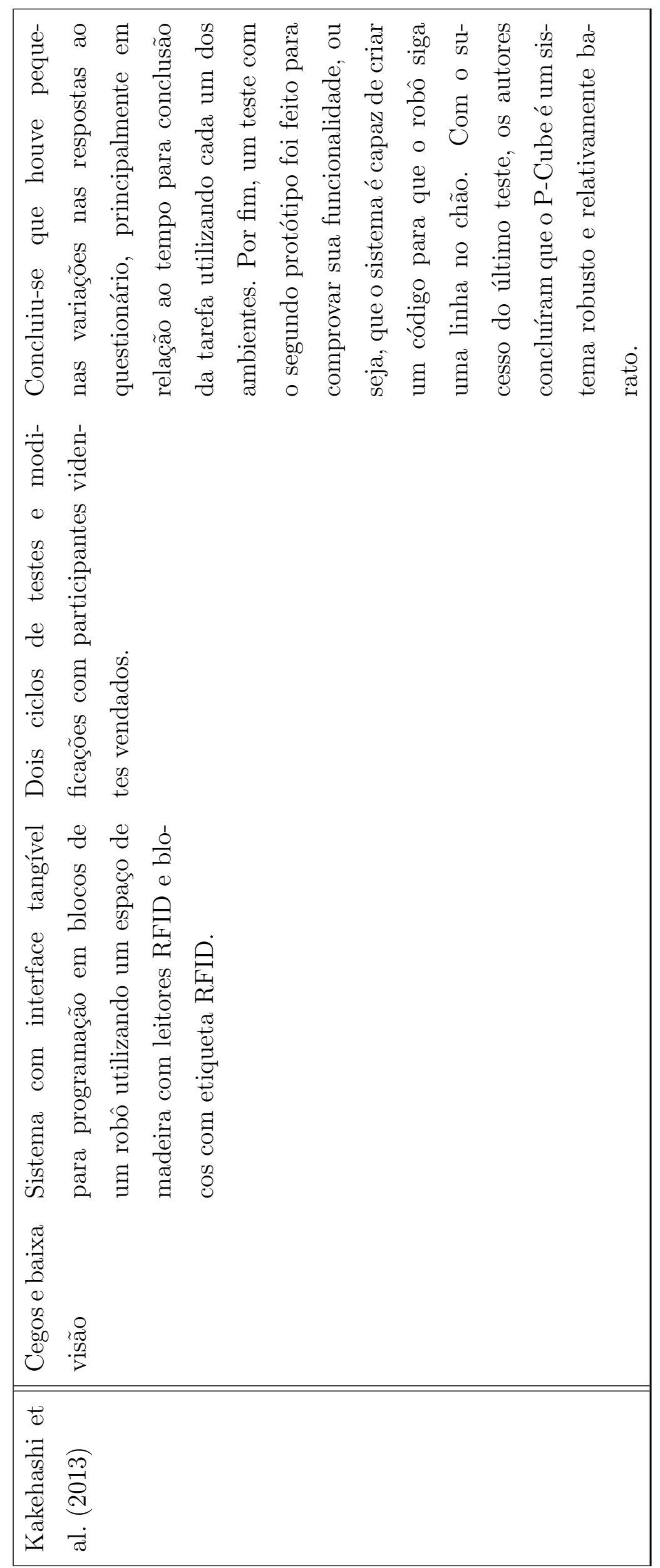




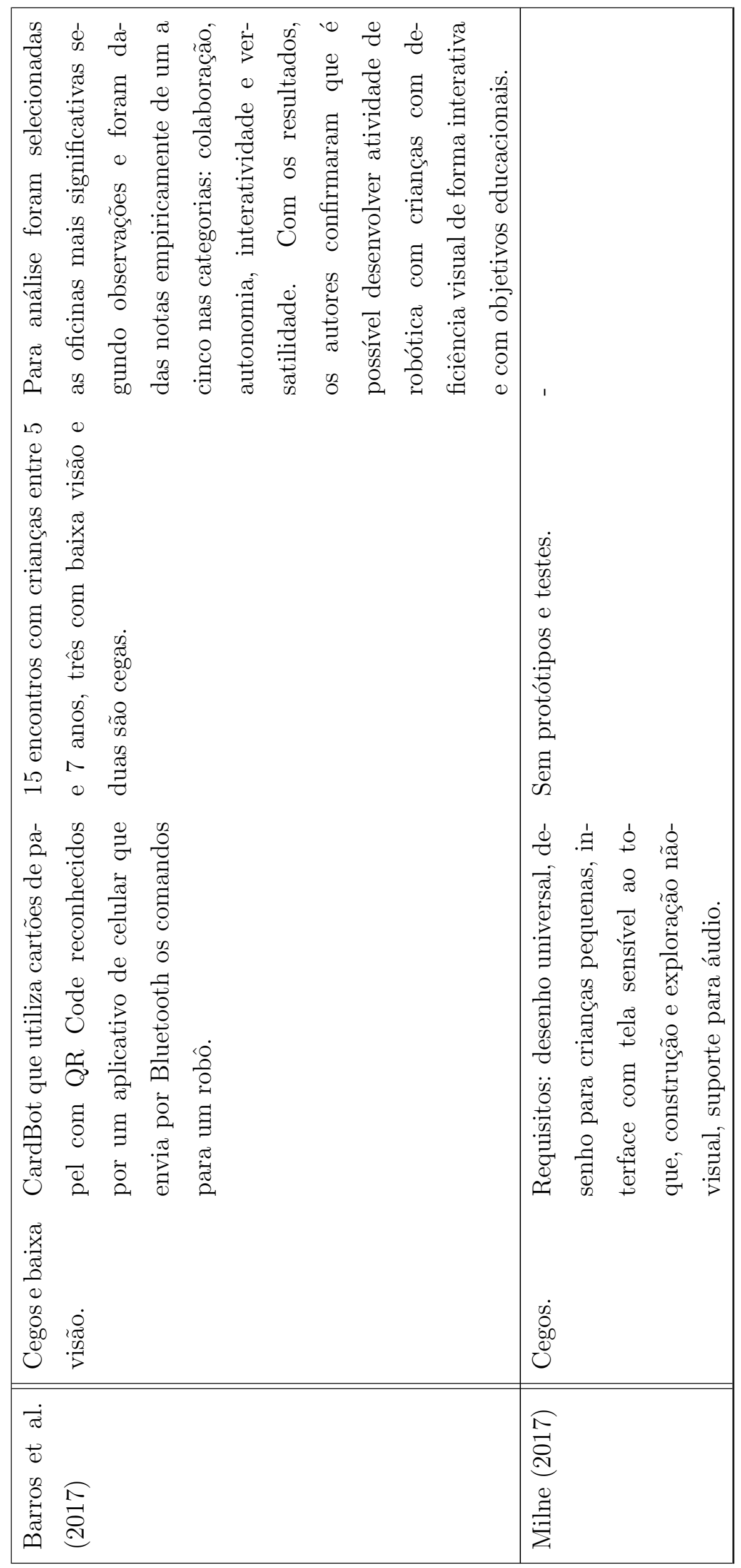




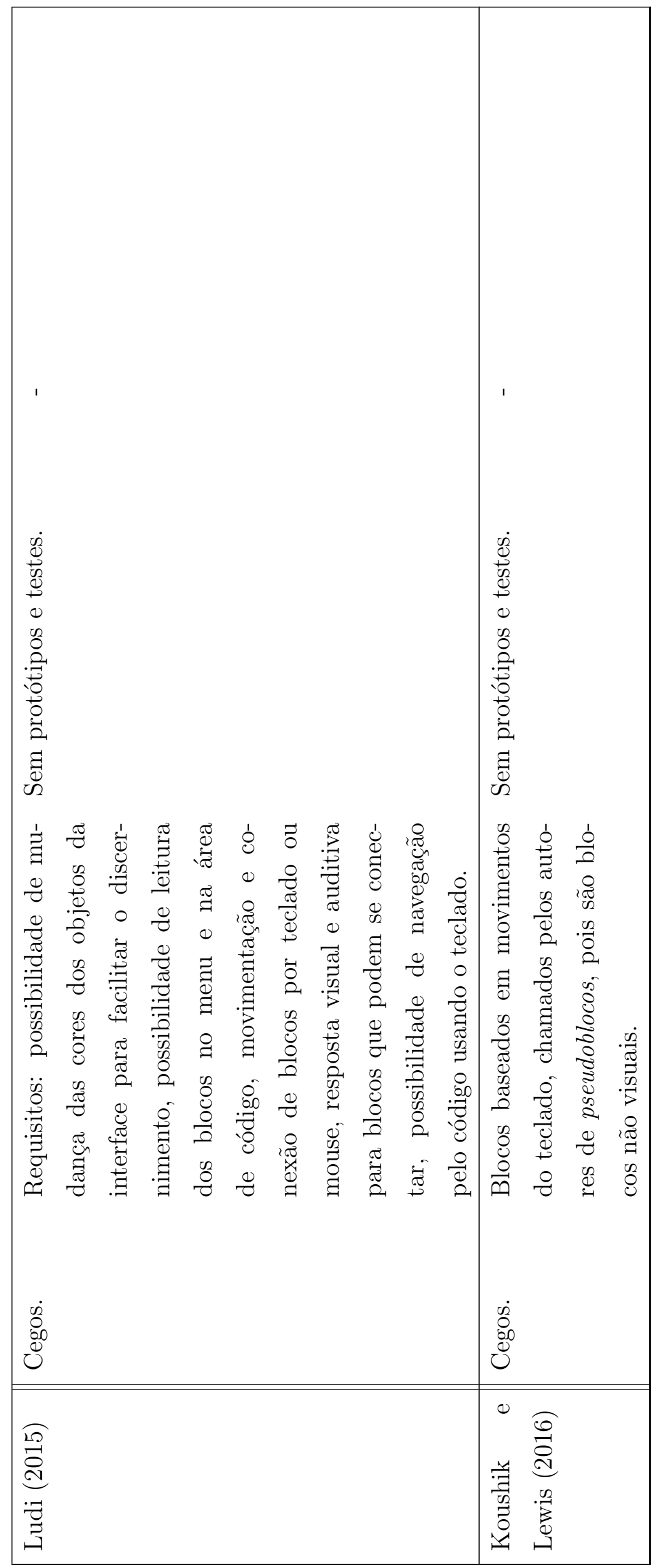




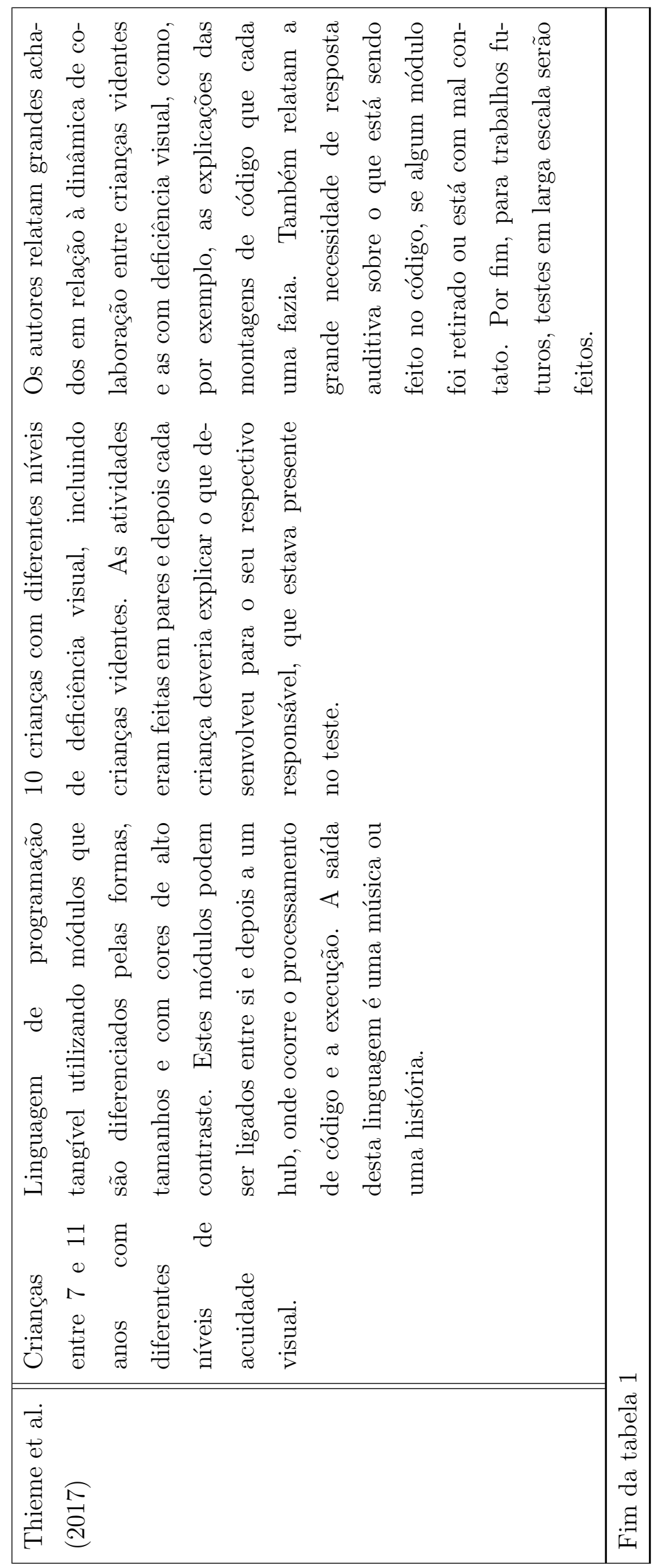




\subsection{Considerações}

Este levantamento sobre interfaces para ensinar e engajar crianças com deficiência visual a programar mostra a escassez de pesquisas sobre esse tema. Foram comentados projetos encontrados em duas bibliotecas digitais muito importantes, IEEE e ACM, e na maioria deles, como afirmam seus autores, mais testes com usuários e melhorias ainda são necessários. Wagner et al. (2016) expressa preocupação pela falta de uma solução inclusiva no caso de programação de blocos. Conclui-se que é de grande importância o desenvolvimento de uma solução inclusiva para crianças com deficiência visual para que, como ocorre na comunidade Scratch com crianças videntes, elas se envolvam em atividades de programação e se beneficiem das habilidades que podem ser desenvolvidas por meio dessas atividades.

Além da necessidade de inclusão, o presente trabalho busca no desenho universal uma forma de trabalho em grupo entre crianças cegas e videntes. Alguns trabalhos encontrados na literatura citam o trabalho em grupo. Barros et al., 2017; Kakehashi et al., 2013) e, principalmente, os autores Thieme et al. (2017) aprofundaram-se em como as interações entre estas crianças acontecem e podem ser benéficas, indo além de apenas habilidades provindas do ensino da programação.

A partir dos trabalhos encontrados, percebe-se que há uma lacuna nesta área de pesquisa: a falta de união das ideias já descritas em alguns trabalhos como funcionais para solução do problema de exclusão de crianças com deficiência visual e levantamento de novas ideias que possam não somente solucionar o problema já mencionado, mas também adicionar benefícios, como a possibilidade de trabalho em grupo.

Desta forma, o presente trabalho busca por recomendações para um sistema inclusivo de atividades de programação com linguagem tangível. Esta busca inclui aspectos de engenharia para desenvolvimento de protótipos e escolhas de tecnologias, desenho para criação das peças tangíveis e ensino para atingir propósitos educacionais. Assim, o presente trabalho têm relevância não somente na área de Engenharia, mas também nas áreas de Design e Educação. 


\section{MATERIAIS E MÉTODOS}

Para realização deste trabalho houve o levantamento na literatura das principais áreas e conceitos presentes no projeto, incluindo introdução à programação, Interface de Usuário Tangível, Deficiência Visual e Desenho Universal. Também foi feito um levantamento na literatura de trabalhos correlatos e uma conversa com uma pessoa com deficiência visual que administra um grupo de discussão sobre cegos programadores com o objetivo de conhecer as ferramentas utilizadas por pessoas com deficiência visual na programação e também na aprendizagem dos conceitos. A partir das informações obtidas, formalizou-se a hipótese deste trabalho que, para ser comprovada, necessita do desenvolvimento de um protótipo e avaliação deste com usuários.

Para o desenvolvimento do protótipo, adotou-se a metodologia Plan-D-Check-Act (PDCA) (Deming, 1986). As etapas deste trabalho, seguindo esta metodologia, podem ser vistas na figura 18. O planejamento caracterizou-se pelo levantamento de requisitos e elaboração da arquitetura, seguido pelo desenvolvimento do protótipo a partir de tecnologias que atentem aos requisitos e arquitetura do planejamento. Em seguida, testes foram feitos e analisados, voltando à primeira etapa de planejamento. 
Figura 18: Etapas do desenvolvimento do protótipo seguindo Metodologia PDCA

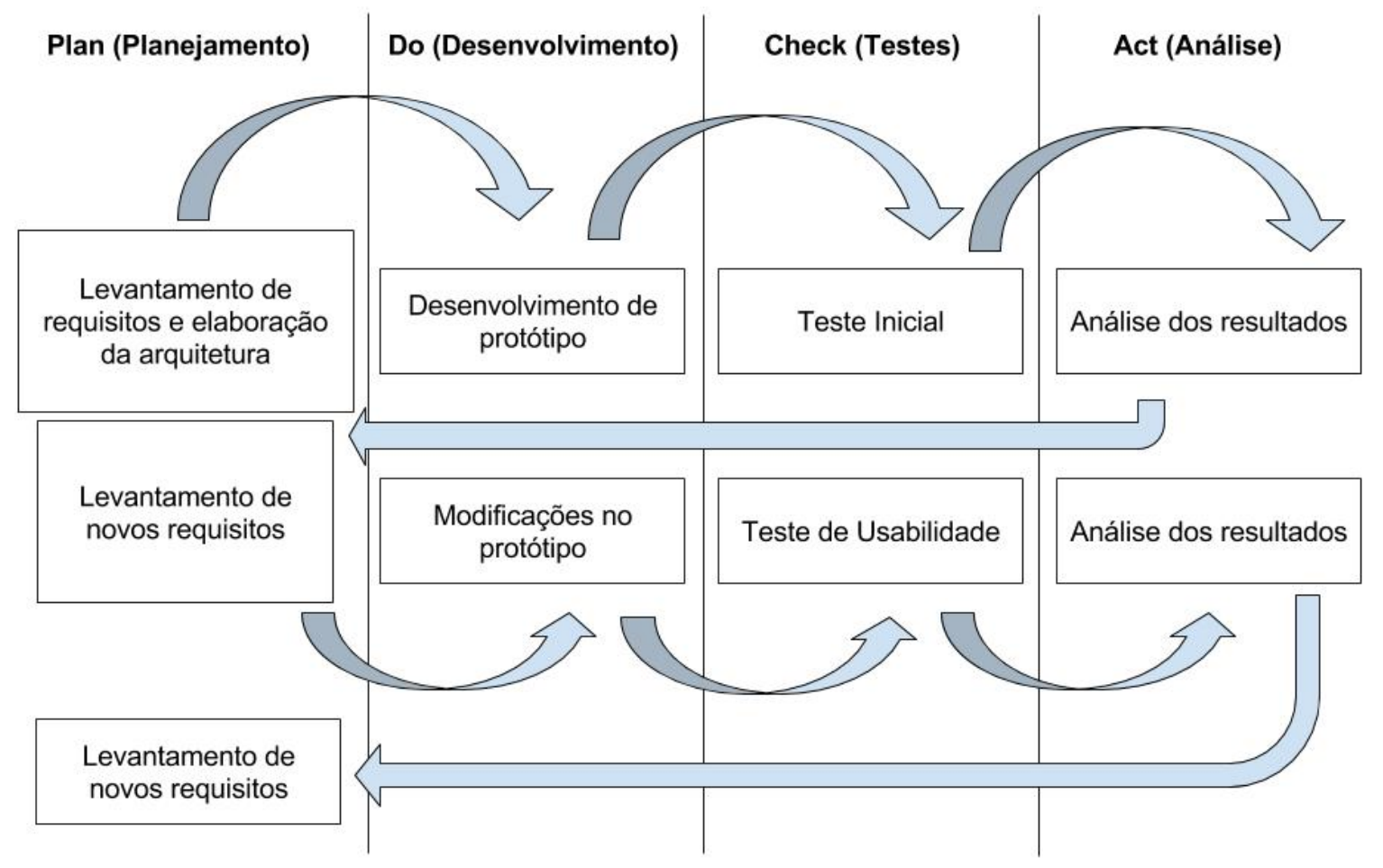

Fonte: Elaborada pela autora

Os testes foram elaborados com o objetivo de observar crianças cegas e videntes interagindo com o protótipo do sistema. Esta observação busca por formas de atender aos princípios de Desenho Universal. Com isso, a utilização do sistema deve ser flexível, simples, intuitiva, com informação perceptível, tolerante a erros, de baixo esforço físico e com espaço para integração de dispositivos de Tecnologia Assistiva. O resultado final deve ser um sistema que possui uso equitativo por crianças cegas e videntes.

Para realizar o primeiro conjunto de testes, chamado de teste inicial, foram necessários crianças ou adultos videntes ou com deficiência visual. Eles participaram individualmente e realizaram atividades de interação com o sistema por aproximadamente 50 minutos. Durante toda a atividade, os participantes foram questionados sobre suas decisões, o que esperavam para a saída da programação que realizaram e para explicarem, peça a peça, a programação desenvolvida. Ao fim das atividades, foi realizado um questionário que aborda as mesmas questões que o roteiro, mas com termos mais facilmente compreensíveis para as crianças, incluindo perguntas abertas para que pudessem se expressar mais livremente sobre a experiência vivenciada nos testes. Também foi feita uma análise do desempenho nas atividades em uma escala de 1 a 3, sendo 1 insatisfatório, 2 satisfatório e 3 muito satisfatório. As atividades foram gravadas a fim de verificação posterior dos 
testes, o que facilita a observação mais detalhada da interação entre o participante e o sistema. O guia para coleta de dados do teste está no Apêndice A.

Após as modificações do sistema de acordo com os resultados do teste inicial descrito anteriormente, foram realizados testes de usabilidade. Estes testes são formados por atividades que priorizam o entendimento de conceitos fundamentais de programação e também possibilitam que crianças interajam juntas com o sistema. Os testes contaram com crianças, de 5 a 12 anos, com pelo menos uma criança com deficiência visual. As atividades foram divididas entre atividades de conceitos de programação, individuais, e em grupo. As atividades de conceito são desafios que precisam ser resolvidos a partir de conceitos de programação, sendo eles: sequência, decisão e repetição. As atividades em grupo são projetos livres e tem por objetivo observar o comportamento das crianças enquanto brincam juntas com o sistema. O tempo de duração do teste é de aproximadamente 50 minutos por criança. Os questionamentos da pesquisadora sobre as decisões das crianças e a programação se mantêm como feito nos testes anteriores.

Ao fim, cada criança responde a um questionário de usabilidade que está no Apêndice C. Este questionário foi feito a partir de tradução livre do System Usability Scale (SUS) desenvolvido por John Brooke (1986 apud Lewis e Sauro, 2009), que possui dez afirmações com respostas em escala Likert de cinco pontos em que a posição cinco significa concordo totalmente e a um, discordo totalmente. Também foi feita uma análise de desempenho de acordo com a observação da pesquisadora com a mesma escala dos testes anteriores, conforme o guia do Apêndice B. Todas as atividades foram gravadas a fim de permitir análises da interação das crianças com o sistema e também, no caso da atividade em grupo, da interação entre as crianças.

Os testes foram aprovados pelo Comitê de Ética em Pesquisa do Hospital Universitário da USP sob Certificado de Apresentação para Apreciação Ética (CAAE) 67842917.7.0000.0076 e os documentos de aprovação estão no Anexo A. 


\section{PROPOSTA DE SISTEMA}

Este capítulo apresenta a proposta de sistema por meio de requisitos funcionais e não funcionais e os protótipos e testes desenvolvidos a partir destes requisitos.

\section{$5.1 \quad$ Requisitos}

Os requisitos descritos a seguir são embasados na literatura, nas conversas com profissionais das áreas de interesse deste projeto e nos resultados dos testes realizados.

\subsubsection{Requisitos funcionais}

1. O sistema reconhece peças tangíveis presentes em uma área delimitada;

2. O sistema gera uma lista com as peças na ordem em que estão na área do código;

3. O sistema cria os blocos digitais no Scratch de acordo com a lista de peças;

4. O sistema executa a programação;

5. O sistema emite sons em resposta a determinadas interações do usuário.

O primeiro requisito funcional é de grande importância, pois é a primeira função executada pelo sistema e que promove as outras funções. Assim, a partir deste requisito de reconhecimento, o sistema gera a lista referente ao segundo requisito e, em seguida, é capaz de criar os blocos digitais no Scratch, o terceiro requisito. A execução da programação, quarto requisito, também depende da criação dos blocos, já que a execução da programação é feita dentro do ambiente Scratch. O último requisito é importante para facilitar a interação com crianças cegas e uma forma alternativa às respostas visuais presentes no Scratch, confirmando à elas que certas interações ocorreram com sucesso. 


\subsubsection{Requisitos não funcionais}

1. O sistema é uma linguagem de programação tangível formada por peças tangíveis que representam comandos de programação;

2. O sistema possui desenho universal;

3. Crianças cegas e videntes conseguem identificar e diferenciar as peças tangíveis da programação;

4. Crianças cegas e videntes conseguem unir as peças tangíveis pelos encaixes;

5. As peças tangíveis possuem o sistema Braille;

6. As peças tangíveis possuem graus de liberdade de movimentação limitados quando colocadas na área de programação;

7. A programação formada pelas peças tangíveis é entendida por crianças cegas e videntes;

8. As crianças cegas e videntes executam a programação no momento que desejarem;

9. A saída da programação é percebida pelas crianças cegas e videntes;

10. O sistema segue os princípios de desenho do Scratch: mais tinkerable, mais significativo e mais social (Resnick et al., 2009).

Os requisitos não funcionais caracterizam o sistema como uma linguagem de programação tangível e com os princípios de Desenho Universal e do Scratch. Assim, a construção do código de programação é feita por meio de peças tangíveis que representam funções e conceitos de programação. O desenho destas peças é acessível tanto para crianças videntes quanto para cegas, pois possuem identificação tátil e visual e o encaixe entre elas, o código que formam e a saída da programação podem ser experimentados independentemente da acuidade visual. Também, em relação ao desenho, por ser baseado nos blocos digitais e ideias do Scratch, o sistema permite que não exista instruções do que ou como deve ser programado, ou seja, a programação flui naturalmente, que a criança possa criar algo em que ela tenha interesse pessoal e que ela interaja com outras crianças. Outros requisitos serão explicados posteriormente neste documento. 


\subsection{Arquitetura do protótipo do sistema}

A metodologia, descrita no capítulo 4, foi seguida para iniciar as tomadas de decisões principalmente sobre as tecnologias do protótipo do sistema. Foram feitos levantamentos na literatura e uma conversa com com uma pessoa cega e que gerencia um grupo de cegos programadores. Esta conversa trouxe, por parte do entrevistado, o desconhecimento de qualquer ferramenta para a aprendizagem de programação para crianças e também que, em sua maioria, as pessoas cegas utilizam meios comuns a todos para o aprendizado, como livros e buscas na Internet. Entretanto, houve uma contribuição importante nesta conversa: a preocupação da pessoa em relação ao abandono do Sistema Braille. Hoje as crianças possuem livros digitais e computadores com leitores que dispensam o uso do braille. Esta preocupação também foi demonstrada por professores da educação especializada, demonstrando que o Sistema Braille precisa estar presente no projeto.

O levantamento da literatura levou à escolha da interface do sistema como sendo tangível. Ela foi escolhida baseando-se no fato do tato ser um sentido importante para pessoas cegas, o que pode ser percebido com a tendência em adicionar interações hápticas em sistemas acessíveis à estas pessoas. Assim, surgiu o interesse em sair do digital e testar um protótipo com peças físicas. A partir desta escolha, iniciaram-se algumas pesquisas sobre como seria o reconhecimento das peças tangíveis. Partindo da literatura e também da intenção da pesquisadora de desenvolver algo de fácil replicação por alguém sem conhecimentos técnicos na área de tecnologia, o processamento de imagens utilizando uma webcam foi definido como a melhor escolha. Este envolve a colocação de imagens predeterminadas, chamadas de marcadores, nas peças para diferenciá-las e uma webcam para capturar as imagens.

Outra decisão foi desenvolver o protótipo como uma nova forma de interação com o Scratch 3.0. Esta decisão aconteceu a partir da visita ao LLK, grupo que desenvolveu o Scratch e teve grande importância para o projeto. Esta importância é devido à utilização da versão que ainda será lançada do Scratch, a versão 3.0. Assim, com alguns ajustes, o protótipo poderá ser utilizado junto a este em escolas ou ambientes informais. Também decidiu-se por utilizar somente peças de comandos de som, pois as saídas do Scratch, em sua maioria, são somente visuais.

Podemos representar o protótipo a partir da arquitetura apresentada na figura $19 \square^{1}$

A figura 20 apresenta o protótipo do sistema com suas partes principais: o computador

\footnotetext{
${ }^{1}$ Créditos à figura da webcam: By Mazenl77 (FindIcons) [CC BY or CC BY 3.0-2.5-2.0-1.0 (〈http: //creativecommons.org/licenses/by/3.0-2.5-2.0-1.0 )], via Wikimedia Commons
} 
Figura 19: Arquitetura do protótipo do sistema

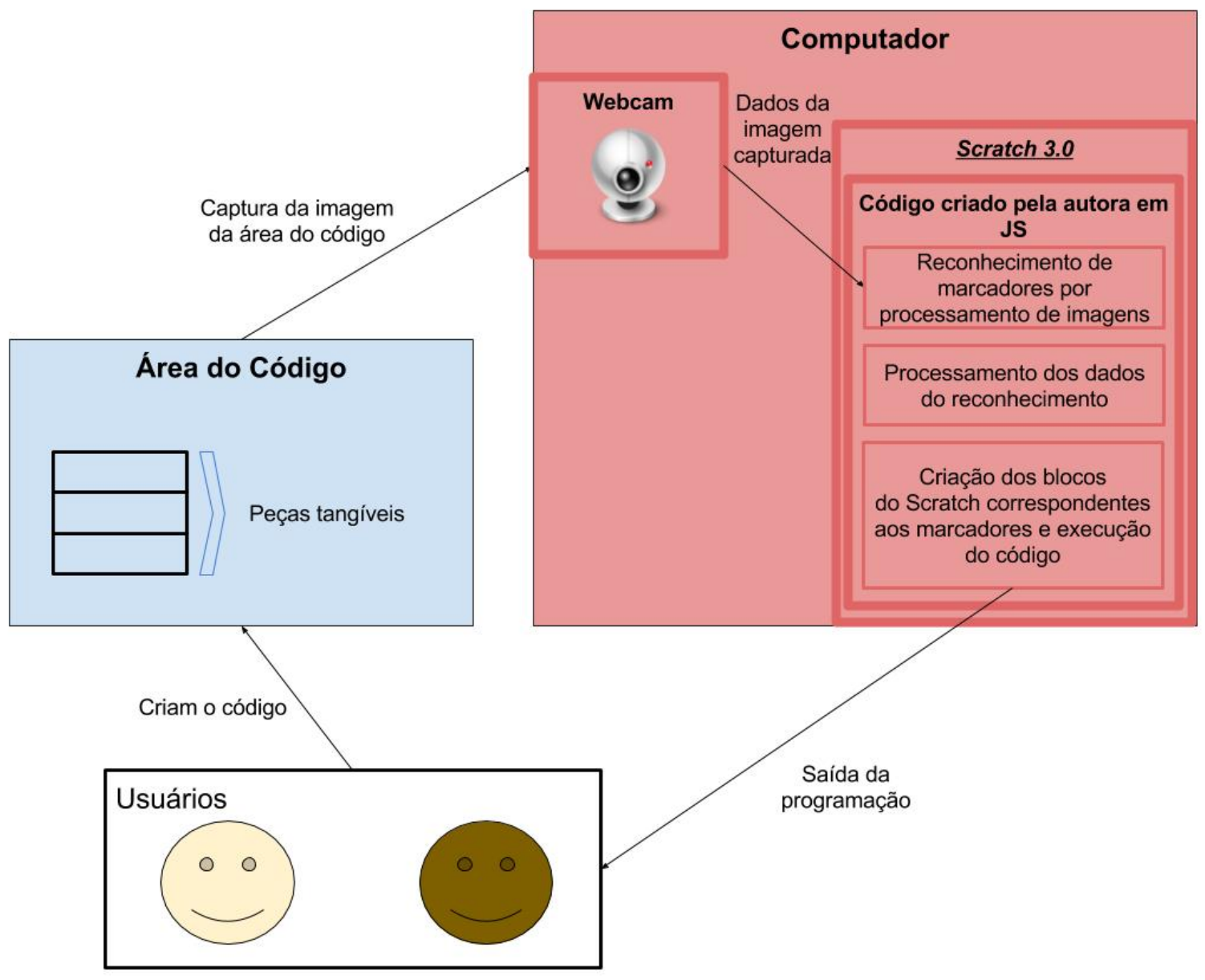

Fonte: Elaborada pela autora

(1) e o suporte montado de lego (3) com a webcam (2) que registra as imagens da área de código em uma superfície plana delimitada (4). O computador utilizado nos testes possui sistema operacional Ubuntu 16.04LTS, processador Intel CORE i5 4210U e memória RAM com 8GB. A webcam utilizada é a Microsoft LifeCam VX-7000, com resolução de 2MP para vídeo e gravação widescreen e está apresentada na figura 21 ao lado da estrutura de lego montada. 
Figura 20: Protótipo do sistema e suas partes principais

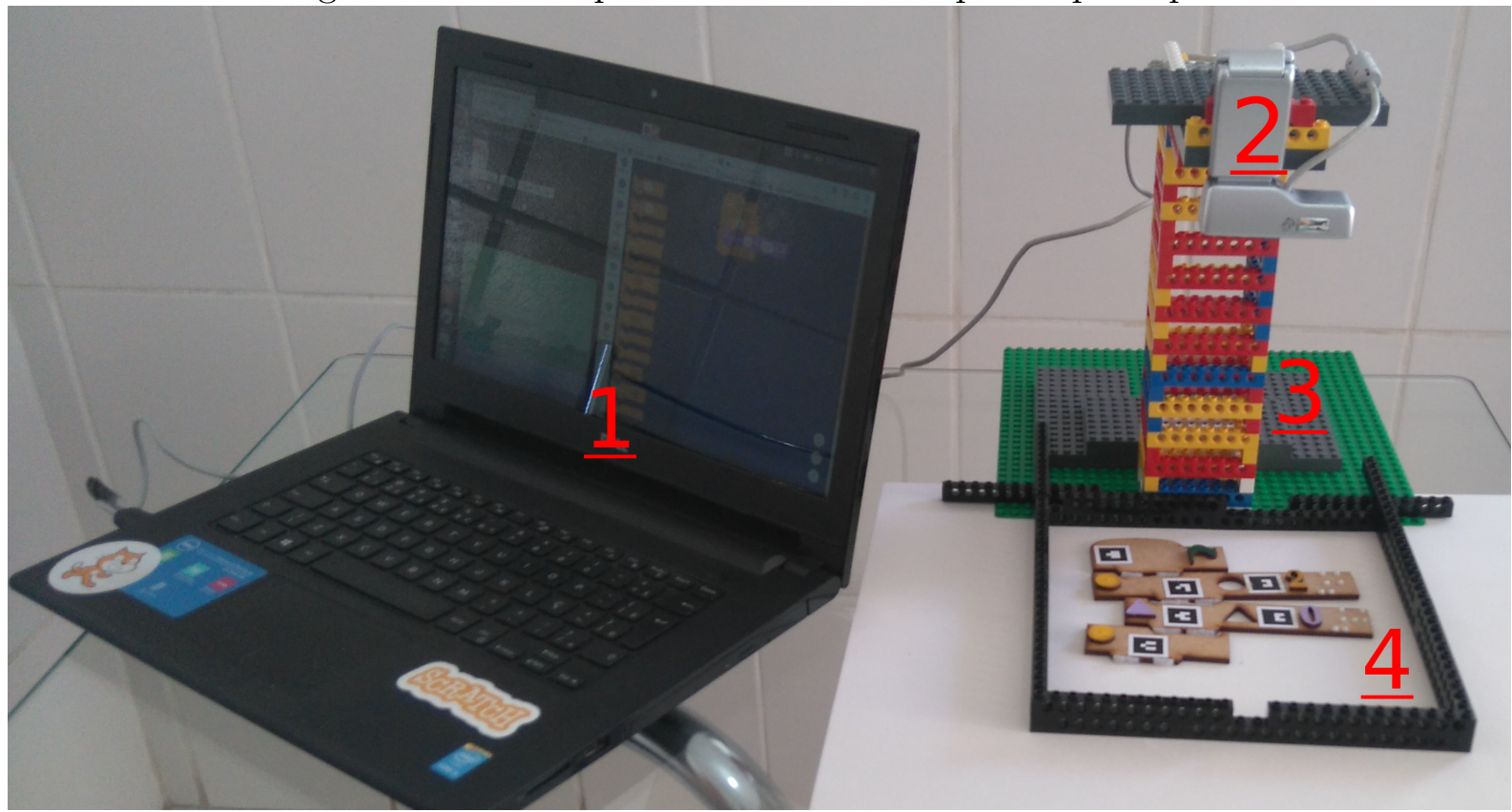

Fonte: Elaborada pela autora

Figura 21: Imagem da estrutura de Lego à esquerda e webcam à direita

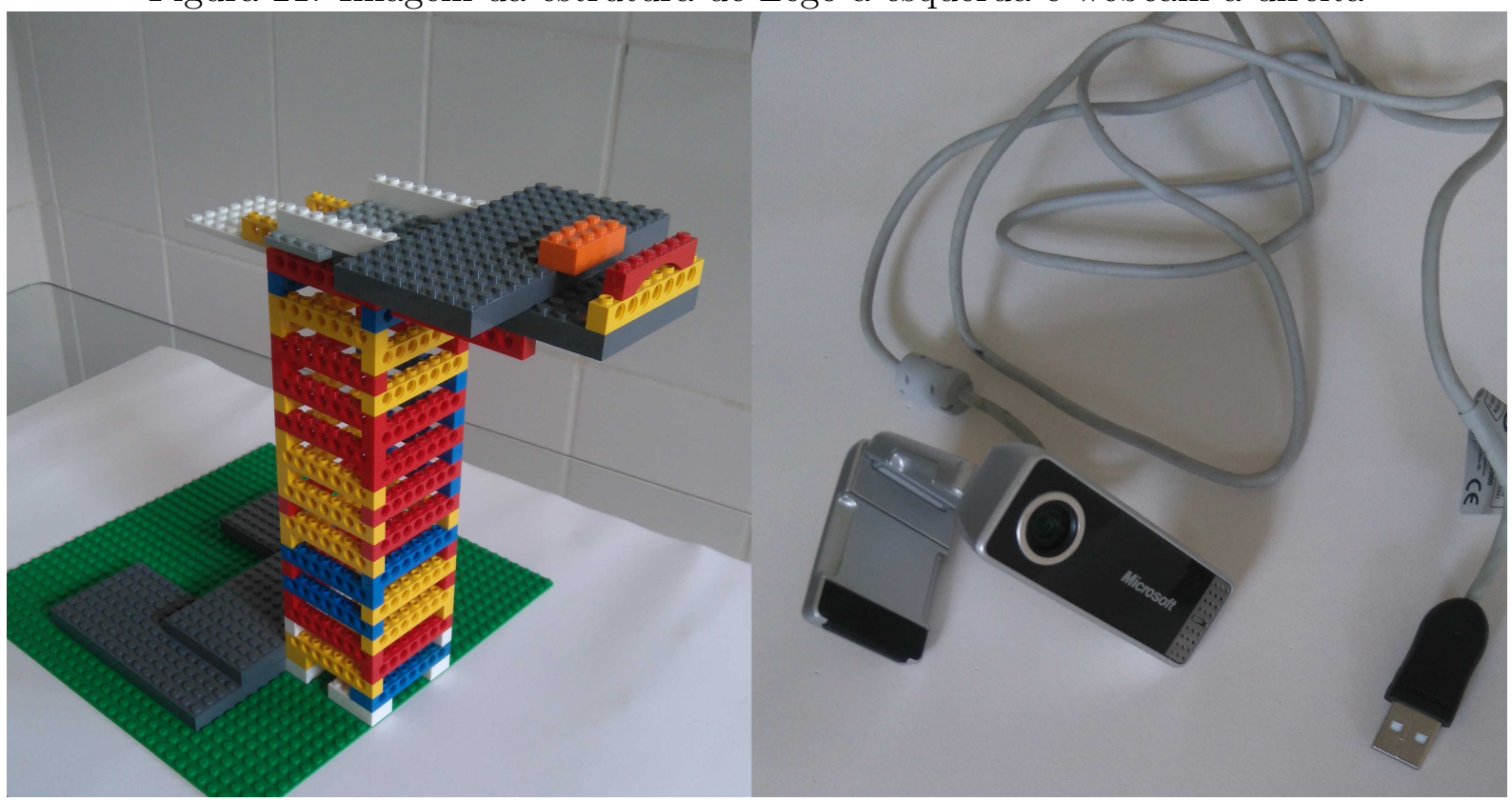

Fonte: Elaborada pela autora 


\subsection{Primeiros protótipos e testes}

Iniciaram-se alguns testes para definição de como seria o reconhecimento das peças tangíveis a partir de processamento de imagens utilizando uma webcam. A primeira biblioteca encontrada foi a TOP Code ${ }^{2}$ escrita em Java e utilizada no Tern (Horn e Jacob, 2007), um ambiente de programação tangível para crianças. Apesar de se apresentar funcional para esta etapa de reconhecimento, esta biblioteca não permitia fácil integração ao Scratch 3.0, que tem seu código em JavaScript. Partiu-se então, antes de iniciar uma integração entre o Scratch e o Top Code, para uma busca por outra biblioteca de reconhecimento de imagens escrita em JavaScript.

Tentou-se a partir de reconhecimento de códigos de barras, mas houve limitações em relação à resolução da imagem para obtenção do código, o que exigiria uma câmera de alta resolução, ao número de códigos reconhecidos em uma imagem e também à falta de liberdade de posição das peças com o código, já que a leitura não era feita se o código de barras estivesse muito inclinado.

Por fim, encontrou-se a biblioteca ARToolKit.js, ou seja, a biblioteca ARToolKit, utilizada em aplicações de Realidade Aumentada, portada para JavaScript. Assim, a integração com o Scratch foi facilitada e uma funcionalidade muito importante do protótipo já estava funcionando: uma peça tangível sobre a mesa se tornava um bloco digital no Script do Scratch como mostrado na figura 22 .

Figura 22: Peça tangível da esquerda é criada no Scratch como um bloco

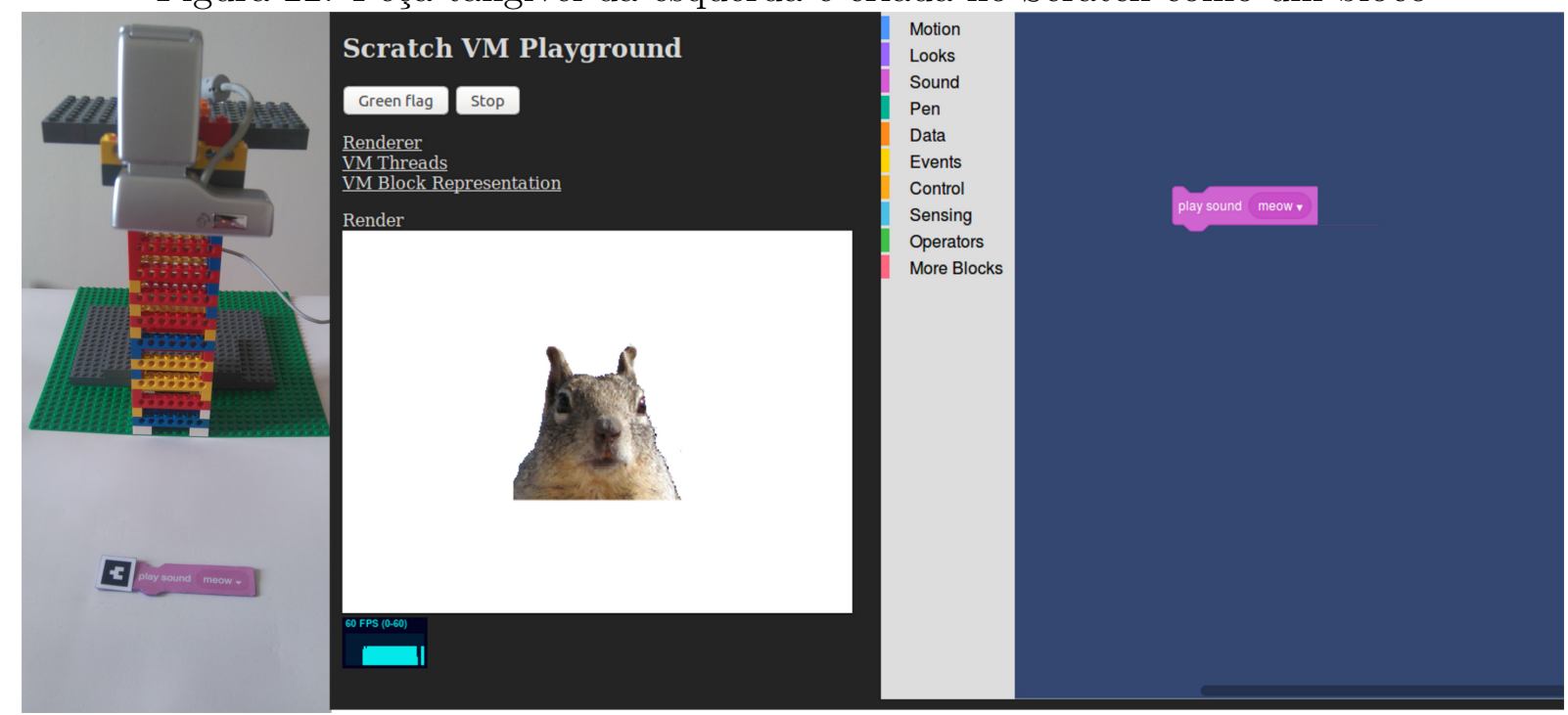

Fonte: Elaborada pela autora

\footnotetext{
${ }^{2}$ The TopCode computer vision library. Disponível em: $\langle$ http://users.eecs.northwestern.edu/ mhorn/ topcodes $\rangle$
} 
Percebeu-se que a utilização desta biblioteca necessitava de uma pequena borda branca ao redor dos marcadores para que o reconhecimento fosse bem sucedido. Mais detalhes deste reconhecimento estão descritos em 5.4 .2 na página 85 .

Algumas modificações foram necessárias para criação de mais de um bloco. Estas modificações exigiram o entendimento de como os blocos no Scratch eram criados a partir do mouse, interação padrão, e depois unidos de acordo com as instruções dadas pelo usuário, que também eram pelo mouse. Também foram desenvolvidas rotinas para criação dos blocos de controle do Scratch que possuem blocos em seu interior que, no caso do primeiro protótipo, é a repetição.

Na área de código, as crianças montam as peças, que possuem marcadores de Realidade Aumentada. A imagem desta montagem é capturada por uma webcam e é processada pela biblioteca ARToolKit.js gerando uma repetição infinita de identificação dos marcadores e suas posições espaciais. Esta biblioteca é utilizada para formar uma lista ordenada dos marcadores. Isto é feito supondo que sempre o início do código montado pela criança é o marcador de número zero, que representa a bandeira verde, e também que a criança pode montar somente uma pilha de peças. Assim, a lista já mencionada é formada repetidamente e sempre esvaziada quando o marcador do número zero é encontrado. As figuras 23 e 24 mostram o fluxograma geral do código desenvolvido e um com maior profundidade da função de criação dos blocos no Scratch, respectivamente. Na figura 23, os processos em rosa simbolizam os processos feitos pela biblioteca utilizada e não foram, desta forma, feitos pela autora. Também se nota na figura 23 o paralelismo existente no código, pois há qualquer momento que a criança pressionar a tecla de espaço do teclado o código criado a partir das peças tangíveis será executado. E estes processos feitos a partir do evento do teclado utilizam listas que estão em constante modificação no fluxo da esquerda e esta utilização faz com que seja necessário um controle que interrompa a modificação dessas listas, que é feito pelo indicador de parar leitura, uma variável booleana. 
Figura 23: Fluxograma do código desenvolvido

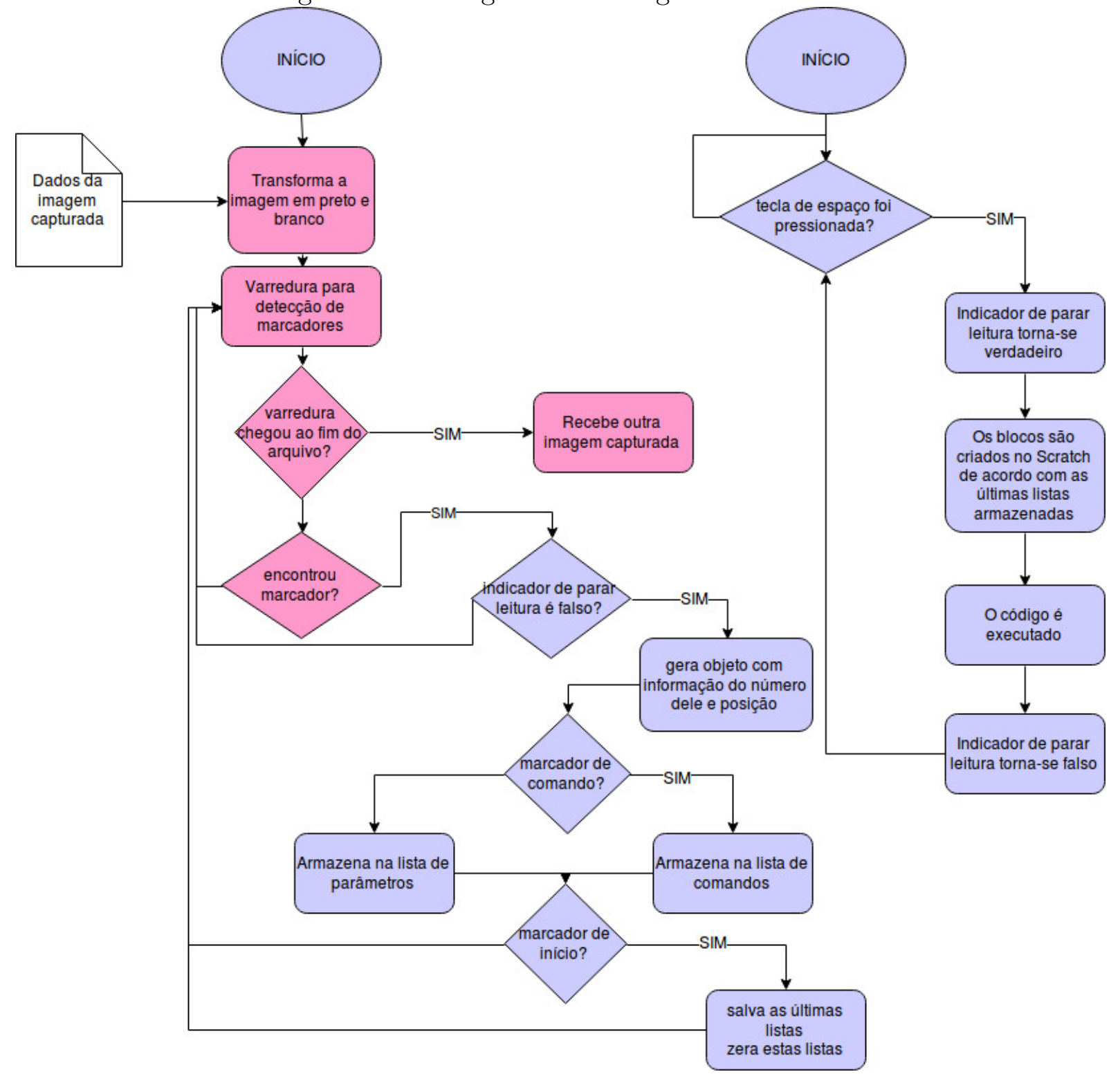

Fonte: Elaborada pela autora 
Figura 24: Fluxograma do código para criação de blocos no Scratch

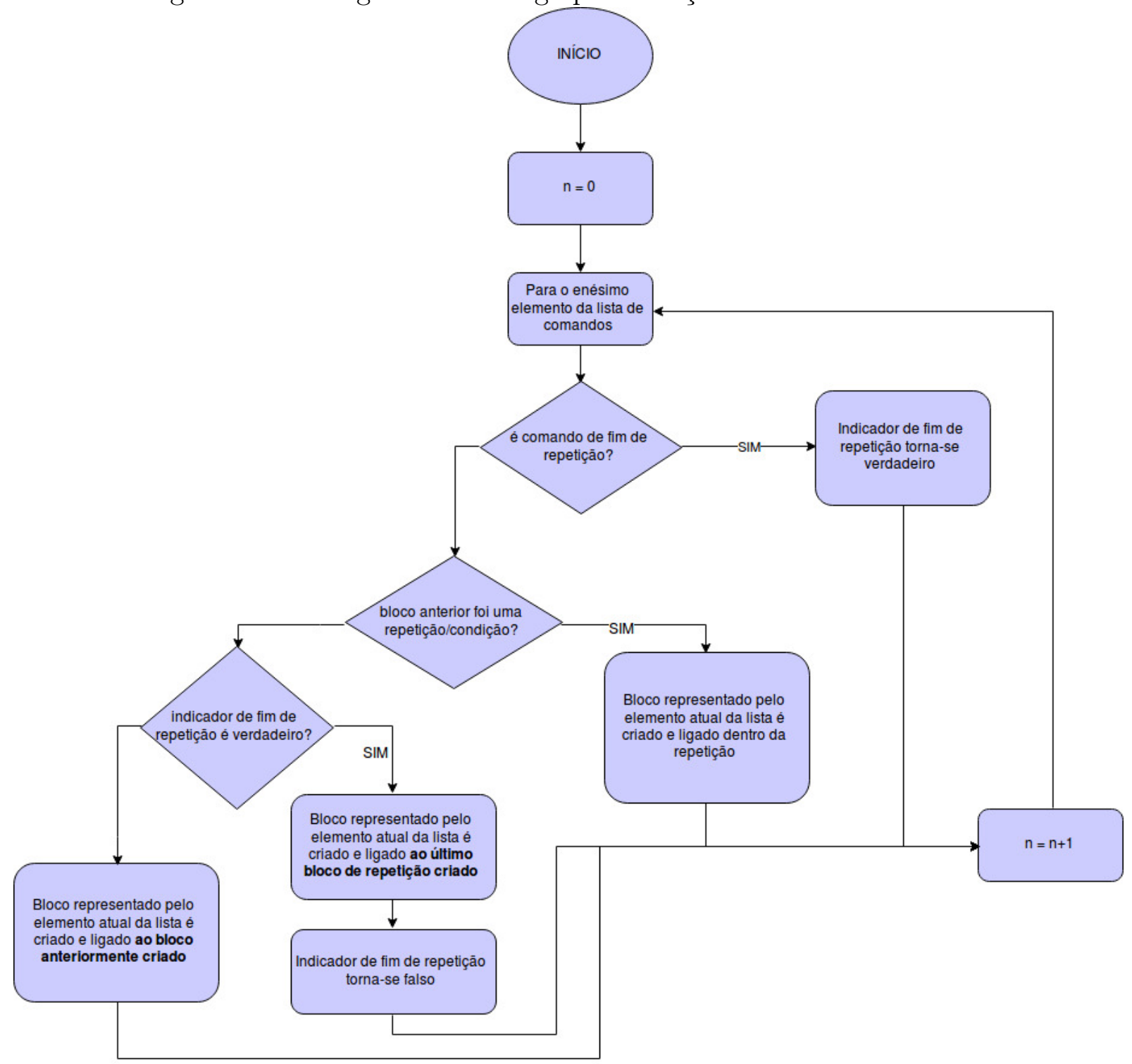

Fonte: Elaborada pela autora 
O código pode ser visto em

$\langle$ https://github.com/isabela-angelo/scratch-tangible-blocks〉. No Apêndice D encontrase uma explicação da estrutura de código e como executar este código desenvolvido. E no Apêndice E, o código desenvolvido.

Como exemplo, se tivermos três peças: marcador 0 seguida pelo marcador 1 e depois pela marcador 2, a leitura de marcadores seria, de forma infinita: 2, 1, 0, 2, 1, 0 e assim por diante. Esta leitura inicia no marcador 2 devido ao posicionamento da webcam que está gerando a imagem processada. Assim, o marcador 2 seria identificado e adicionada primeiro à lista e depois o marcador 1. Com a identificação do marcador 0, a lista de marcadores é zerada, o zero é adicionado e voltamos para a repetição de identificação de marcadores, adicionando o 2 e depois o 1 , e assim de forma repetitiva.

Ainda neste exemplo, se forem estas as três peças montadas pela criança, para executálas é necessário apertar a tecla de espaço no teclado. O resultado desta ação é a paralisação da geração da lista de marcadores e utilização da última lista gerada para a criação dos blocos no Scratch. Esta última lista é formada por 0, 2 e 1, nesta ordem.

A criação dos blocos no Scratch se inicia com a exclusão de todos os blocos que podem estar no Scratch. Depois, a última lista de marcadores é modificada, obtendo a ordem correta dos marcadores: 0, 1 e 2, e funções são chamadas para criação de blocos, feita a partir de um dicionário, com as chaves sendo os números dos marcadores e os valores, os blocos do Scratch, e o encaixe entre eles. Ainda em relação ao exemplo, tem-se a chave 0 com o valor "greenFlag_block", chave 1 com valor "meow_block"e a chave 2 com o valor "drum_block". Por último, uma função é chamada para executar a programação, cuja saída são baseadas em sons, e a repetição da geração da lista de marcadores volta a ser feita até a próxima vez que a criança decidir apertar a tecla de espaço, ou seja, queira executar a programação feita.

Em relação aos parâmetros, a lógica é parecida. As peças de parâmetros são reconhecidas a partir de marcadores, do fim para o início da pilha de peças, e seus números são salvos em uma lista de parâmetros. Esta lista também é reiniciada toda vez que o marcador de número 0 é reconhecido. Na função de criação dos blocos do Scratch, a última lista de marcadores é invertida e funções são chamadas para mudança dos parâmetros dos blocos depois da criação de cada um.

Em seguida, as decisões passaram a ser em relação ao desenho das peças: tamanho, conexão para a união entre elas, cores, formas e identificação para pessoas videntes e com deficiência visual. Inicialmente, as peças eram feitas com Ethylene Vinyl Acetate 
(EVA), mas já se percebeu a necessidade de um material rígido para que a montagem da programação fosse facilitada. As opções que teriam esta rigidez necessária são: papelão e Medium Density Fiberboard (MDF). Pela facilidade de compra e preço, o papelão foi escolhido para testar as questões de desenho das peças. Os desenhos das peças foram feitos no programa Inkscap $£^{3}$ e cortadas utilizando uma cortadora laser. Assim, as peças possuem as características listadas a seguir.

- as peças têm o mesmo formato dos blocos do Scratch, ou seja, são retangulares e possuem encaixes para que as peças se unam formando uma sequência de peças na vertical. A diferença em relação ao Scratch é o tamanho dos encaixes, que foram aumentados com o objetivo de facilitar a junção das peças como pode ser visto na figura 28 ,

- cada peça tem uma forma geométrica em relevo no início da peça que representa seu comando. Então, por exemplo, a peça "tocar som" tem um triângulo em relevo e todos com este mesmo comando também. As figuras 26 e 27 mostram a representação de peças de som por triângulos e as de controle por círculos;

- se um conjunto de peças tem comandos parecidos, este possui a mesma forma geométrica, mas desenhos em relevo são acrescentados à forma, como por exemplo um ponto em alto relevo. A figura 26 tem um exemplo de dois comandos diferentes de som: tocar som e tocar tambor, nesta ordem, e se percebe um ponto em relevo no triângulo da segunda peça;

- as peças possuem parâmetros padrões, como por exemplo o som "miau" para a peça "tocar som". Antes deste parâmetro há um buraco de encaixe, mais ou menos no meio da peça, de mesma forma geométrica da peça para que o parâmetro seja trocado;

- as peças de parâmetros são peças diferenciadas. Estes são chapas retangulares, com um forma geométrica de suas respectivas peças de comando de uma lado e do outro possuem a mesma forma geométrica também em relevo para encaixe como pode ser visto na figura 29. Dando um exemplo, a peça "tocar som" além do triângulo em relevo no início do bloco possui um buraco em forma de triângulo onde se pode encaixar outro parâmetro e mudar o parâmetro padrão. Esta mudança acontece porque o projeto utiliza processamento de imagens e os blocos de parâmetros tapam o parâmetro padrão;

\footnotetext{
${ }^{3}$ Disponível em: $\langle$ https://inkscape.org/ $\rangle$
} 
- cada forma geométrica possui uma cor seguindo a ideia de conjunto de peças com comandos parecidos. Isto também é utilizado no Scratch, onde há conjunto de blocos de controle, de sons, de movimento, entre outros, com cores determinadas e que são seguidas neste projeto de linguagem de programação tangível;

- peças que possuem comandos que se relacionam às condições e repetições, ou seja, que possuem peças em seu interior, possuem um desenho diferente do Scratch. Neste último, por ser digital, os blocos se estendem conforme mais blocos são inseridos dentro deles. Para manter a analogia de ter algumas peças dentro de um outra peça, este projeto utiliza o conceito de indentação como pode ser visto na figura 30. A peça inicial de repetição possui o encaixe para o próxima peça mais para o centro, fazendo com que a próxima peça fique mais para o lado direito, como se estivesse indentada. E assim para as peças seguintes, que podem estar dentro desta peça de repetição. Para finalizar, há a peça de fim de repetição que não existe no Scratch e que possui o encaixe mais para a esquerda para a próxima peça, o que finaliza a indentação e as peças voltam a ficar alinhados com as anteriores à repetição.

Durante a prototipagem com papelão, percebeu-se a dificuldade no encaixe das peças, pois o papelão utilizado não era maciço, o que fazia uma peça enroscar na outra. Assim, para os testes iniciais, as peças em MDF já foram produzidas. 
Figura 25: Exemplos das peças de comando e parâmetros

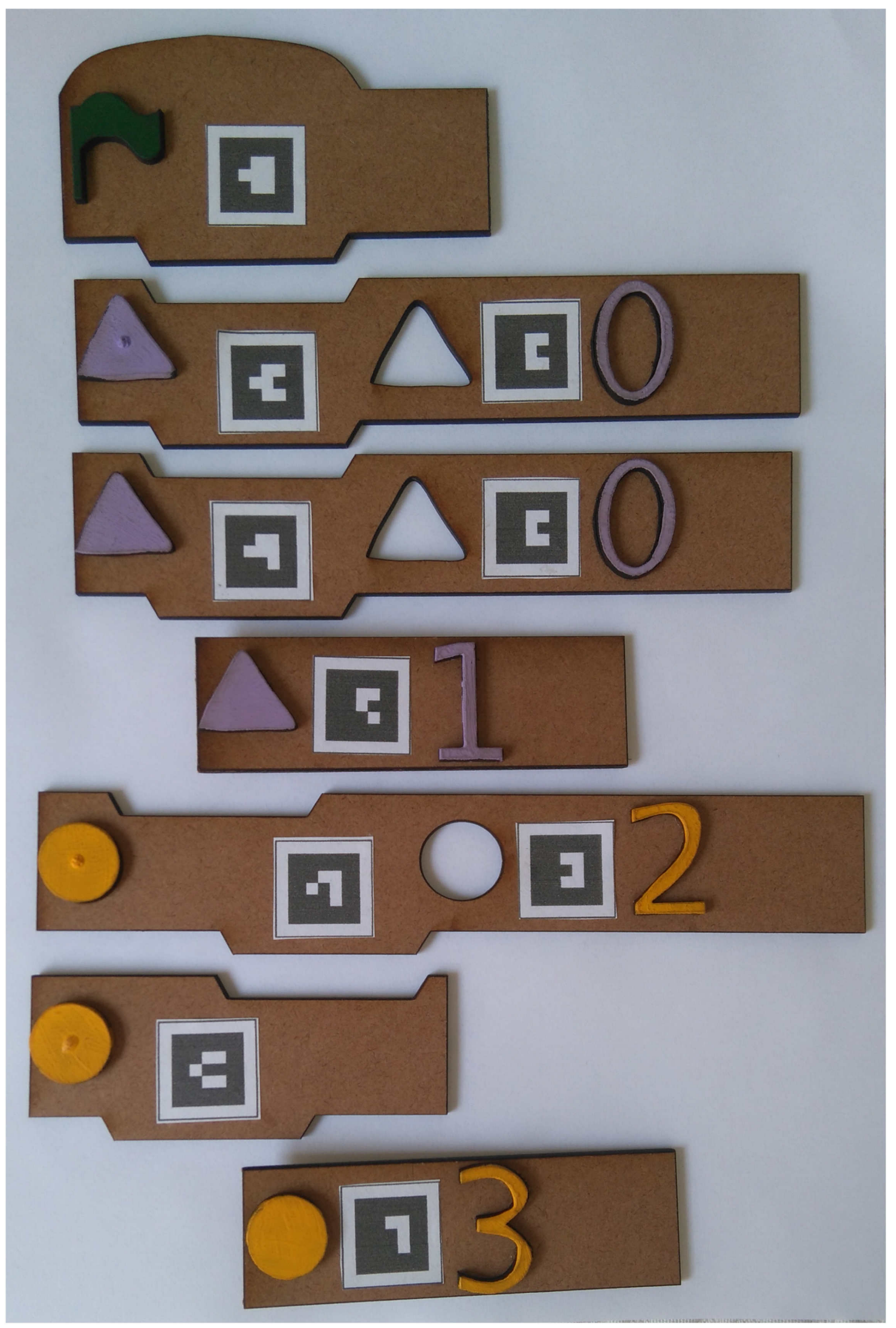

Fonte: Elaborada pela autora 
Figura 26: Triângulos em relevo identificam peças de comando de som e seus parâmetros

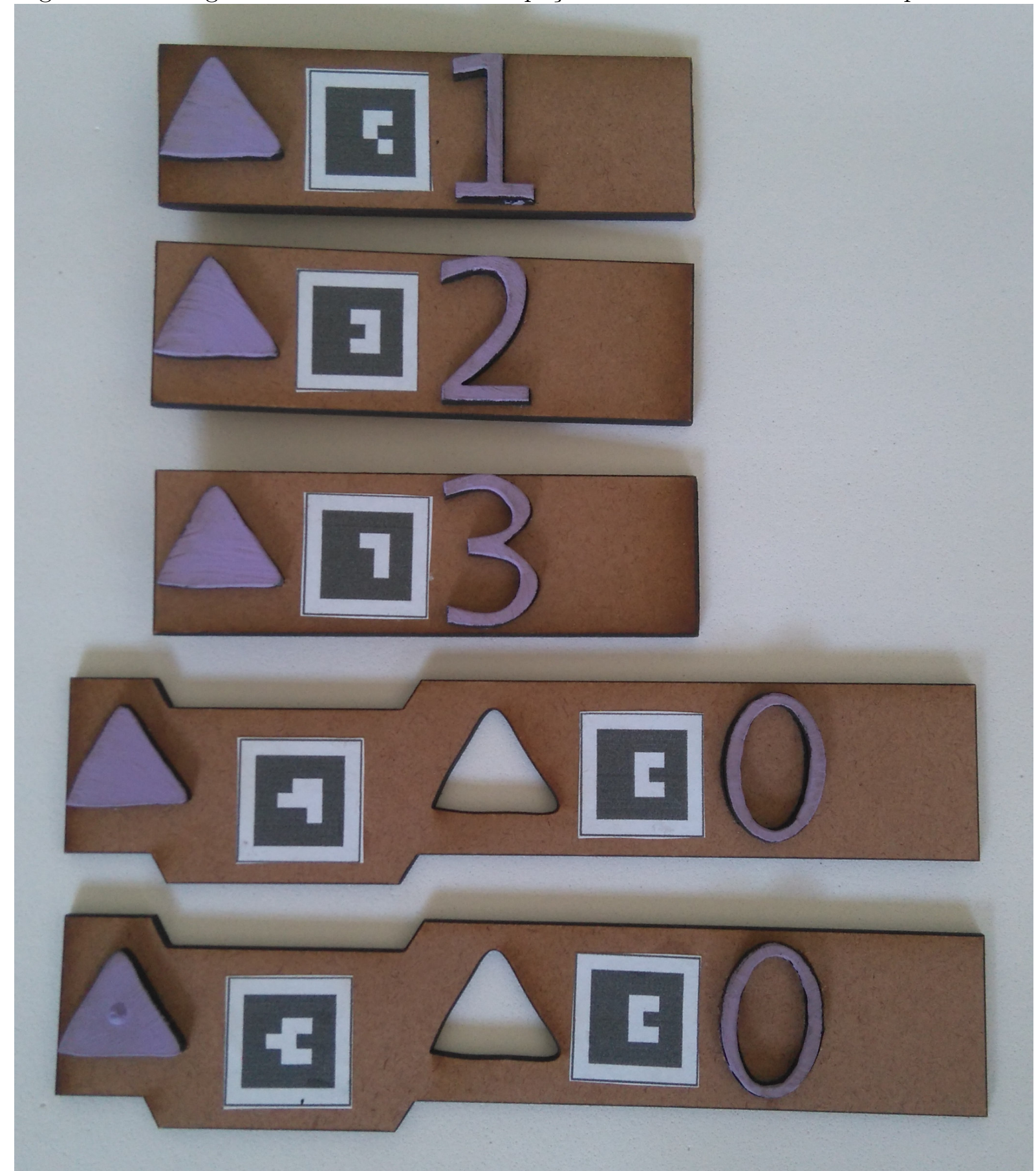

Fonte: Elaborada pela autora 
Figura 27: Círculos em relevo identificam peças de comando de controle e seus parâmetros
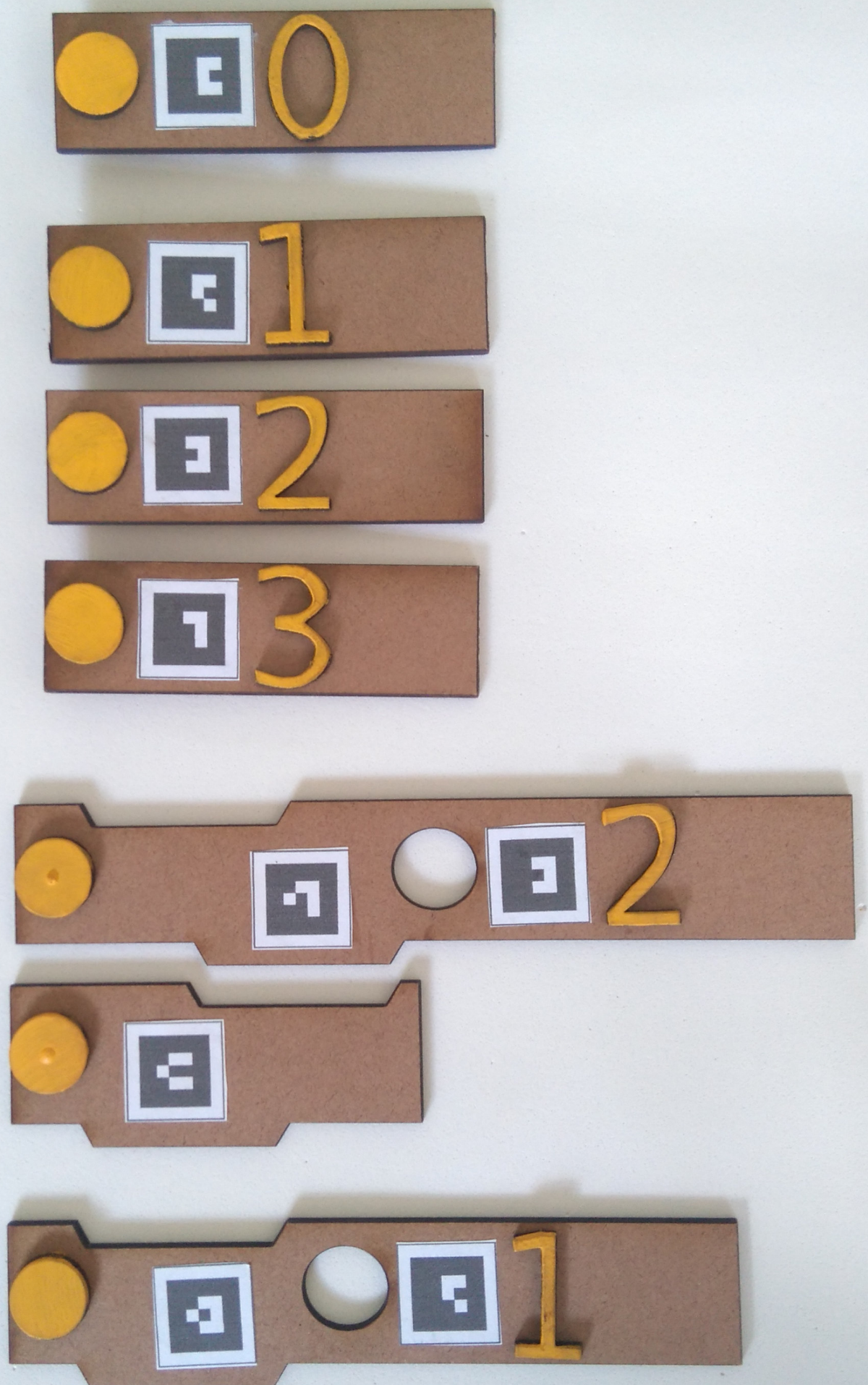

Fonte: Elaborada pela autora 
Figura 28: Encaixe entre peças de comandos

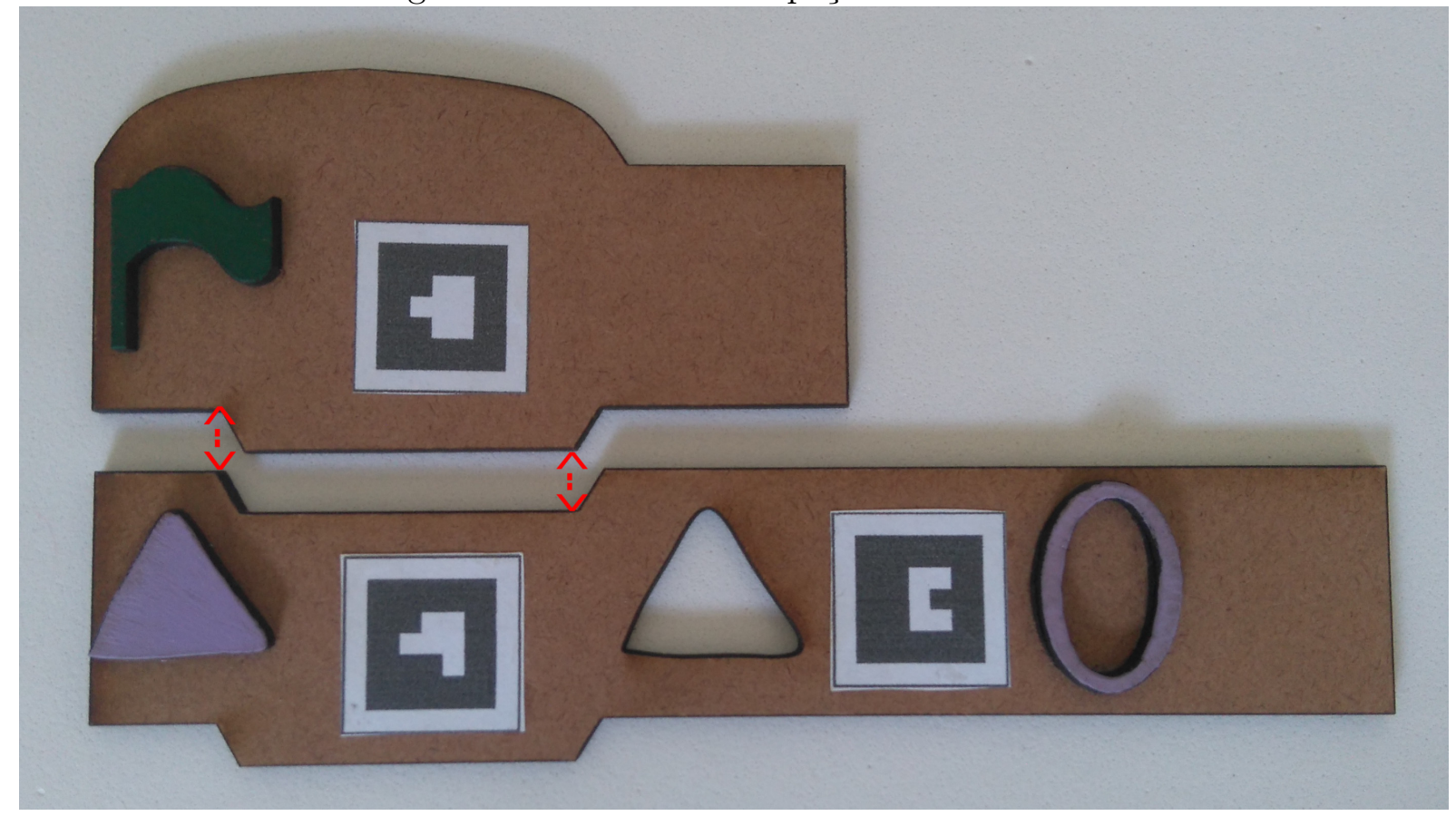

Fonte: Elaborada pela autora 
Figura 29: Peças de parâmetros com os encaixes embaixo e os buracos para estes encaixes nas peças de comandos

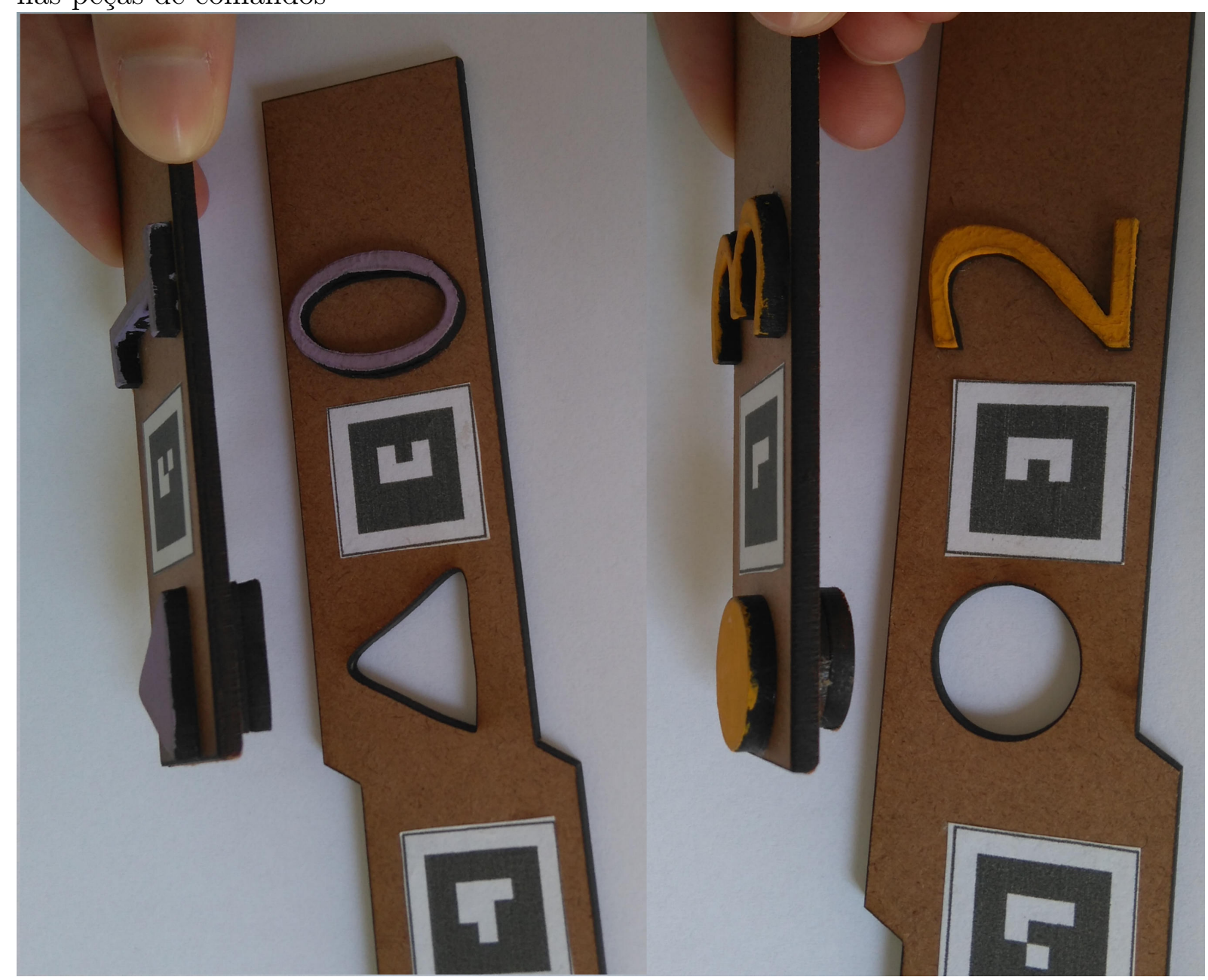

Fonte: Elaborada pela autora 
Figura 30: Indentação gerada pelas peças de início e fim de repetição

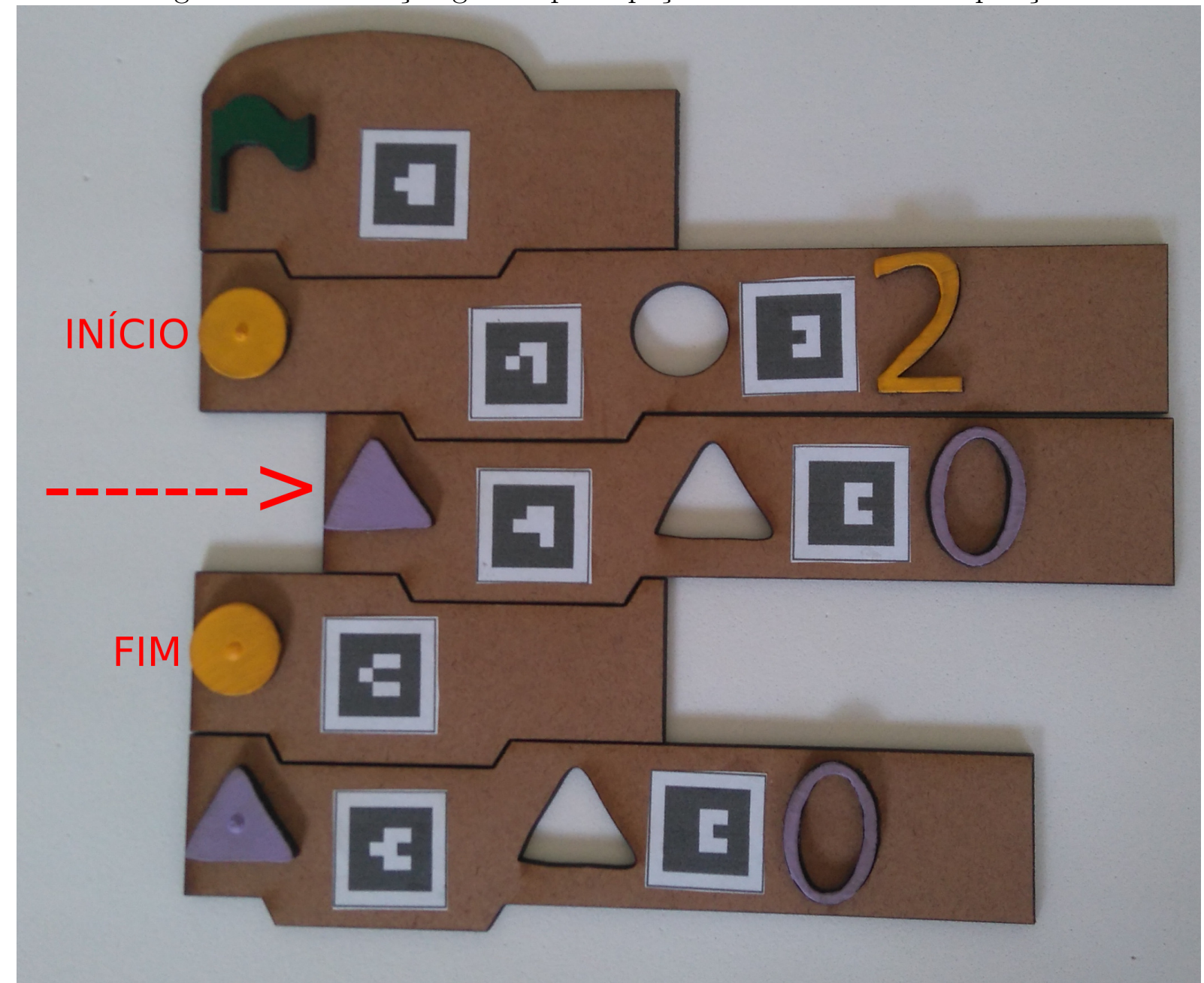

Fonte: Elaborada pela autora 


\subsubsection{Pré-testes e teste inicial}

O primeiro teste com usuários do protótipo, chamado de teste inicial, tem foco nas decisões iniciais de projeto, principalmente em relação ao desenho das peças tangíveis. Este primeiro teste é qualitativo, levando em consideração a opinião dos participantes e também a observação da pesquisadora. Neste teste, os dados obtidos guiaram as modificações no protótipo para gerar a versão seguinte.

Estes dados obtidos são baseados em respostas ao questionário e ao roteiro presente do Apêndice A. Cada atividade tem relação com uma função e desenho do protótipo, sendo elas:

1. Reconhecimento das peças:

- todas as peças, menos a peça de repetição, são apresentadas;

- o participante deverá perceber quais peças são diferentes e quais são iguais e dizer o porquê.

2. Como juntar as peças:

- o participante deverá unir as peças e reconhecer a ordem de montagem facilmente;

- as peças que representam o conceito de repetição não serão utilizadas neste momento.

3. Executando uma programação:

- será explicado, no início da atividade, como executar a programação;

- o participante deverá executar a programação depois de montar as peças;

- também deverá explicar a saída dessa programação em relação à programação feita.

4. A peça de repetição:

- o funcionamento da peça de repetição será explicado;

- o participante deverá compreender a montagem de um programa com a peça de repetição;

- essa peça pode ser acrescentada à programação anterior ou à uma nova; 
- deve-se perceber e explicar a diferença em relação à utilização dessa nova peça e entender como seu desenho de encapsulamento funciona, ou seja, que ele forma uma cápsula com um ou mais peças dentro.

\subsubsection{Pré-teste}

Foram realizados pré-testes com pessoas adultas. Uma delas possui um pouco de conhecimento em programação e outras duas sem conhecimento prévio. Todas foram vendadas para estes pré-testes. O participante com conhecimento prévio teve grande facilidade para executar o teste enquanto os outros dois, grande dificuldade. Com isto, pequenas mudanças foram feitas na forma de explicar as atividades para os participantes e também na sequência de realização de duas atividades, que acabaram sendo unidas. Estas duas atividades são a de encaixe e execução, que inicialmente eram realizadas em sequência: a criança aprendia como encaixar peças de comando e de parâmetro e só depois executava a programação. A mudança foi a união, já mencionada: a criança aprende a executar a programação apenas com uma peça, depois é ensinada sobre a mudança de parâmetros, executando novamente a programação, e por fim acrescenta uma nova peça e executa novamente.

Isto facilitou o entendimento da mudança de parâmetros, já que o som da primeira execução antes da mudança foi diferente do som depois da mudança, e também em relação ao entendimento do conceito de sequência de programação, já que a adição de uma peça fez um novo som ser acrescentado. Além disso, percebeu-de a necessidade de sempre questionar as decisões dos participantes em relação à programação e pedir explicações sobre as saídas mesmo que estas foram as que os participantes esperavam para suas programações.

\subsubsection{Aplicação do teste inicial}

O teste inicial foi feito utilizando a versão do protótipo já descrita e houve o envolvimento de 4 participantes sem conhecimento prévio em programação. O perfil de cada participante está na tabela 2, O tempo estimado para o teste era aproximadamente 50 minutos por participante, mas somente os participantes 1 e 2 ficaram dentro deste tempo estipulado. O participante 3 realizou o teste em aproximadamente 20 minutos e o participante 4, que demonstrou muito interesse em entender vários aspectos do sistema, realizou em aproximadamente 1 hora e meia.

Para a pontuação de desempenho, foram feita as observações presentes na tabela 3. 
Tabela 2: Perfil dos participantes do teste inicial

\begin{tabular}{|l||cccc|}
\hline Perfil & Participante 1 & Participante 2 & Participante 3 & Participante 4 \\
\hline Idade & 14 & 8 & 7 & 9 \\
\hline $\begin{array}{l}\text { Utilizou } \\
\text { venda }\end{array}$ & Sim & Sim & Não & Sim \\
\hline
\end{tabular}

Tabela 3: Tabela explicativa da observação de desempenho dos participantes no teste inicial

\begin{tabular}{|c|c|c|c|}
\hline & Pontuação 3 & Pontuação 2 & Pontuação 1 \\
\hline Atividade 1 & $\begin{array}{l}\text { O participante reco- } \\
\text { nheceu todas as peças } \\
\text { e as diferenciou sem } \\
\text { dificuldades }\end{array}$ & $\begin{array}{l}\text { O participante preci- } \\
\text { sou de ajuda para di- } \\
\text { ferenciar as peças e } \\
\text { isto persistiu durante } \\
\text { todo o teste }\end{array}$ & $\begin{array}{l}\text { O } \\
\text { mesmo com ajticipante } \\
\text { não conseguiu dife- } \\
\text { renciar as peças }\end{array}$ \\
\hline Atividade 2 & $\begin{array}{l}\text { O participante jun- } \\
\text { tou as peças com fa- } \\
\text { cilidade }\end{array}$ & $\begin{array}{l}\text { O participante pre- } \\
\text { cisou de ajuda para } \\
\text { juntar as peças e } \\
\text { isto persistiu durante } \\
\text { todo o teste }\end{array}$ & $\begin{array}{l}\text { O participante não } \\
\text { conseguiu juntar as } \\
\text { peças mesmo com } \\
\text { ajuda }\end{array}$ \\
\hline Ativ & $\begin{array}{l}\text { O participante criava } \\
\text { uma programação e } \\
\text { sua saída era a espe- } \\
\text { rada em todos os ca- } \\
\text { sos }\end{array}$ & $\begin{array}{l}\text { O participante preci- } \\
\text { sou de ajuda, mas en- } \\
\text { tendia e, em caso de } \\
\text { alguma mudança na } \\
\text { programação, conse- } \\
\text { guia explicar o que } \\
\text { seria a saída dela }\end{array}$ & $\begin{array}{l}\text { O participante } \\
\text { mesmo com ajuda } \\
\text { não conseguiu en- } \\
\text { tender os códigos de } \\
\text { programação criadas }\end{array}$ \\
\hline Atividade 4 & $\begin{array}{l}\text { O participante enten- } \\
\text { deu e conseguiu pro- } \\
\text { gramar utilizando as } \\
\text { duas peças que repre- } \\
\text { sentam repetição sem } \\
\text { dificuldades }\end{array}$ & $\begin{array}{l}\text { O participante preci- } \\
\text { sou de ajuda, mas } \\
\text { entendeu como pro- } \\
\text { gramar outro exem- } \\
\text { plo com as peças de } \\
\text { repetição }\end{array}$ & $\begin{array}{l}\text { O participante } \\
\text { mesmo com ajuda } \\
\text { não conseguiu enten- } \\
\text { der como utilizar a } \\
\text { peça de repetição }\end{array}$ \\
\hline
\end{tabular}

Os resultados do teste inicial podem ser vistos na tabela 4 e na figura 31. 


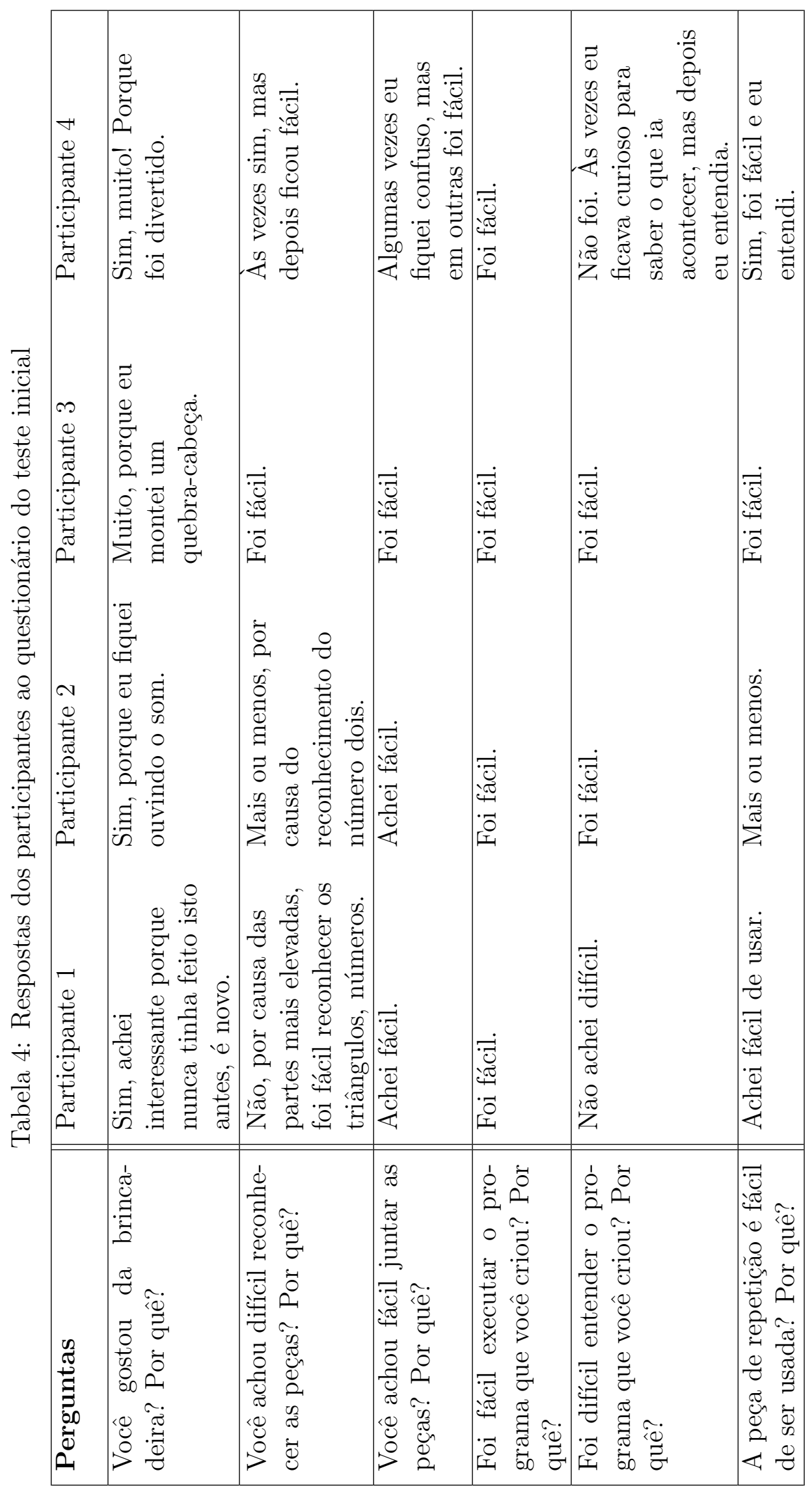


Figura 31: Gráfico dos desempenhos dos participantes segundo a observação da pesquisadora no teste inicial

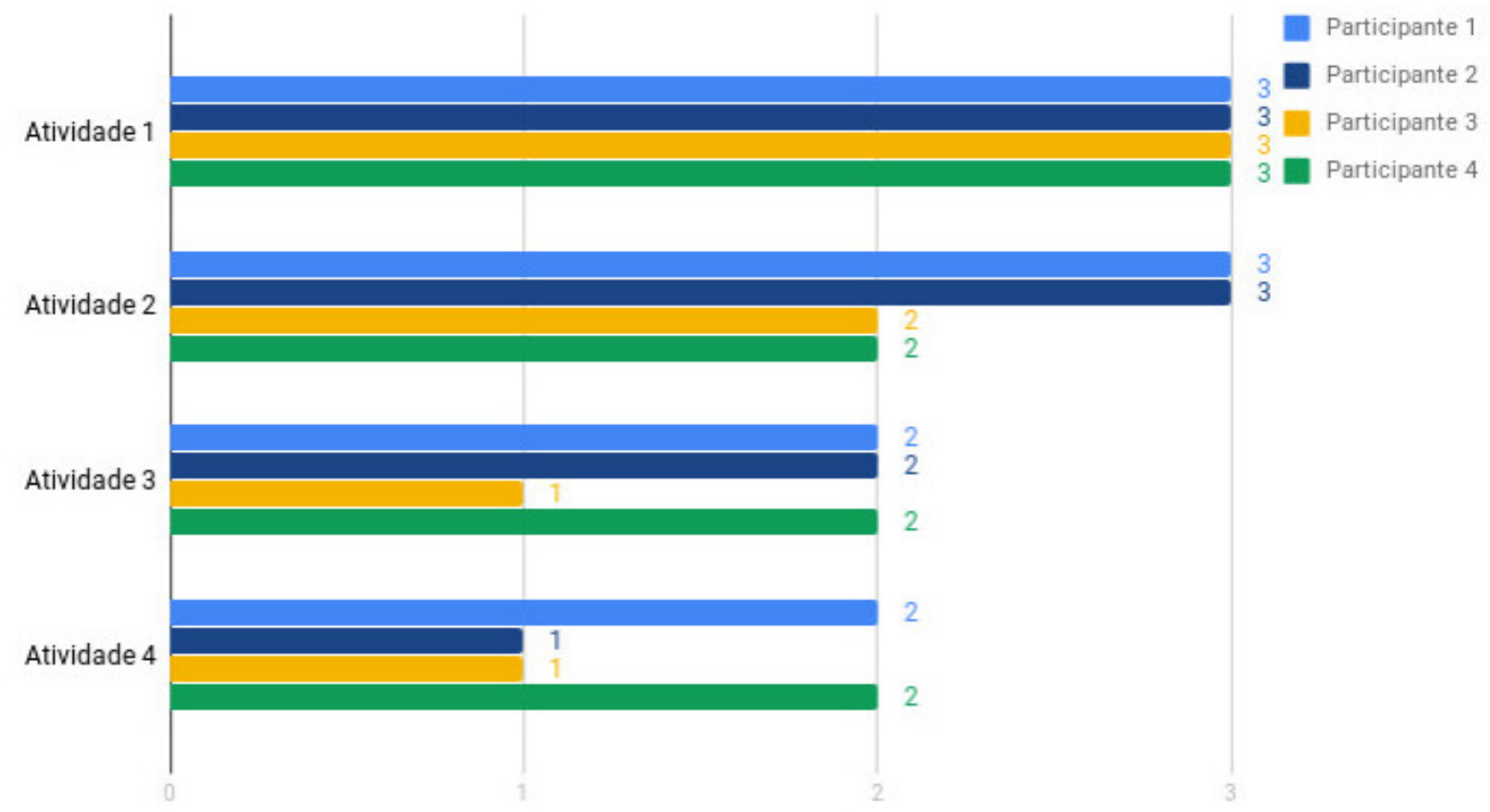

Fonte: Elaborada pela autora 


\subsubsection{Considerações}

Nos resultados do teste inicial, nota-se que a atividade de identificação das peças foi facilmente realizada pelas crianças. Todas perceberam as diferentes formas em relevo e os números, o que é suficiente para a diferenciação entre as peças. As outras atividades já demonstraram as possíveis necessidades de mudanças no protótipo.

A atividade de junção das peças foi realizada com razoável dificuldade. Os participantes, na maioria das vezes, se perdiam, não achando os encaixes entre peças e nem os encaixes para os parâmetros ou não tinham certeza se estava encaixado ou não, mostrando que a parte de encaixe de peças precisa ser melhorada.

Nas próximas atividades, pode-se concluir que a dificuldade foi conceitual, ou seja, os conceitos de programação de sequência e repetição parecem necessitar de mais tempo de exploração ou de explicação para o entendimento.

Escolher uma tecla do teclado, no caso a barra de espaço, para a execução da programação foi facilmente entendido e realizado pelos participantes.

Também é interessante notar a diferença de interesse dos participantes em relação às atividades e as respostas ao questionário. O participante 4 demonstrou grande empolgação enquanto as participantes 2 e 3 não demonstraram interesse e em particular a 3, a mais nova, nem em entender o que estava acontecendo. A participante 1, mais velha, teve o melhor desempenho e se mostrou atenciosa para entender o que estava na programação. Em relação às respostas ao questionários, os participantes tendiam a responder que acharam fácil. Isto é contrário à observação da pesquisadora, já que eles apresentaram dificuldades na realização de algumas atividades. Desta forma, a gravações e observação foram muito importantes para as considerações feitas sobre os testes já que somente os questionários não seriam suficientes para a percepção das reais dificuldades e facilidades dos participantes. 


\subsection{Protótipo final e testes de usabilidade}

A partir das consideração do teste inicial descritas anteriormente e conversas com profissionais da área de Desenho Universal, Design e Educação Especializada, as seguintes modificações foram feitas no protótipo 4 .

- um nova peça foi adicionada ao protótipo: espere até pressionar uma tecla do teclado. Assim, o conceito de decisão está presente no protótipo sendo desenvolvido. Na figura 32 pode-se notar que esta peça foi criada unindo dois blocos do Scratch. Esta união se encaixa em dois princípios para criação de kits de criação para crianças: "make it as simple as possible - and maybe more"e "choose black boxes carefully" (Resnick e Silverman, 2005). Ou seja, este novo comando é uma caixa preta que recebe a informação do teclado e tem uma resposta para a criança simplificando o comando que na verdade precisaria de dois blocos no Scratch: um de esperar por uma tecla e outro do reconhecimento da tecla. Esta simplificação facilitou a realização dos testes, que tinham tempo bem limitado, e atendeu o requisito de compreensão do conceito de decisão, mas não é uma exigência para protótipos posteriores;

- velcro foi colado nas laterais das peças para facilitar o encaixe entre elas (exceto entre as peças de comando e parâmetro), como pode ser visto na figura 33 .

- retirou-se os desenhos geométricos em relevo das peças de parâmetro para evitar confusões entre estas peças e as de comando;

- foi adicionado braille para representar os parâmetros. Este Braille é maior que o Braille padrão para que crianças com diferentes níveis de aprendizado Braille possam compreendê-lo. Neste protótipo, foi colado meia pérola para representar cada ponto Braille como visto na figura 34 ;

- dois sons foram adicionados à interação: um logo após a criança pedir a execução da programação, apertando a barra de espaço, e outro quando a programação já está pronta e será executada em seguida. Com isso, a criança tem resposta de que o comando de execução foi feito corretamente e também de quando a programação inicia;

${ }^{4} \mathrm{~A}$ criação de letras e números para o desenho do protótipo necessitam de créditos: By Coloringbuddymike - Own work, CC BY-SA 3.0, 〈https://commons.wikimedia.org/w/index. php?curid=24819321,$\quad\langle$ https://commons.wikimedia.org/wiki/File:Classic_alphabet_numbers_chart_at_ coloring-pages-for-kids-boys-dotcom.svg $\rangle$ 
- o tempo para criação dos blocos digitais no Scratch também foi mudado de uma espera fixa de 5 segundos para um tempo variável de acordo com o número de peças tangíveis detectadas. O objetivo é dar uma resposta mais rápida para a criança sem causar erros no protótipo;

- integração à uma versão mais nova do código do Scratch 3.0 que pode ser visto na figura 35.

Figura 32: Exemplo de utilização da condição se uma tecla for pressionada e sua representação em blocos no Scratch 3.0

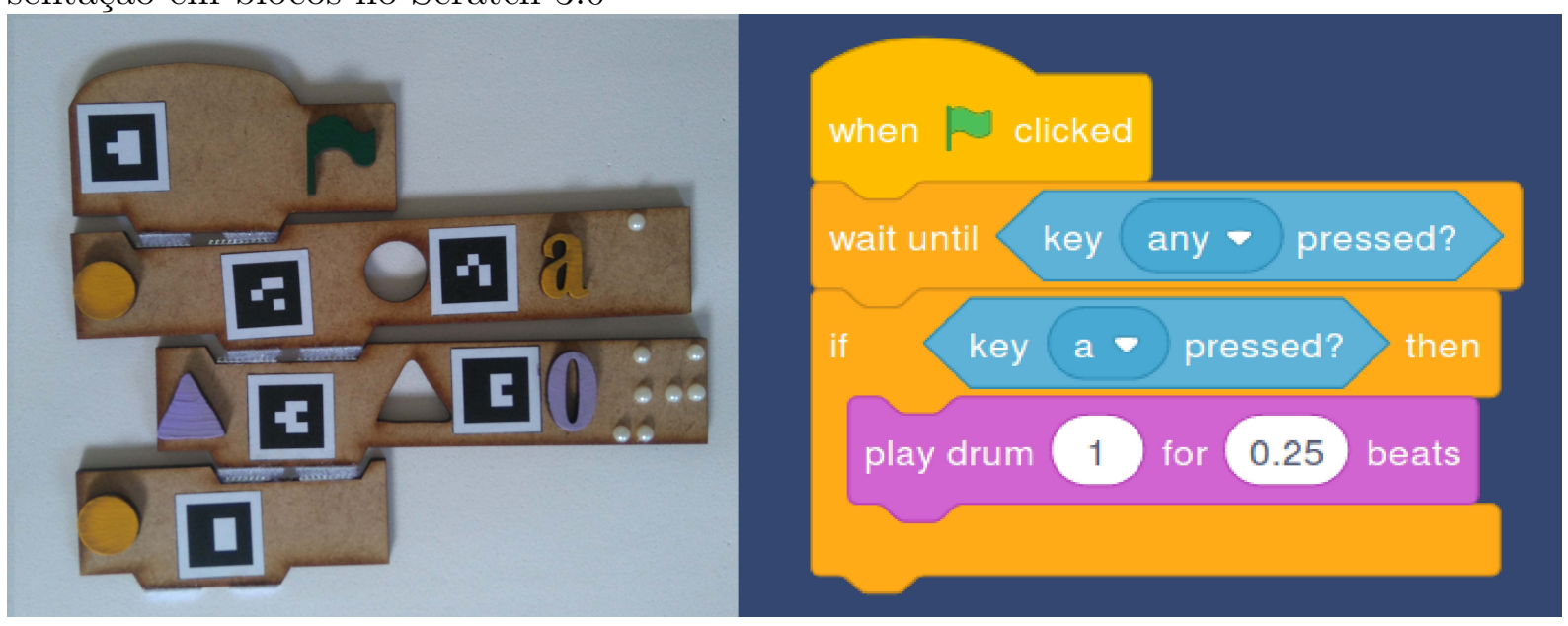

Fonte: Elaborada pela autora

Figura 33: Velcro colocado no encaixe das peças de comando

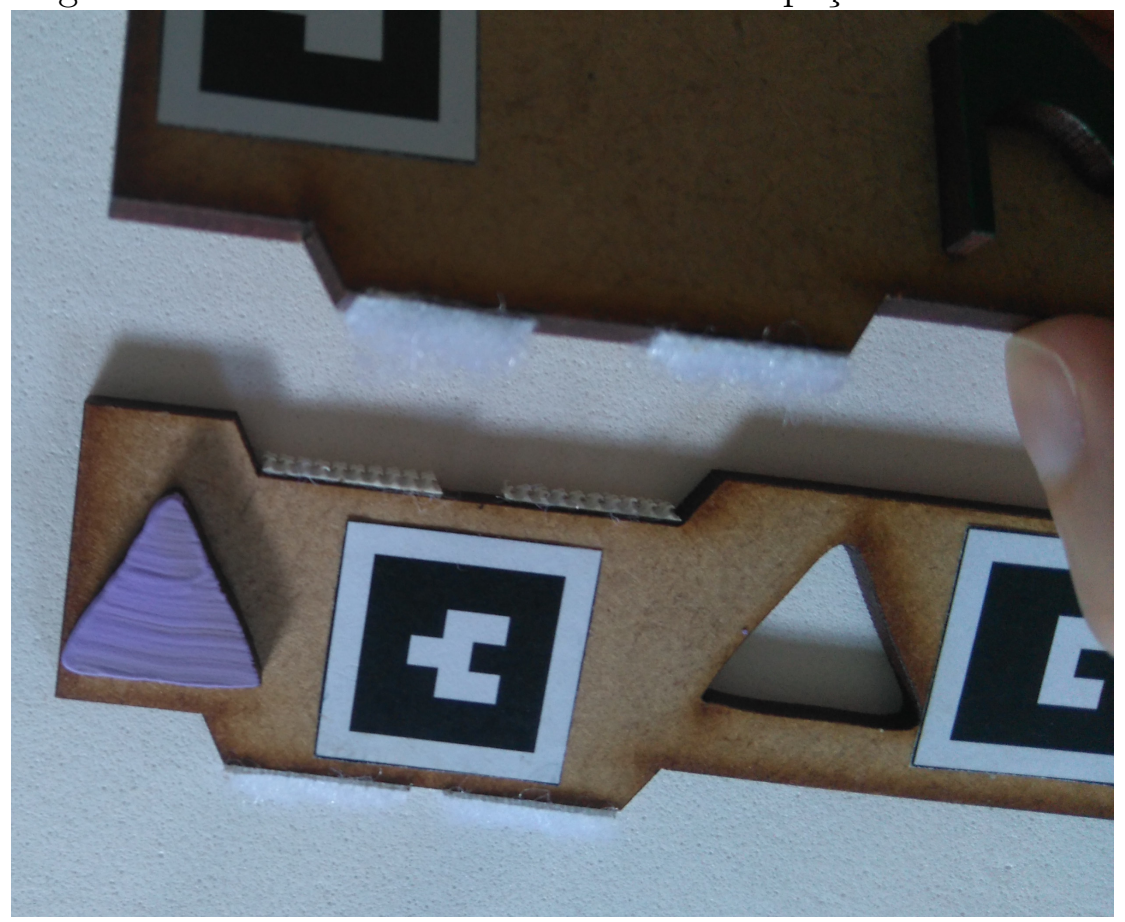

Fonte: Elaborada pela autora 
Figura 34: Braille presente nas peças de parâmetro

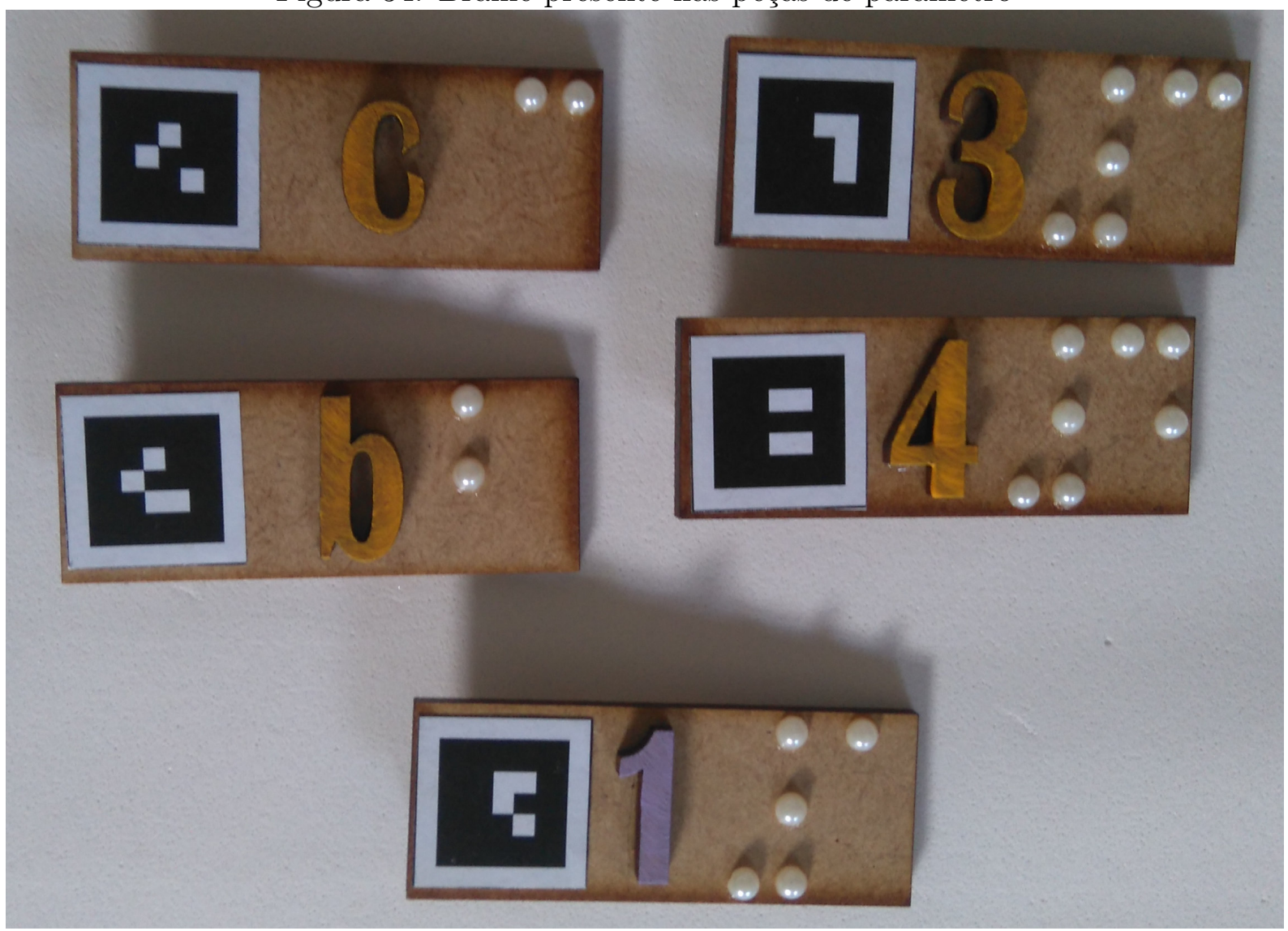

Fonte: Elaborada pela autora

Figura 35: Exemplo de código com peças tangíveis à esquerda e uma versão mais nova do Scratch VM Playground com o código à direita

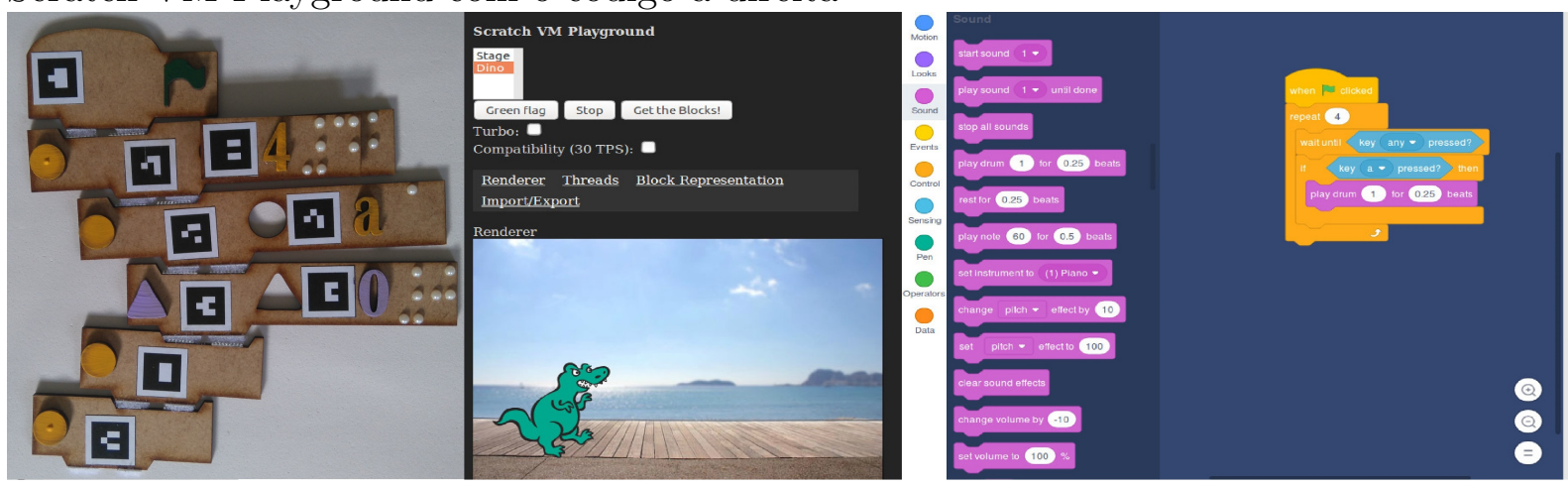

Fonte: Elaborada pela autora 


\subsubsection{Teste de usabilidade}

Nas atividades dos testes de usabilidade, a avaliação é feita de acordo com a observação da pesquisadora e um questionário respondido pela criança. Este desempenho é focado na compreensão de conceitos de programação, sendo eles: sequência, decisão e repetição. Cada um deles foi testado a partir de desafios propostos à criança participante e estes testes estão descritos a seguir.

- Desafio da sequência: a criança deve tocar sons em uma sequência determinada

- a peça de som é apresentada à criança, que a coloca no Código e o executa;

- outra peça de som é adicionada pela criança, executando a programação novamente;

- é explicado como mudar o parâmetro da peça de som e a criança escolhe uma peça para mudar este parâmetro. Por fim, ela executa a programação novamente;

- o desafio é proposto de acordo com a ordem que a última programação foi feita.

- Desafio da decisão: escolher uma tecla e um som para ser tocado quando esta tecla é pressionada

- a peça do comando "quando uma tecla for pressionada"é apresentada e explicada à criança;

- a primeira montagem da programação com esta nova peça é feita com o auxílio da pesquisadora;

- a programação é desmontada e o desafio proposto é para que a criança faça a programação sozinha com outros parâmetros.

- Desafio da repetição: escolher um som para ser repetido em um número determinado de vezes

- a peça de repetição é apresentada e explicada à criança;

- com o auxílio da pesquisadora, a primeira montagem da programação com esta nova peça é feita;

- a programação é desmontada e o desafio é que a criança faça a programação sozinha com outros parâmetros. 
- Atividade livre em grupo: um grupo de crianças escolhem uma ordem de sons para programarem no protótipo.

No fim, o questionário SUS é aplicado para obtenção da opinião da criança sobre o protótipo.

\subsubsection{Aplicação do teste}

O teste de usabilidade foi realizado com duas crianças cegas congênitas. Ambas têm 10 anos, mas, por diferença de alguns meses, estão em anos escolares diferentes: a primeira, participante 1, acabou de terminar o quinto ano e a segunda, participante 2, o quarto ano. Nenhuma delas tinham conhecimento prévio de programação. Os testes foram acompanhados por pelo menos uma professora e duraram aproximadamente 50 minutos como previsto. O perfil de cada participante deste teste está na tabela 5 .

Tabela 5: Perfil dos participantes do teste de usabilidade

\begin{tabular}{|l||cc|}
\hline Perfil & Participante 1 & Participante 2 \\
\hline Idade & 10 & 10 \\
\hline Série & $5^{\circ}$ Ano & $4^{\circ}$ Ano \\
\hline Visão & Cego congênito & Cego congênito \\
\hline
\end{tabular}

Dois pontos importantes da aplicação do teste: por problemas com o horário, a atividade que estava prevista para ser realizada com as duas crianças brincando juntas não foi feita e não foi utilizado a parte do sistema de reconhecimento de imagens, sendo que a pesquisadora fez manualmente a conversão da programação tangível para a digital. Este último ponto facilitou com que o foco do teste fosse na interação da criança com a peças tangíveis e não sofresse interferência de erros na parte do software de reconhecimento de imagens.

Em relação à pontuação do desempenho nos desafios, a observação foi feita com base na tabela 6 .

Os resultados do desempenho das crianças estão na figura 36. Em relação ao questionário, a participante 1 teve pontuação no SUS de 62,5 e a participante 2 de 100 . 
Tabela 6: Tabela explicativa da observação de desempenho dos participantes no teste de usabilidade

\begin{tabular}{|l|lll|}
\hline & Pontuação 3 & Pontuação 2 & Pontuação 1 \\
\hline \multirow{5}{*}{ Desafios } & A criança conse- \\
& $\begin{array}{l}\text { A criança cumpriu o } \\
\text { desafio sem dificulda- } \\
\text { des. }\end{array}$ & $\begin{array}{l}\text { realizar o desafio, ajuda não conseguiu } \\
\text { explicando os pas- entender como cum- } \\
\text { sos após ajuda da prir o desafio. } \\
\text { pesquisadora. }\end{array}$ \\
\hline
\end{tabular}

Figura 36: Gráfico dos desempenhos dos participantes segundo a observação da pesquisadora no teste de usabilidade

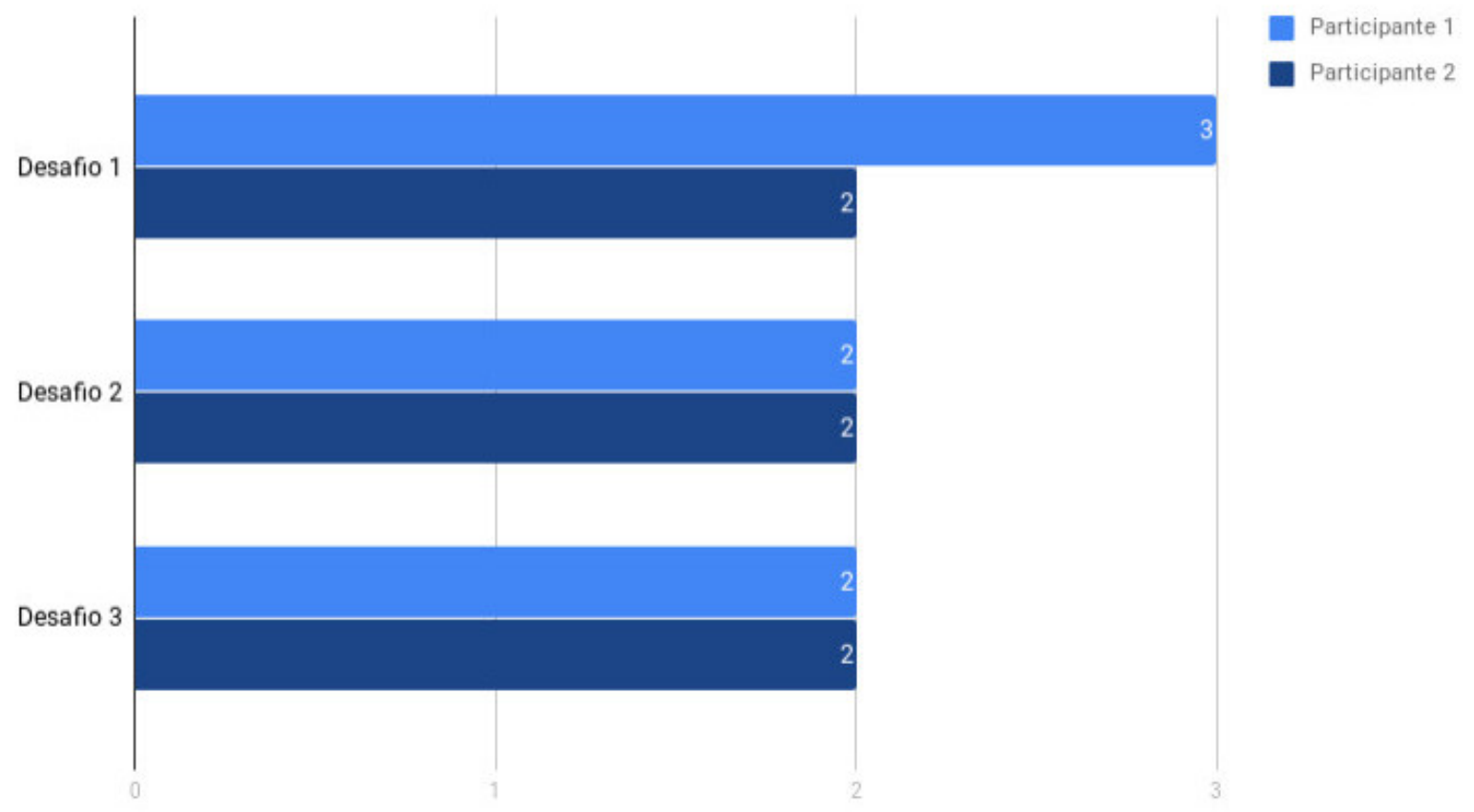

Fonte: Elaborada pela autora 


\subsubsection{Considerações}

O teste de usabilidade foi essencial para observação de crianças cegas interagindo com o protótipo. Estas observações, seguindo o método de pesquisa adotado, geraram novos requisitos para o sistema a fim de melhorar a interação com os usuários, neste caso, com foco em crianças cegas.

Estes requisitos, devido à forma como os testes foram aplicados, restringem-se ao desenho das peças. O primeiro é a necessidade de que as peças fiquem fixas quando colocadas na área de Código do sistema. Esta necessidade foi comentada por uma professora do ensino especializado quando foi apresentado um protótipo anterior, que não possuía velcro nas peças. Este requisito é um requisito forte, ou seja, de grande importância para o sistema, pois dificultou, como já previsto pela professora, a exploração da programação feita pelas crianças nos testes de usabilidade. Mesmo com a colocação do velcro para encaixe das peças de comando, as peças de parâmetros eram somente encaixadas em cima das peças de comandos. Assim, as crianças acabavam desmontando a programação enquanto tateavam para reconhecimento e também quando estavam mudando peças. Esta dificuldade foi a causadora da nota baixa no SUS da participante 1, pois ela demonstrava muito aborrecimento e desânimo para explorar a programação. Durante o teste, ela dizia que iria desmontar e oferecia resistência em tatear a programação que havia feito. Estas reações não foram observadas na participante 2, que parecia mais tranquila diante das peças que se bagunçavam. Em ambos os casos, a falta de mais fixação da peças prejudicou a interação, causando dificuldade na mudança de peças e reconhecimento do que havia sido programado.

Outro requisito forte é a presença do sistema Braille nas peças. As crianças utilizaram este sistema para reconhecer os parâmetros, apesar da participantes 2 ter achado difícil reconhecer por causa do tamanho dos pontos, maiores do que o Braille padrão que ela já sabe ler. Percebe-se que não é óbvio o reconhecimento do sistema Braille aumentado e, segundo profissionais da área, não há uma idade certa para que a criança tenha fluência no sistema Braille com o tamanho padrão.

Outro aspecto de desenho que precisa de mudança é a representação tangível das peças de repetição e de decisão criada. No Scratch, os blocos têm capacidade de se estender para incluir mais blocos e, para não perder a capacidade de inclusão de vários blocos, as peças tangíveis foram criadas com começo e fim, separadas. Esta separação complicou em todos os testes, do inicial e de usabilidade, a explicação dos conceitos. Por isso, unir este fim e começo é importante e um desafio de desenho deste sistema. 
Outro desafio encontrado pela pesquisadora foi na área de educação. A interação com crianças cegas não é óbvia e a falta de experiência da pesquisadora provavelmente causou problemas durante as explicações. Um exemplo é o auxílio para entendimento da programação. Supondo que crianças cegas congênitas têm dificuldades com noção espacial (Cuturi et al., 2016), deve-se ter cautela para demonstrar como percorrer e entender o código criado com as peças tangíveis. A autora, em algumas situações, segurava a mão da criança para auxiliar no entendimento do código, percorrendo-o peça por peça, mas às vezes distanciava a mão da criança da mesa e colocava em outra peça, dificultando a montagem mental da ordem do código feita pela criança. O tateamento do código deve ser de modo contínuo, sem, por exemplo, erguer a mão e pular para outra parte, para que a montagem espacial do código seja entendida corretamente pela criança.

Vale também considerar um erro no desenho das peças que pode ser visto na figura 35. A peça de parâmetro desenhada para corte não cobre totalmente o parâmetro já presente na peça de comando, o que gerou algumas confusões para entendimento da mudança de parâmetros. Pode-se perceber na figura mencionada que a peça de início de repetição possui o parâmetro quatro e um pedaço do braille do número dois.

\subsubsection{Teste de reconhecimento de marcadores do sistema}

Para garantir que o reconhecimento de marcadores realizado pela biblioteca ARToolKit.js atende ao requisito do sistema de reconhecer múltiplos marcadores, ou seja, as peças tangíveis, testes específicos foram feitos para checagem deste reconhecimento.

Em testes primários com a biblioteca, já percebeu-se algumas configurações necessárias para que ela funcionasse corretamente. Em primeiro lugar, os marcadores precisam de uma borda branca de alguns milímetros para que ele seja reconhecido, pois eles estão em peças de cor escura e isto dificulta o reconhecimento por causa do contraste. A cor de fundo da área do código onde a criança coloca as peças também é branca para aumentar o contraste. Outro ponto é o posicionamento da área do código de uma forma que a luz incidente não cause sombra devido à presença do usuário ou da estrutura que segura a webcam e tenha uma única fonte, como uma lâmpada ou janela durante o dia. O último ponto percebido é a necessidade da webcam estar perpendicular à superfície onde ficam as peças para diminuir distorções na imagem.

Voltando ao teste do reconhecimento de marcadores, as configurações comentadas anteriormente foram utilizadas. A webcam estava à aproximadamente $20 \mathrm{~cm}$ de distância da superfície e os marcadores têm tamanho $22 \times 25 \mathrm{~cm}$. A figura 37 mostra como foi feito 
o código da checagem.

Figura 37: Fluxograma do código do protótipo do sistema com checagem do reconhecimento de marcadores em verde

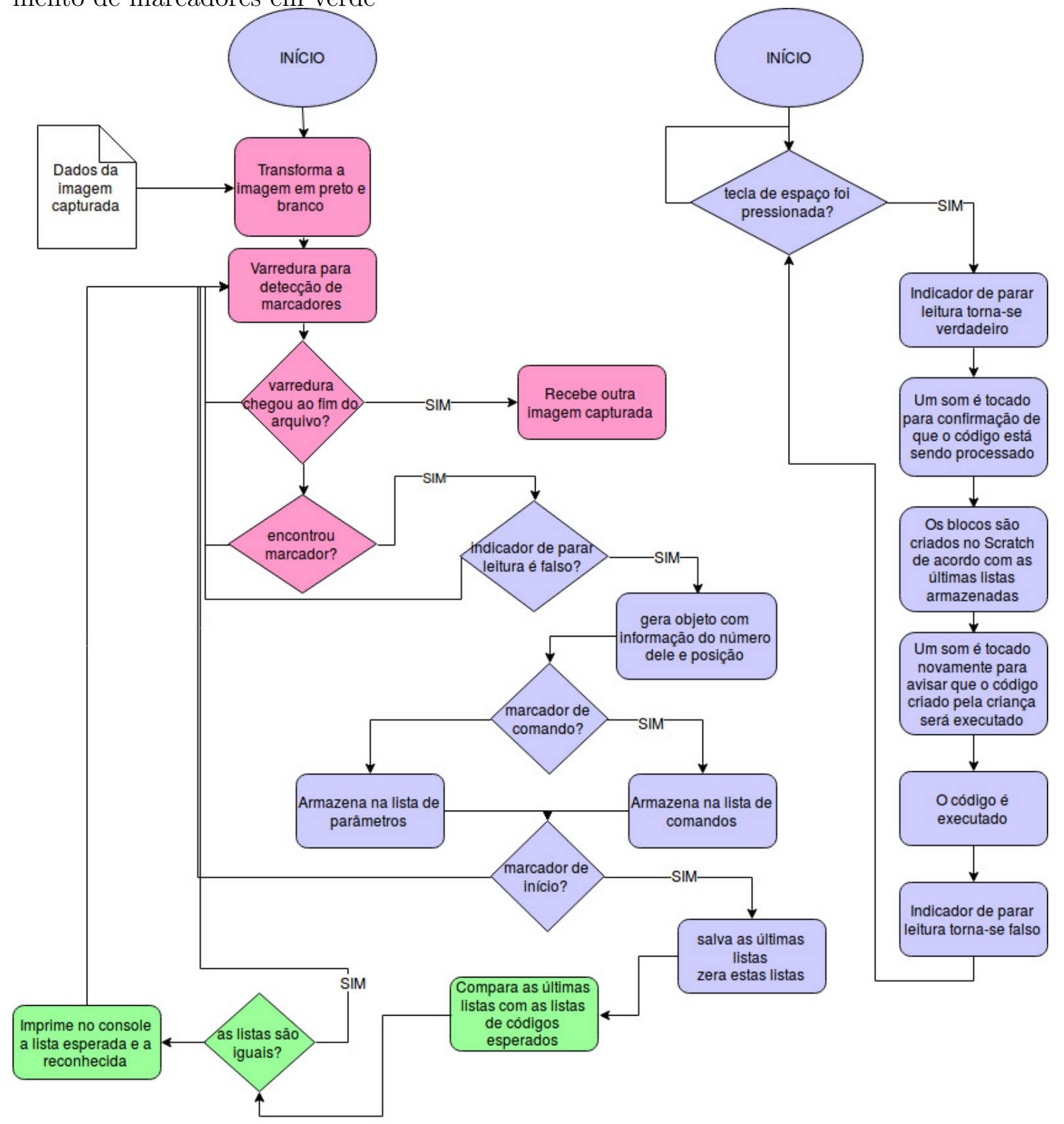

Fonte: Elaborada pela autora

Todas as peças do protótipo do sistema foram utilizadas formando alguns conjuntos de códigos pra o testes. Estes códigos estão presentes na figura 38 e, em ordem alfabética, são:

a) peça da bandeira verde seguida da peça tocar tambor com parâmetro zero;

b) peça da bandeira verde seguida das peças tocar tambor com parâmetro zero e, 
novamente, tocar tambor com parâmetro zero;

c) peça da bandeira verde seguida das peças tocar tambor com parâmetro um e tocar tambor com parâmetro zero;

d) peça da bandeira verde seguida das peças de início de condição com parâmetro a, tocar tambor com parâmetro zero e fim de condição;

e) peça da bandeira verde seguida das peças de início de condição com parâmetro b, tocar tambor com parâmetro zero e fim de condição;

f) peça da bandeira verde seguida das peças de início de repetição com parâmetro dois, tocar tambor com parâmetro zero e fim de repetição;

g) peça da bandeira verde seguida das peças de início de repetição com parâmetro dois, tocar tambor com parâmetro zero, fim de repetição e tocar tambor com parâmetro zero;

h) peça da bandeira verde seguida das peças de início de repetição com parâmetro três, tocar tambor com parâmetro zero, fim de repetição e tocar tambor com parâmetro um;

i) peça da bandeira verde seguida das peças de início de repetição com parâmetro três, tocar tambor com parâmetro zero, tocar tambor com parâmetro um e fim de repetição 
Figura 38: Conjunto de peças testadas no teste do reconhecimento de marcadores

a)

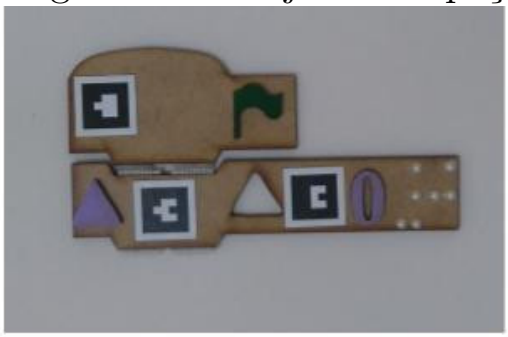

d)

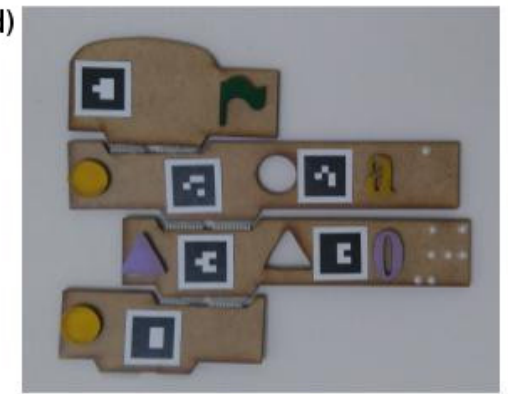

g)

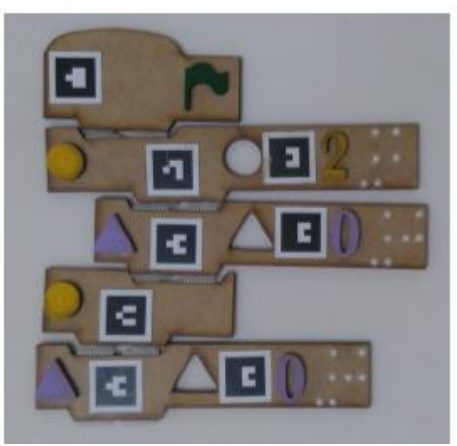

b)

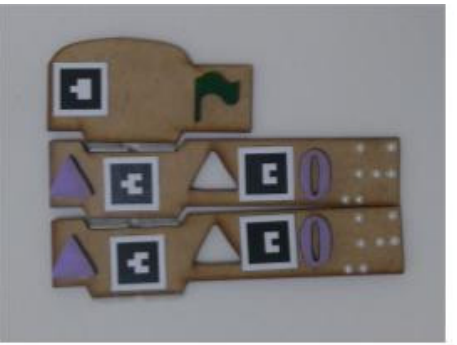

e)

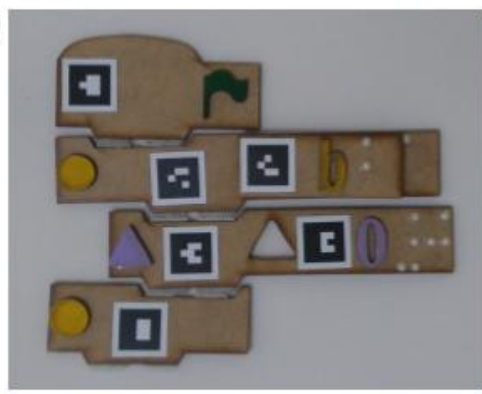

h)

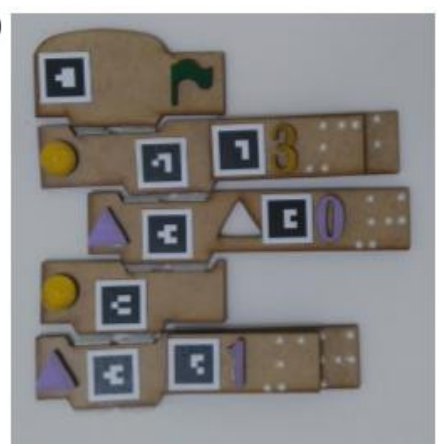

c)

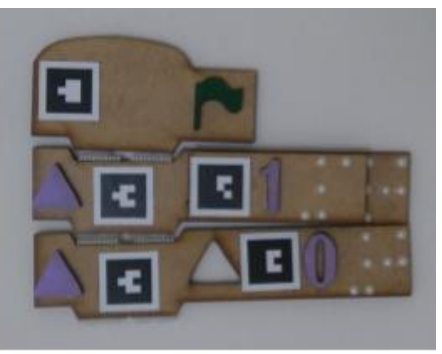

f)

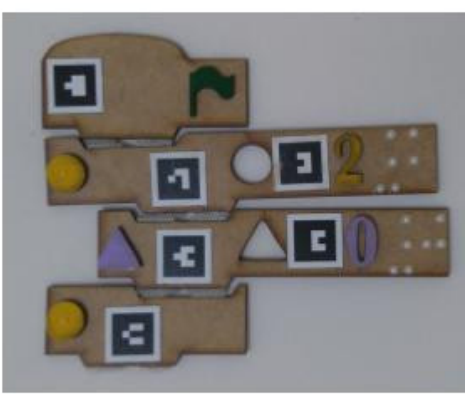

i)

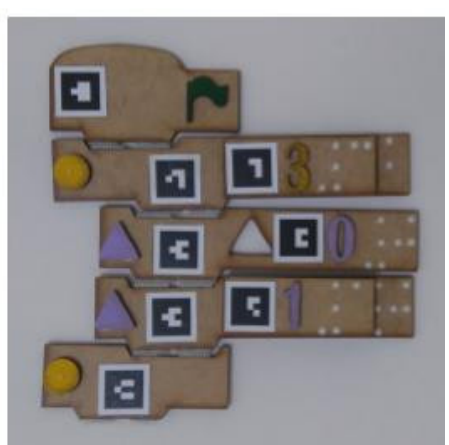

Fonte: Elaborada pela autora 
Todos os códigos testados seguiram o seguinte padrão:

1. o código era montado na área de código;

2. o protótipo era executado pelo browser e a permissão para utilizar a webcam era cedida;

3. o console do browser era aberto e esperava-se uns 20 segundos para checagem dos erros de reconhecimento;

4. a tecla espaço era apertada para geração dos blocos no Scratch;

5. um marcador era obstruído para checar se o console avisava da falta deste marcador;

6. o teste era refeito atualizando a página pelo menos 3 vezes.

\subsubsection{Considerações}

Os testes 1, 3, 4, 5 e 9 funcionaram sem erros de reconhecimento. No teste 2, em alguns casos, as primeiras listas de reconhecimento possuem dois zeros, um no início e outro no fim. Estes erros não atrapalham a utilização do protótipo já que em poucos segundos as listas passam a ficar corretas.

Quando o teste 6 foi feito, as primeiras listas de reconhecimento só constavam o marcador de parâmetro da peça de repetição. Isto também durou poucos segundos e as listas voltaram a ficar corretas. Este mesmo erros de reconhecimento de parâmetro ocorreu nos testes 7, com um dos parâmetros da peça "tocar tambor", e 8, com o parâmetro zero da peça "tocar tambor".

Os testes demonstram que há erros no reconhecimento, mas que estes erros não atrapalham o funcionamento do protótipo, pois acontecem somente no início da leitura dos marcadores, durando poucos segundos. Estes segundos são irrelevantes em relação ao tempo da criança terminar de montar o código e apertar a tecla de espaço para a execução. 


\section{CONCLUSÕES}

\subsection{Discussão dos principais resultados}

O protótipo do sistema passou por ciclos de testes com usuários: o teste inicial e o teste de usabilidade. Apesar do teste inicial ter envolvido somente participantes videntes, a observação da interação deles com o protótipo foi de grande importância para melhorias no protótipo. Nesta primeira fase de testes, percebeu-se que a forma de identificação das peças são suficientes para a criação de uma programação com elas. Esta percepção também foi mostrada pela opinião dos participantes. Em outras decisões de projeto, modificações se mostraram necessárias. Um exemplo é o encaixe entre as peças de comando, que deve ser muito fácil de ser realizado para que a brincadeira aconteça de maneira exploratória e não tediosa. A falta de algo que prenda as peças entre si pelo encaixe foi percebida e modificada para o teste posterior. De forma geral, os testes desta primeira fase foram muito satisfatórios para a observação do primeiro contato entre o protótipo e os usuários.

Em um segundo momento, após as modificações no protótipo de acordo com as considerações dos testes mencionados e com percepções de profissionais da área de educação especializada, design, tecnologia assistiva e desenho universal, foram realizados testes de usabilidade. Neste caso, duas crianças cegas congênitas participaram e observações muito importantes foram levantadas em relação à usabilidade do sistema para crianças cegas, que não participaram nos primeiros testes.

Uma das observações levantadas foi em relação ao encaixe das peças tanto de comandos quanto de parâmetros. Uma professora da área de educação especializada para crianças com deficiência visual comentou em relação ao primeiro protótipo que há necessidade de fixação entre as peças para facilitar a montagem do código. No segundo protótipo, velcro foi colocado nos encaixes entre as peças de parâmetros, mas esta medida não se mostrou suficiente para manter a montagem do código fixo. As duas crianças participantes dos testes tiveram dificuldades ao tatear o código montado para reconhecimento e ao mudar peças, pois as peças se moviam e bagunçavam o código montado. Este aspecto gerou 
muita frustração para uma das participantes que dizia não querer mudar ou tatear o código porque as pecinhas iriam sair do lugar onde ela havia colocado.

Outra observação levantada foi em relação ao Sistema Braille. Não há uma idade padrão para uma criança cega ter fluência em Braille segundo conversa com uma professora da educação especializada. Desta forma, pensou-se em utilizar um Braille aumentado considerando que as crianças cegas com fluência e sem fluência leriam sem dificuldades, pois é o utilizado no ensino de Braille. Entretanto, os testes mostraram que crianças com fluência no Sistema Braille podem não conseguir ou apresentar lentidão em reconhecer o sistema aumentado. As duas criança participantes dos testes precisaram de ajuda para este reconhecimento embora uma delas tenha dispensado esta ajuda e reconhecido sozinha após algum tempo brincando com o protótipo.

Adicionalmente, foram feitos testes para checagem do reconhecimento de marcadores. Esta checagem tornou-se necessária devido a características particulares exigidas quando se lida com processamento de imagens, principalmente em relação à iluminação do ambiente. Percebeu-se que o reconhecimento tem funcionamento satisfatório quando há somente uma fonte de luz no ambiente que não causa sombras devido aos usuários ou ao suporte da webcam.

\subsection{Recomendações para desenvolvimento de sistema}

O protótipo do sistema apresentou resultados positivos em relação à interação com crianças. Elas brincaram de programar utilizando as peças tangíveis e apesar das dificuldades relatadas, a maioria delas alcançou desempenhos satisfatórios. A participação de crianças cegas foi de grande importância para geração de novos requisitos deste sistema que garantem seu desenho universal.

Entre os requisitos levantados há a necessidade da presença do sistema Braille e da fixação das peças de parâmetros nas peças de comandos e das peças de comandos entre si, mas de uma forma que não atrapalhe a mudança de alguma delas. Isto favorece a exploração de novas possibilidades de código e a depuração, pontos chaves para um ambiente de programação para crianças. Outros requisitos foram levantados de acordo com o que foi encontrado na literatura.

Entre os requisitos encontrados na literatura, pode-se destacar os princípios de desenho do Scratch. O sistema proposto no presente trabalho representa uma nova forma de interação com o Scratch. Os blocos digitais são representados por peças tangíveis e 
movidos manualmente e não por mouse. Sendo uma versão alternativa de interação, os princípios do Scratch se mantêm. Consequentemente, o sistema é mais tinkerable, mais significativo e mais social. Adicionalmente, há requisitos mais gerais relacionados às peças físicas. Estes foram baseados nos trabalhos P-Cube (Kakehashi et al., 2013), CardBot (Barros et al., 2017) e Torino (Thieme et al., 2017) nos aspectos de reconhecimento tátil e visual, com formas e cores diferentes.

Com este sistema sendo uma linguagem tangível, pode-se concluir que crianças podem brincar juntas (Suzuki e Kato, 1993) e se beneficiar desta aprendizagem em grupo (Thieme et al. 2017). Desta forma, é importante que o sistema tenha Desenho Universal, pois crianças cegas e videntes estão juntas nas salas de aulas e podem brincar e aprender juntas. Assim deve-se evitar ao máximo tecnologias que as segreguem, preferindo a utilização de tecnologias assistivas para apoiar a interação de crianças com deficiências mais graves.

Também é importante destacar que as escolhas do protótipo foram feitas levando em consideração a facilidade de reprodução do sistema e baixo custo, como é o caso da escolha por reconhecimento de imagens. O sistema tem código aberto e pode ser utilizado e personalizado por professores em salas de aulas ou por outros em ambientes informais. Assim pode-se escolher outras formas de reconhecimento de peças, como o Radio-Frequency Identification (RFID) utilizado em um sistema encontrado na literatura, e também outros materiais para as peças.

O objetivo principal desta pesquisa foi investigar o tema, propor, desenvolver e testar um sistema para incluir crianças cegas em atividades de introdução à programação. Concluiu-se com esta pesquisa que este sistema deve ser um ambiente de linguagem de programação tangível e deve possuir Desenho Universal. O protótipo desenvolvido é um exemplo de como este sistema pode ser desenvolvido e foi utilizado para encontrar requisitos mais específicos com relação à usabilidade além dos já encontrados na literatura. Portanto a contribuição deste trabalho foi levantar as características de ambientes de programação desenvolvidos para crianças com deficiência visual, desenvolver um sistema a partir destas características levantadas e, considerando o contexto inclusivo das salas de aula, propor recomendações a partir dos testes com crianças cegas e videntes.

\subsection{Dificuldades enfrentadas e limitações da pesquisa}

O maior desafio deste projeto foi sua característica multidisciplinar, incluindo design e educação. Na área de design, foram desafios: criar os desenhos das peças para serem 
cortadas, escolher o material das peças, as formas de encaixe e transposição das peculiaridades do Scratch para o tangível, como foi o caso dos blocos extensíveis no digital. Na área da educação, o maior desafio foi o desenvolvimento dos testes já que eles incluem aprendizados de conceitos e interação com crianças com deficiência.

Com relação à engenharia, o maior desafio foi a mudança constante de versões do Scratch 3.0, pois ele ainda está em desenvolvimento. Mudanças no código eram necessárias para a integração com versões mais novas. Outro desafio foi a escolha do reconhecimento de imagens, que apesar de ser a melhor solução supondo sua fácil reprodução por outras pessoas sem conhecimento técnico, apresentou requisitos a mais, como a necessidade de condições determinadas de iluminação no ambiente.

Também ocorreram limitações principalmente em relação ao número restrito de testes. Apesar disto, as recomendações se mantém já que foram embasadas também em opiniões de profissionais das áreas abrangidas pelo presente trabalho e por trabalhos correlatos.

\subsection{Trabalhos Futuros}

Um trabalho futuro de grande importância é a realização de testes de grande escala, como workshops, pois estes proporcionariam maiores informações sobre a interação com o protótipo do sistema e levariam a identificar mais requisitos. De forma mais específica, pode-se separar os trabalhos futuros em áreas:

\section{- Design}

É necessário aprofundar os testes de usabilidade para modificar o desenho das peças desta linguagem tangível de desenho universal a fim de que seja mais fácil de ser entendida e manipulada pelas crianças.

- Educação

Na área de educação, é interessante pensar em como seriam as atividades utilizando o protótipo do sistema com o intuito de várias crianças aprenderem juntas. Pode-se pensar também em criar micromundos baseados nos Micromundos Scratch, em que cada atividade utiliza determinadas peças. Estes micromundos são uma solução para o problema da limitação do número de peças que pode ser utilizado já que são peças tangíveis e ocupam espaço físico.

- Engenharia

Alguns desafios pendentes são: 
- Continuar o desenvolvimento do código para integrar ao Scratch 3.0 em sua versão final, ainda não lançada;

- Permitir que os projetos criados na linguagem tangível sejam compartilhados na comunidade Scratch.

- Melhorar o sistema para que inclua crianças com baixa visão e outras deficiências, como:

* deficiência física que afeta os membros superiores, pois estes membros são os utilizados para a interação com a interface;

* deficiência auditiva, já que a última versão do protótipo possui respostas somente auditivas para a saída do código de programação. 


\section{REFERÊNCIAS}

BARROS, R. P. et al. Cardbot-assistive technology for visually impaired in educational robotics: Experiments and results. IEEE Latin America Transactions, IEEE, v. 15, n. 3, p. 517-527, 2017.

BRENNAN, K.; BALCH, C.; CHUNG, M. Creative computing. Harvard Graduate School of Education, 2014.

CAPOVILLA, D.; KRUGEL, J.; HUBWIESER, P. Teaching algorithmic thinking using haptic models for visually impaired students. In: IEEE. Learning and Teaching in Computing and Engineering (LaTiCE), 2013. [S.1.], 2013. p. 167-171.

CHAWLA, K. et al. Dr. wagon: a'stretchable'toolkit for tangible computer programming. In: ACM. Proceedings of the 12th international conference on interaction design and children. [S.1.], 2013. p. 561-564.

CUTURI, L. F. et al. From science to technology: Orientation and mobility in blind children and adults. Neuroscience \& Biobehavioral Reviews, Elsevier, v. 71, p. 240-251, 2016.

DEMING, W. Out of the Crisis. [S.l.]: Cambridge: MIT Press, 1986.

ELOY, A. A. da S.; LOPES, R. de D.; ANGELO, I. M. Uso do scratch no brasil com objetivos educacionais: uma revisão sistemática. RENOTE (Revista Novas Tecnologias na Educação), v. 15, n. 1, 2017. ISSN 1679-1916. Disponível em: 〈http://dx.doi.org/10.22456/1679-1916.75164〉.

Fundação Dorina Nowill para Cegos. O que é deficiência? 2017. Disponível em: 〈https: //www.fundacaodorina.org.br/a-fundacao/deficiencia-visual/o-que-e-deficiencia/ $\rangle$. Acesso em: 04 de dezembro de 2017.

GORDON, M.; ACKERMAnN, E.; BREAZEAL, C. Social robot toolkit: Tangible programming for young children. In: ACM. Proceedings of the Tenth Annual ACM/IEEE International Conference on Human-Robot Interaction Extended Abstracts. [S.1.], 2015. p. $67-68$.

HORN, M. S.; JACOB, R. J. Tangible programming in the classroom with tern. In: ACM. CHI'O'7 extended abstracts on Human factors in computing systems. [S.l.], 2007. p. 1965-1970.

HOWARD, A. M.; PARK, C. H.; REMY, S. Using haptic and auditory interaction tools to engage students with visual impairments in robot programming activities. IEEE transactions on learning technologies, IEEE, v. 5, n. 1, p. 87-95, 2012.

KAKEHASHI, S. et al. P-cube: Block type programming tool for visual impairments. In: IEEE. Technologies and Applications of Artificial Intelligence (TAAI), 2013 Conference on. [S.l.], 2013. p. 294-299. 
KANE, S. K.; BIGHAM, J. P. Tracking@ stemxcomet: teaching programming to blind students via $3 \mathrm{~d}$ printing, crisis management, and twitter. In: ACM. Proceedings of the 45th ACM technical symposium on Computer science education. [S.1.], 2014. p. 247-252.

KOUSHIK, V.; LEWIS, C. An accessible blocks language: Work in progress. In: ACM. Proceedings of the 18th International ACM SIGACCESS Conference on Computers and Accessibility. [S.1.], 2016. p. 317-318.

LEWIS, J. R.; SAURO, J. The factor structure of the system usability scale. In: SPRINGER. International conference on human centered design. [S.1.], 2009. p. 94-103.

LUDI, S. Position paper: Towards making block-based programming accessible for blind users. In: IEEE. Blocks and Beyond Workshop (Blocks and Beyond), 2015 IEEE. [S.1.], 2015. p. $67-69$.

LUDI, S. L.; ELLIS, L.; JORDAN, S. An accessible robotics programming environment for visually impaired users. In: ACM. Proceedings of the 16th international ACM SIGACCESS conference on Computers \& accessibility. [S.1.], 2014. p. 237-238.

MALONEY, J. et al. Scratch: a sneak preview [education]. In: IEEE. Creating, connecting and collaborating through computing, 2004. Proceedings. Second International Conference on. [S.1.], 2004. p. 104-109.

MALONEY, J. et al. The scratch programming language and environment. ACM Transactions on Computing Education (TOCE), ACM, v. 10, n. 4, p. 16, 2010.

MCNERNEY, T. S. Tangible programming bricks: An approach to making programming accessible to everyone. Tese (Doutorado) - Massachusetts Institute of Technology, 1999.

MILNE, L. R. Blocks4all: making block programming languages accessible for blind children. ACM SIGACCESS Accessibility and Computing, ACM, n. 117, p. 26-29, 2017.

RESNICK, M. et al. Scratch: programming for all. Communications of the ACM, ACM, v. 52, n. 11, p. 60-67, 2009.

RESNICK, M.; SILVERMAN, B. Some reflections on designing construction kits for kids. In: ACM. Proceedings of the 2005 conference on Interaction design and children. [S.1.], 2005. p. 117-122.

SDH-PR. Cartilha do Censo 2010 - Pessoas com Deficiência. Luiza Maria Borges Oliveira / Secretaria de Direitos Humanos da Presidência da República (SDR/PR) / Secretaria Nacional de Promoção dos Direitos da Pessoa com de Ciência (SNPD) / CoordenaçãoGeral do Sistema de Informações sobre a Pessoa com Deficiência; Brasília : SDHPR/SNPD, 2012. Disponível em: 〈http://www.pessoacomdeficiencia.gov.br/app/sites/ default/files/publicacoes/cartilha-censo-2010-pessoas-com-deficienciareduzido.pdf). Acesso em: 04 de dezembro de 2017.

SDH-PR. Resultados Preliminares da Amostra - Censo 2010. 2017. Disponível em: $\langle$ http://www.pessoacomdeficiencia.gov.br/app/indicadores/censo-2010〉. Acesso em: 04 de dezembro de 2017.

STORY, M. F. Maximizing usability: the principles of universal design. Assistive technology, Taylor \& Francis, v. 10, n. 1, p. 4-12, 1998. 
SUZUKI, H.; KATO, H. Algoblock: a tangible programming language, a tool for collaborative learning. In: Proceedings of 4 th European Logo Conference. [S.l.: s.n.], 1993. p. 297-303.

THIEME, A. et al. Enabling collaboration in learning computer programing inclusive of children with vision impairments. In: ACM. Proceedings of the 2017 Conference on Designing Interactive Systems. [S.l.], 2017. p. 739-752.

TSUR, M. Scratch Microworlds: introducing novices to scratch using an interest-based, open-ended, scaffolded experience. Tese (Doutorado) - Massachusetts Institute of Technology, 2017.

ULLMER, B. A. Models and mechanisms for tangible user interfaces. Tese (Doutorado) - Massachusetts Institute of Technology, 1997.

WAGNER, A. et al. Raising the awareness of accessibility needs in block languages. In: ACM. Proceedings of the 47th ACM Technical Symposium on Computing Science Education. [S.1.], 2016. p. 497-497.

WANG, D. et al. E-block: a tangible programming tool for children. In: ACM. Adjunct proceedings of the 25th annual ACM symposium on User interface software and technology. [S.1.], 2012. p. 71-72. 


\title{
APÊNDICE A - GUIA PARA COLETA DE DADOS DO TESTE INICIAL
}

\author{
Nome: \\ Idade:
}

Tabela 1: Tabela de avaliação pelo observador do desempenho na realização das atividades pelo usuário no teste inicial

\begin{tabular}{|l|l|l|l|l|}
\hline Atividade & Insatisfatório & Satisfatório & $\begin{array}{l}\text { Muito Satis- } \\
\text { fatório }\end{array}$ & Anotações \\
\hline $\begin{array}{l}\text { 1:Reconhecimento } \\
\text { das peças }\end{array}$ & & & & \\
\hline $\begin{array}{l}\text { 2:Como juntar as } \\
\text { peças }\end{array}$ & & & & \\
\hline $\begin{array}{l}\text { 3:Executando } \\
\text { uma programação }\end{array}$ & & & & \\
\hline $\begin{array}{l}\text { 4:A peça de re- } \\
\text { petição }\end{array}$ & & & & \\
\hline
\end{tabular}

\section{Questionário para o participante}

1. Você gostou da brincadeira? Por quê?

2. Você achou difícil reconhecer as peças? Por quê?

3. Você achou fácil juntar as peças? Por quê?

4. Foi fácil executar o programa que você criou? Por quê?

5. Foi difícil entender o programa que você criou? Por quê?

6. A peça de repetição é fácil de ser usada? Por quê? 


\title{
APÊNDICE B - GUIA PARA COLETA DE DADOS DO TESTE DE USABILIDADE
}

\author{
FOLHA GUIA PARA DADOS DO TESTE
}

Nome:

Idade:

Tabela 2: Tabela de avaliação pelo observador do desempenho na realização das atividades pelo usuário no teste de usabilidade

\begin{tabular}{|l|l|l|l|l|}
\hline Atividade & Insatisfatório & Satisfatório & $\begin{array}{l}\text { Muito Satis- } \\
\text { fatório }\end{array}$ & Anotações \\
\hline 1: Sequência & & & & \\
\hline 2: Decisão & & & & \\
\hline 3: Repetição & & & & \\
\hline
\end{tabular}




\section{APÊNDICE C - QUESTIONÁRIO DE USABILIDADE}

Participante

Nome:

Idade:

Questionário

1. Eu acho que eu gostaria de brincar de programação mais vezes.

\begin{tabular}{|l|l|l|l|l|}
\hline Discordo totalmente & Discordo & Não sei & Concordo & Concordo totalmente \\
\hline
\end{tabular}

2. Eu achei a brincadeira muito difícil.

\begin{tabular}{|l|l|l|l|l|}
\hline Discordo totalmente & Discordo & Não sei & Concordo & Concordo totalmente \\
\hline
\end{tabular}

3. Eu achei fácil brincar de programação.

\begin{tabular}{|l|l|l|l|l|}
\hline Discordo totalmente & Discordo & Não sei & Concordo & Concordo totalmente \\
\hline
\end{tabular}

4. Eu acho que eu precisaria de ajuda para ser capaz de brincar de programação.

\begin{tabular}{|l|l|l|l|l|}
\hline Discordo totalmente & Discordo & Não sei & Concordo & Concordo totalmente \\
\hline
\end{tabular}

5. Eu achei que as várias peças de programação eram fáceis de serem utilizadas.

\begin{tabular}{|l|l|l|l|l|}
\hline Discordo totalmente & Discordo & Não sei & Concordo & Concordo totalmente \\
\hline
\end{tabular}


6. Eu achei que tinham muitos problemas na brincadeira que me atrapalharam enquanto eu brincava.

\begin{tabular}{|l|l|l|l|l|}
\hline Discordo totalmente & Discordo & Não sei & Concordo & Concordo totalmente \\
\hline
\end{tabular}

7. Eu imagino que a maioria das pessoas aprenderiam a brincar de programação muito rapidamente.

\begin{tabular}{|l|l|l|l|l|}
\hline Discordo totalmente & Discordo & Não sei & Concordo & Concordo totalmente \\
\hline
\end{tabular}

8. Eu achei a brincadeira muito confusa.

\begin{tabular}{|l|l|l|l|l|}
\hline Discordo totalmente & Discordo & Não sei & Concordo & Concordo totalmente \\
\hline
\end{tabular}

9. Eu me senti muito confiante enquanto brincava de programação.

\begin{tabular}{|l|l|l|l|l|}
\hline Discordo totalmente & Discordo & Não sei & Concordo & Concordo totalmente \\
\hline
\end{tabular}

10. Eu achei muito difícil entender como brincar de programação.

\begin{tabular}{|l|l|l|l|l|}
\hline Discordo totalmente & Discordo & Não sei & Concordo & Concordo totalmente \\
\hline
\end{tabular}




\section{APÊNDICE D - ESTRUTURA DO CÓDIGO DESENVOLVIDO}

O código está armazenado em

$\langle$ https://github.com/isabela-angelo/scratch-tangible-blocks〉, A versão presente no branch Develop é a última do protótipo. A versão do primeiro teste está no branch test_1. Para executar o protótipo em sua última versão deve-se abrir um terminal na pasta onde se encontra o código fonte do projeto e dar o comando 'npm start'. Este comando sobe em um servidor local o projeto e, para interagir com ele, abra um browser e vá para 'http://localhost:8073/playground/'. Uma janela aparecerá para autorização e escolha da câmera ligada ao seu computador.

Pode-se detalhar o protótipo em relação ao código desenvolvido para atingir as funcionalidades mencionadas. Para ver o código fonte, abra o projeto a pasta do projeto e vá para 'scratch-tangible-blocks/src/playground/TangBlocks/'. Neste local há os arquivos da biblioteca (artookit*.js), uma pasta chamada Data e também um aquivo chamado gotcha.js, que é o código criado pela autora e pode ser visto no Apêndice D. Os arquivos em JavaScript anteriormente mencionados foram adicionados ao arquivo 'src/playground/index.html' para que sejam executados junto ao Scratch. Outras modificações foram feitas em outros arquivos do projeto original do scratch-vm (〈https: //github.com/LLK/scratch-vm〉), mas, em grande parte, são de utilidade somente para depuração e não para o funcionamento do protótipo. 


\section{APÊNDICE E - CÓDIGO DESENVOLVIDO}

O código abaixo é a parte principal de programação desenvolvida neste trabalho. A linguagem de programação é JavaScript, pois é a linguagem utilizada na interface do Scratch 3.0. O código utiliza a biblioteca ARToolKit.js para reconhecer os marcadores presentes nas peças tangíveis e, a partir deste reconhecimento, obtém o número do marcador e sua posição. O próximo passo é a criação de uma lista dos números dos marcadores ordenadas segundo suas posições, que é utilizada para criação do código em blocos digitais no Scratch.

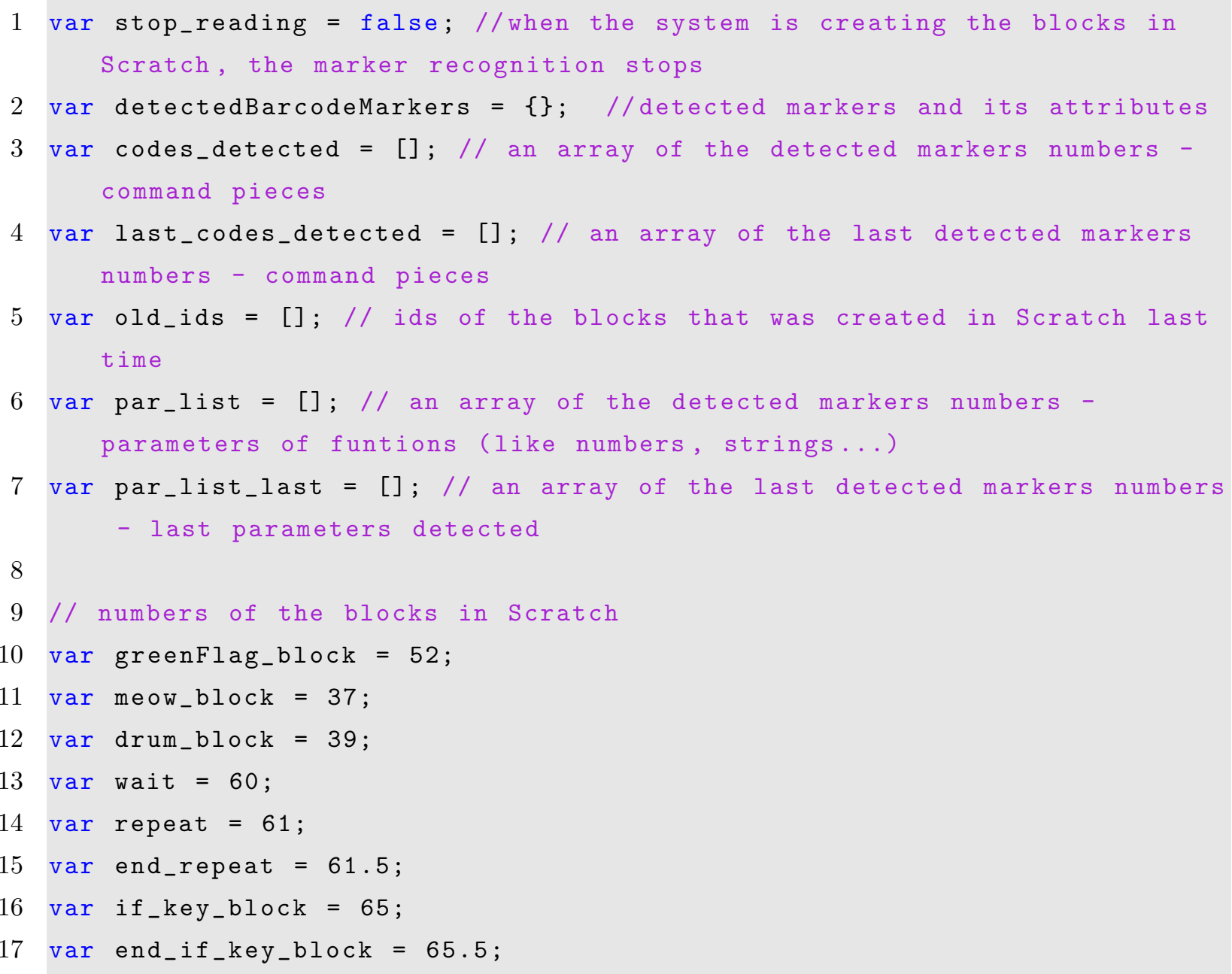




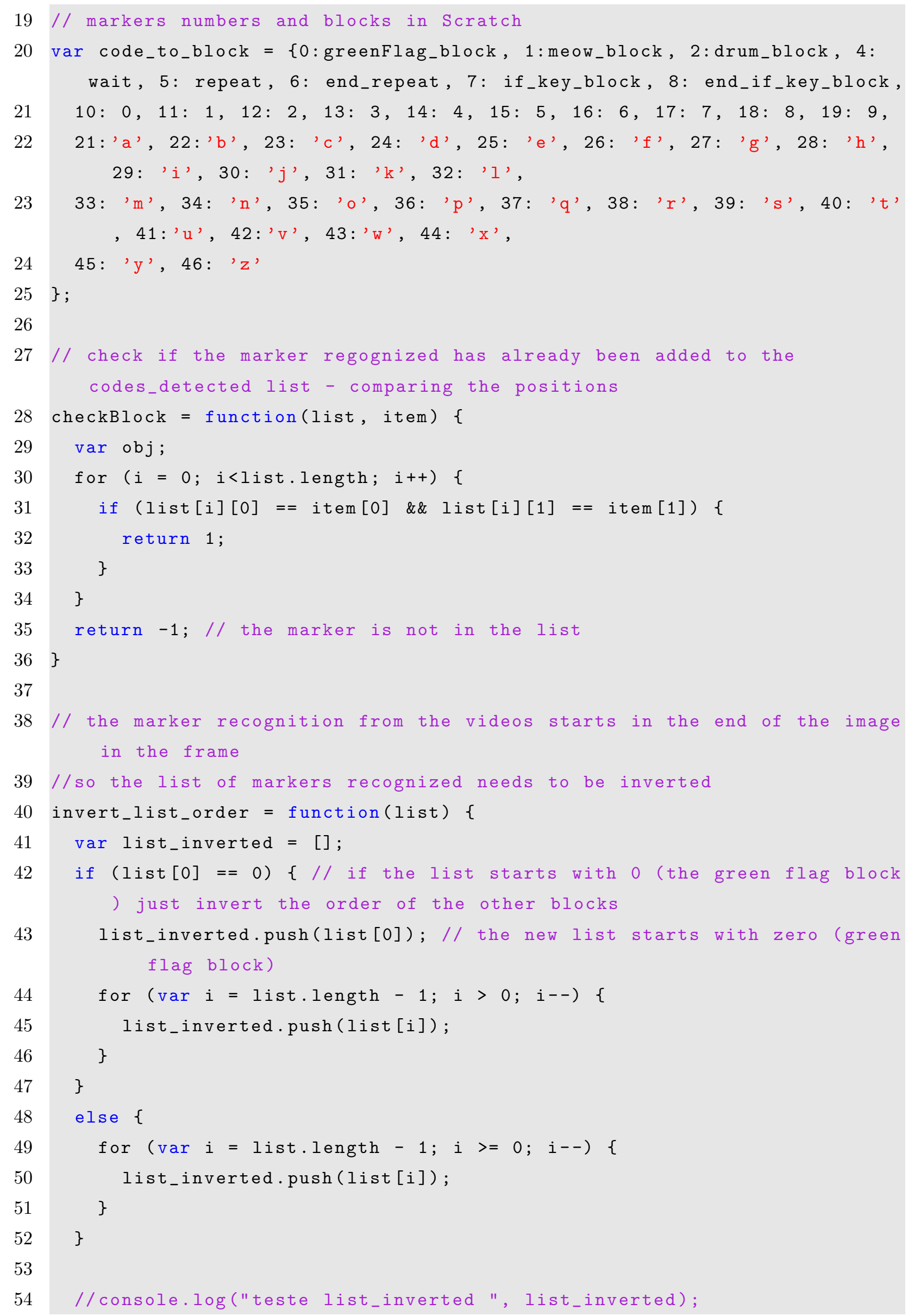


55

$57\}$

58

59

60

61

62

63

64

$66 \quad$

67

68

69

70

81

87

88

89

90

91

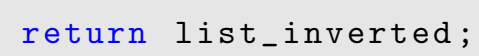




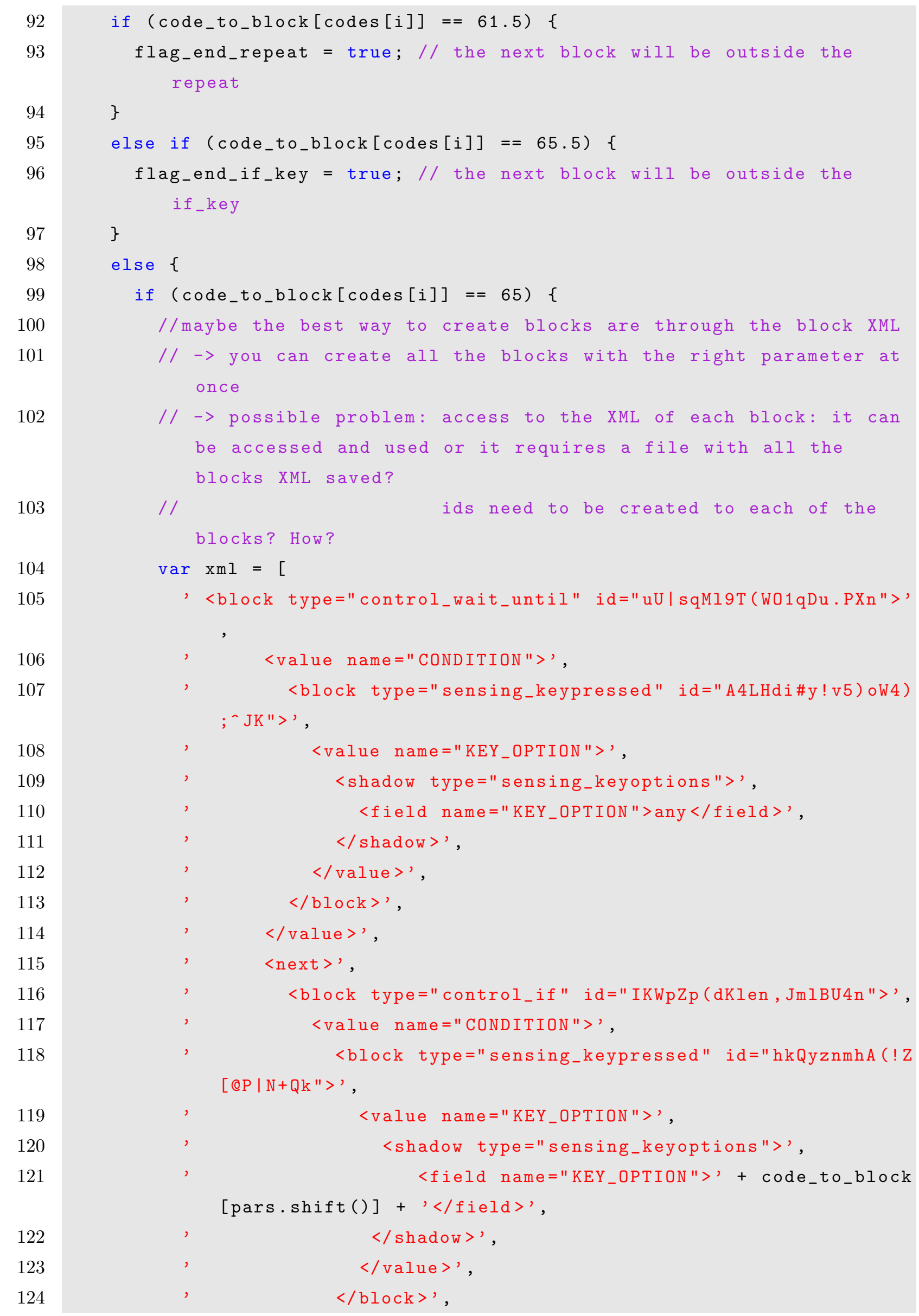




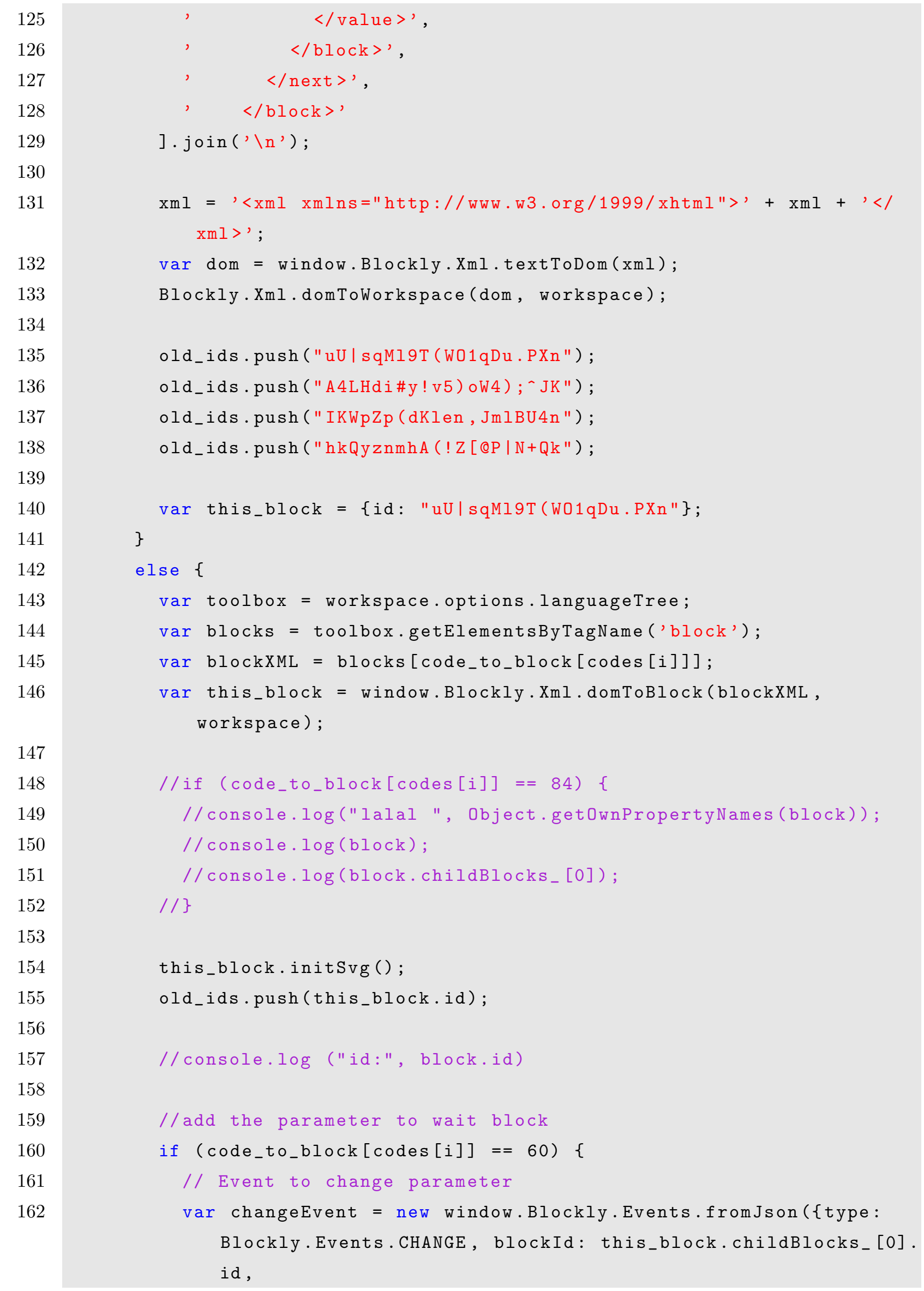


element: "field", name: "NUM", newValue: code_to_block [pars.shift()]\}, workspace);

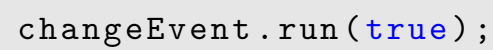


element: "field", name: "NUM", newValue: code_to_block [pars.shift()]\}, workspace);

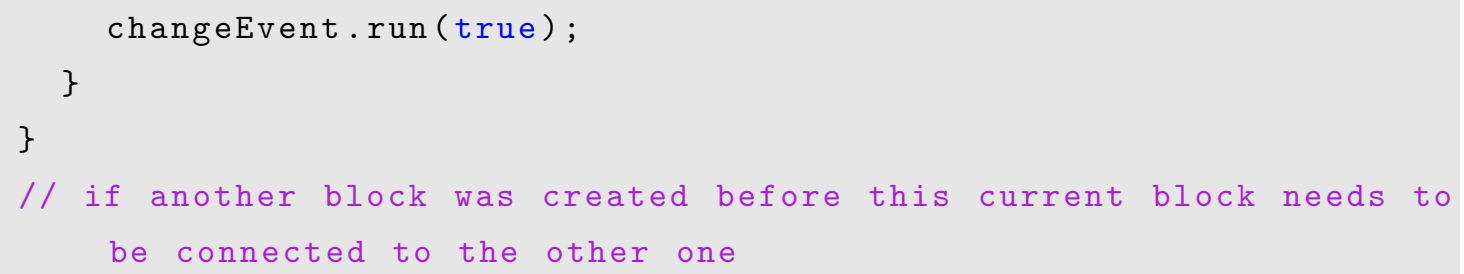




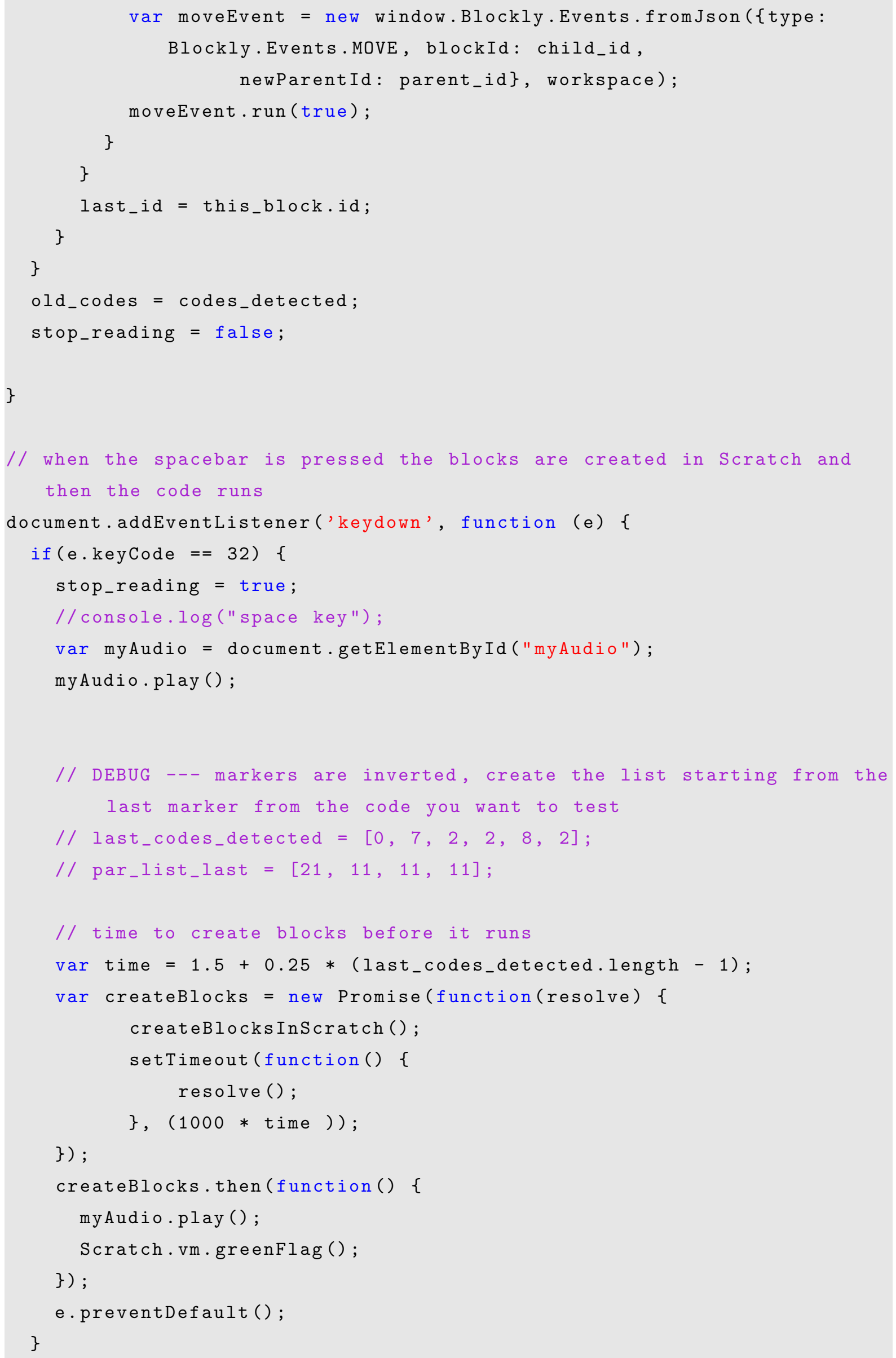




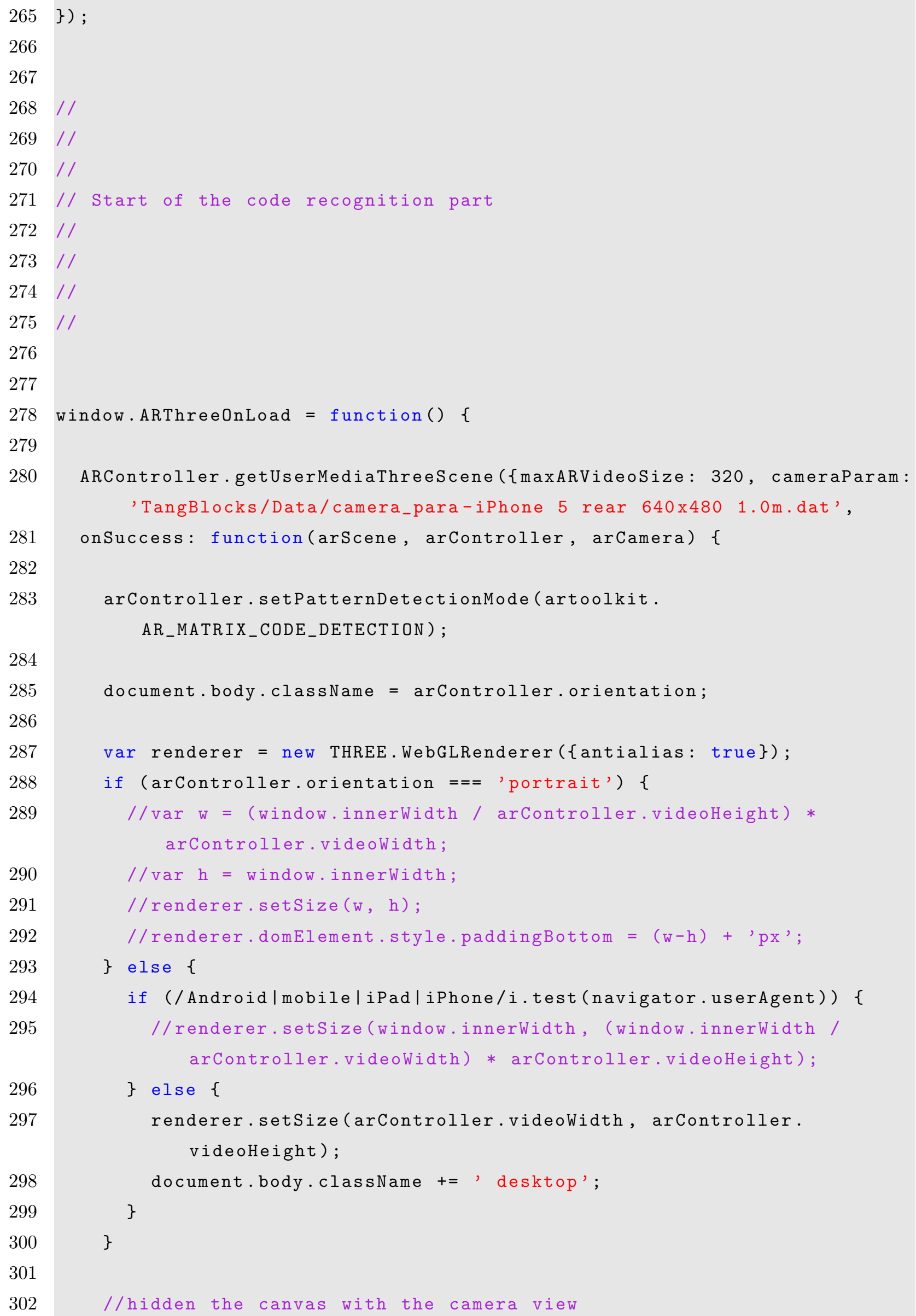




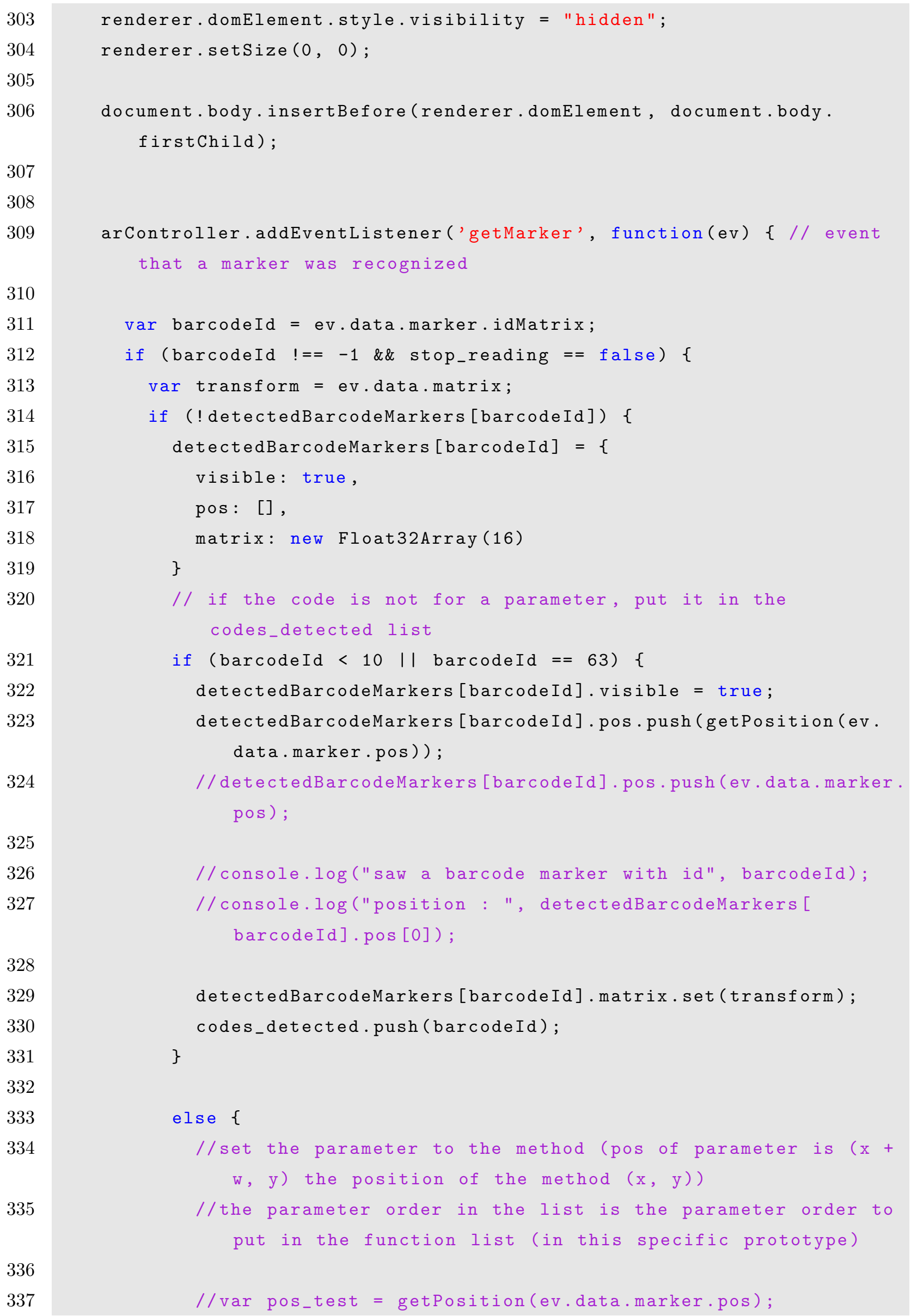




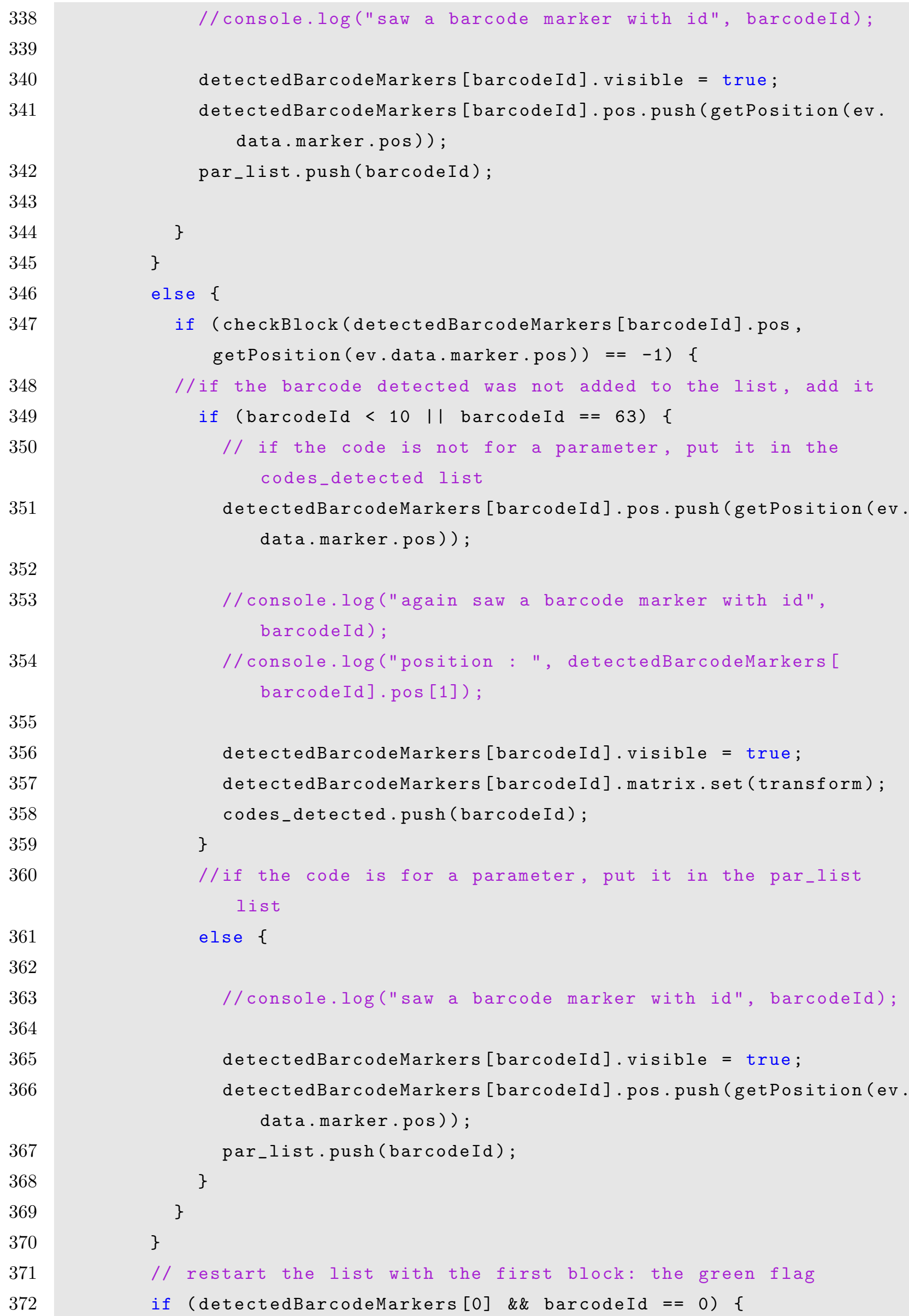




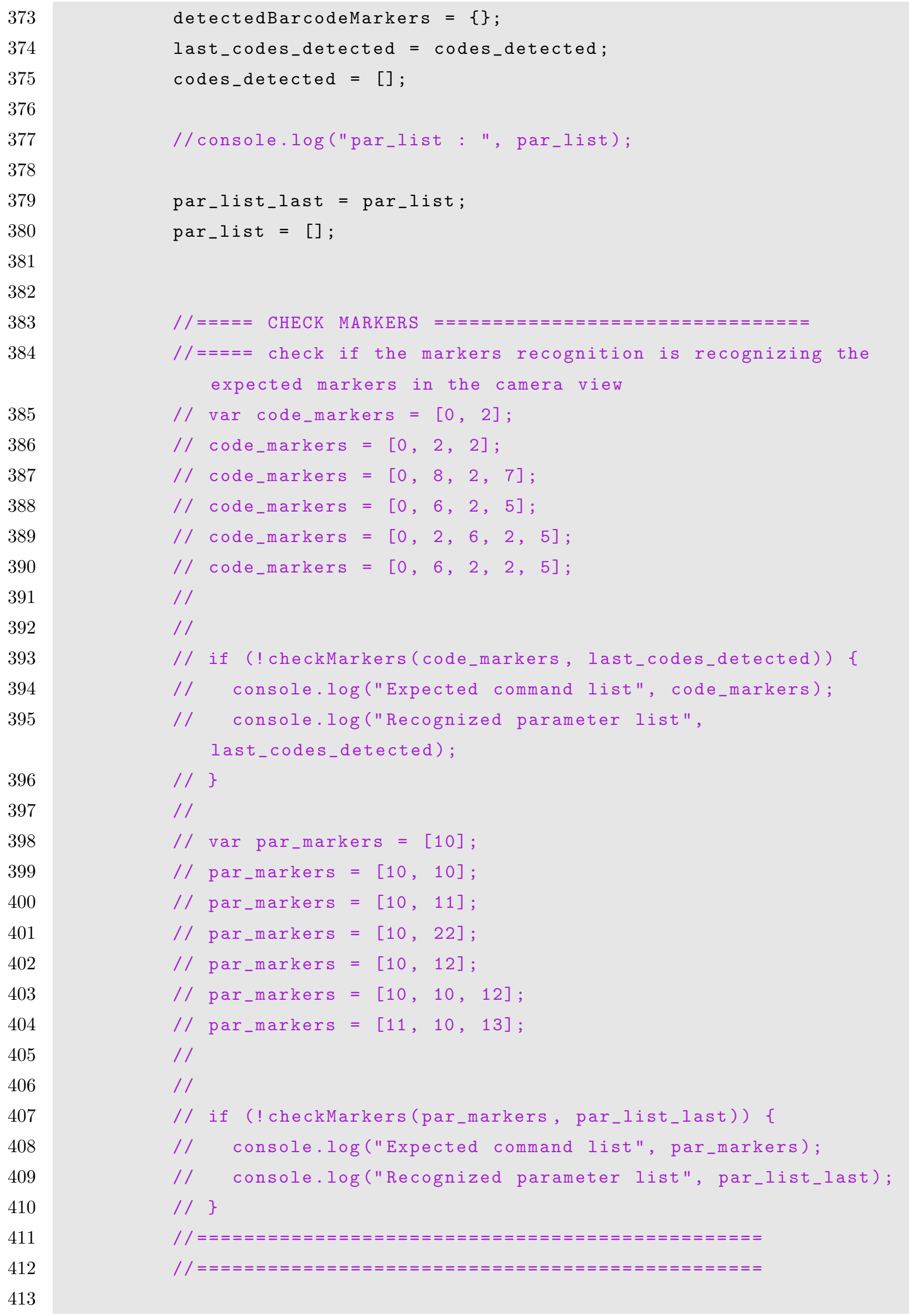




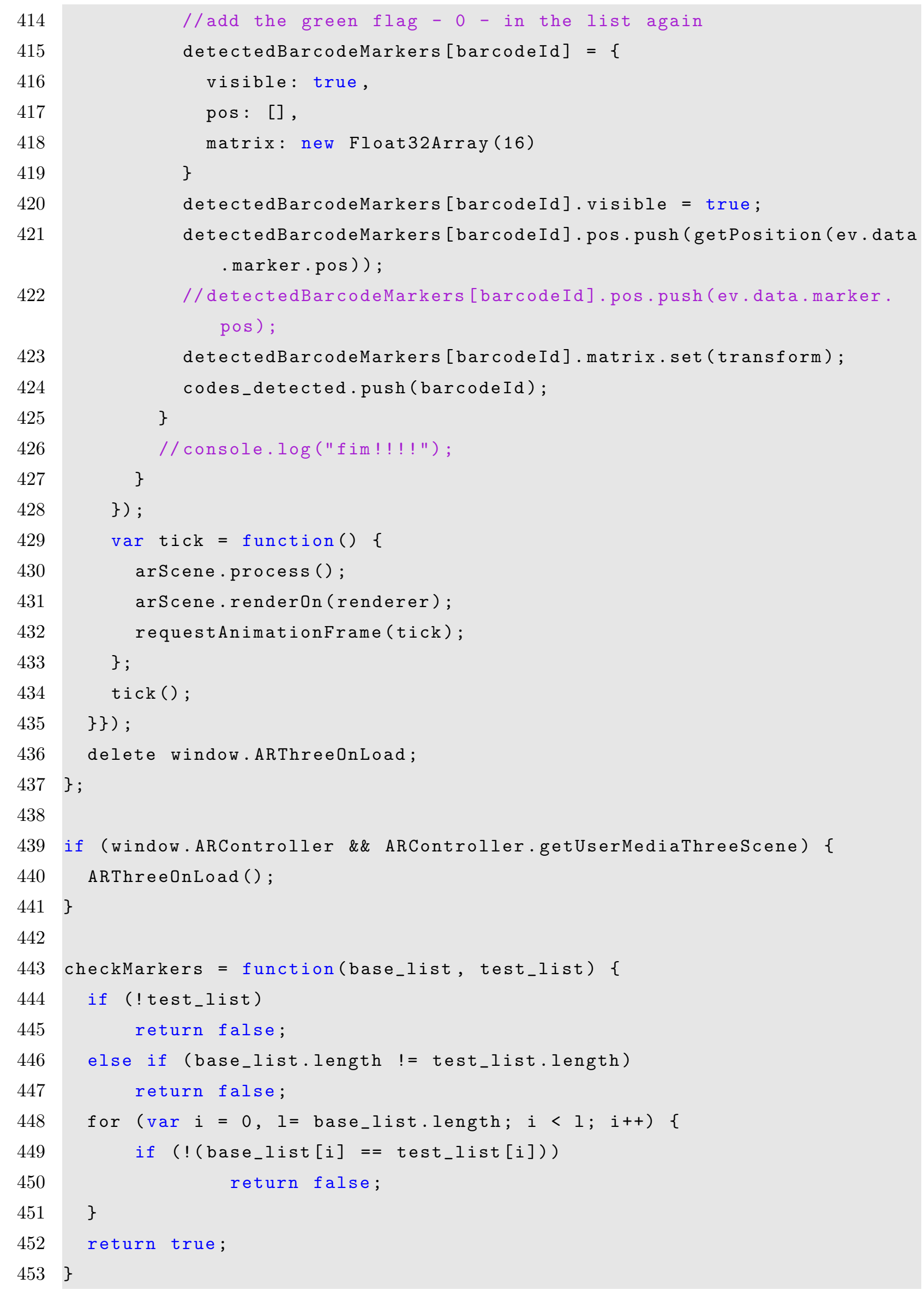


ANEXO A - PARECER CONSUBSTANCIADO DO CEP 


\section{A.1 Parecer inicial}

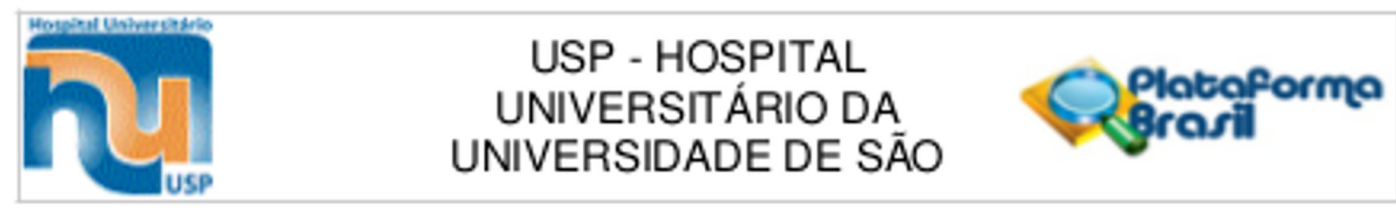

\section{PARECER CONSUBSTANCIADO DO CEP}

\section{DADOS DO PROJETO DE PESQUISA}

Titulo da Pesquisa: Atividades de programaçăo de computador com Crianças com Deficiencia Visual

Pesquisador: ISABELA MART INS ANGELO

Área Temática:

Versäo: 1

CAAE: 67842917.7 .0000 .0076

Instituiçäo Proponente:UNIVERSIDADE DE SAO PAULO

Patrocinador Principal: FUND COORD DE APERFEICOAMENTO DE PESSOAL DE NIVEL SUP

DADOS DO PARECER

Número do Parecer: 2.072 .531

\section{Apresentaçäo do Projeto:}

O sistema desenvolvido neste programa de mestrado é uma interface tangivel para programaçăo de computador focado na inclusăo de crianças $c m$ deficiência visual. Essa interface é baseada em peças tangiveis parecidas com peças de quebra-cabeças, $\infty \mathrm{m}$ cores, formas e reconhecimento tátil, que representam funçðes de programaçăo.

Haverá dois tipos de teste para o projeto: inicial e outro de usabilidade. O teste inicial com usuário consiste em uma brincadeira com atvidades que explorem as caracteristicas do sistema em questäo. Estas atividades estăo listadas abaixo:

Reconhecimento das peças: Todas as peças, menos a peça de repetiçăo, serăo apresentadas e a criança deve conseguir perceber qua is săo diferentes e quais săo iguais e dizer o porquê;

Como juntar as peças: a criança deve conseguir unir as peças do sistema e reconhecer a ordem de montagem tacilmente. Somente as peças escolhidas pelas crianças dentre as anteriormente apresentadas serăo usadas;

Executando uma programaçăo: a criança deve executar a programaçăo que deseja de forma rápida e entender a saída de ssa programaçăo em relaçăo à programaçăo teita. A montagem pode ser a mesma da anterior ou outra diferente. Depois da montagem a criança deverá explicar a saida esperada e comparar com a real saida da programaçăo. Como executar a programaçăo será

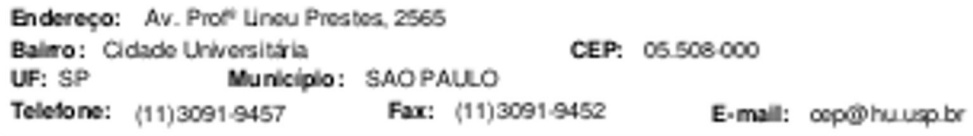




\section{USP - HOSPITAL UNIVERSITÁRIO DA UNIVERSIDADE DE SÃO}

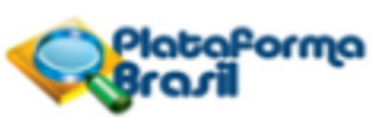

Coniruacio de Pracor : 207253 t

explicado no inicio da atvidade;

A peça de repetçăo: a criança deve compreender a montagem de um programa com a peça de repetiçăo. Essa peça pode ser acrescentada à programaçăo anterior ou à uma nova. A criança deve perceber e explicar a diferença em relaçăo à utilizaçăo dessa nova peça e entender como seu design de encapsulamento funciona.

Para realizar o teste inicial seräo necessárias até 6 crianças, sendo algumas com defciència visual e outras sem essa defciência. Elas participarăo individualmente e realizarăo as atividades anteriormente descritas na mesma sequência que foram apresentadas. Durante os testes a pesquisadora col herá intormaçoes em relaçāo ao desempenho nas atividades em uma escala de 1 a 3 , sendo 1 insatsfatório, 2 satisfatónio e 3 muilo satisfałório, e anotaços de obsenvaçðes relevantes da interaçăo da criança com o sistema. Também será realizado um questionário feito oralmente com a criança ao fim das atividades. Esse que stionário abordará as mesmas quesibes que o roteiro, mas com termos mais acessivels para as crianças e com perguntas abertas. O guia para coleta de dados durante o teste está em anexo.

Com base nessas informaçbes, o sistema poderá ser aprimorado e novas deciscos de projeto seráo teitas. Após isso, novos testes serăo elaborados focando em usabilidade e, desta vez, com duas crianças interagindo ao mesmo tempo com o sistema. Espera-se com isso, atender as necessidades dos usuários.

\section{Objetivo da Pesquisa:}

Hipólese: - É possivel desenvolver uma intertace de programaçăo de computador que permile que crianças com ou sem deficiência visual programem juntas.

Objetivo Primário: - Desenvolver uma interface para incluir crianças com deficienncia visual em atvidades de programaçăo de computador.

Objetivo Secundário: - Pesquisar soluçces para pessoas $\infty \mathrm{m}$ deficiêndia visual na área de programaçăo; Pesquisar os produtos voltados para ensino de programaçäo; Selecionar requisitos para o siste ma de acordo com as pesquisas realizadas; Conceber, projetar, implementar alternativas de interface; Estabelecer testes com os atores envolvidos no sistema (alunos, professores e profissionais de tecnologia assistiva); Obter aprovaçăo do Cominê de Ética em Pesquisa; Realizar testes qualitativos e quanttativos; Analisar os resultados obtidos com as alte mativas desenwolvidas; Publicar e disseminar as con tribuiçoes cientificas e tecnológicas obtidas a partir do trabalho.

Avaliaçäo dos Riscos e Beneficios:

Crtério de Inclusăo: - 3 Crianças com deficiència visual (6 a 12 anos); 3 Crianças sem deficiência

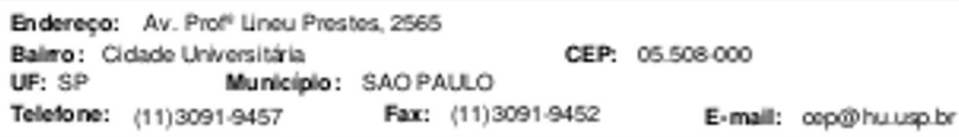




\section{USP - HOSPITAL UNIVERSITÁRIO DA UNIVERSIDADE DE SÃO}

Coninumio de Preor : 2072.53

visual (6 a 12 anos)

Riscos: - Năo há riscos na utilizaçăo do sistema desenvolvido, uma vez que apresenta uma interface semelhante à brinquedos de peças de montar para crianças.

Beneficios: - Esta pesquisa é importante no contexto de educaçăo inclusiva visando crianças com deficiência visual. Por meio dessa interface, essas crianças poderăo brincar conjuntamente com outras. mesmo que sem deficiéncia visual, e se beneficiarem das atvidades de programaçäo, desenvolvendo o pensamento lógico, criatividade e trabaho em grupo.

Comentários e Consideraçōes sobre a Pesquisa:

Muito interessante visando a inclusăo de deficientes visuais.

Consideraçōes sobre os Termos de apresentaçäo obrigatória:

TELA e TCLE impecávels na feltura.

Recomendaçōes:

Năo existem recomendaçbes para o projeto em tela.

\section{Conclusōes ou Pendências e Lista de Inadequaçōes:}

Nă existem.

Consideraçôes Finais a critério do CEP:

O projeto tol apresentado e aprovado na reunilio de hoje. Lembramos que cabe ao pesquisador elaborar e apresentar a este Comitê, relatónios parciais e final, de acordo com a Resoluçăo n² $466 / 2012$ do Conselho Nacional de Saúde, inciso XI.2, letra "d".

Este parecer fol elaborado baseado nos documentos abaixo relacionados:

\begin{tabular}{|c|c|c|c|c|}
\hline Tipo Documento & Arquivo & Postagem & Autor & Situaçă \\
\hline $\begin{array}{l}\text { Declaraçáo de } \\
\text { Pesquisadores }\end{array}$ & Ded_Beneficios_Pesq_isabela_pdf & $\begin{array}{c}03: 05 / 2017 \\
10: 04: 24 \\
\end{array}$ & $\begin{array}{l}\text { Wilma Monteiro } \\
\text { Frésca }\end{array}$ & Aceilo \\
\hline $\begin{array}{l}\text { Declaraçáo de } \\
\text { Pesquilsadores }\end{array}$ & Ded_Compromisso_Pesq_isabela.pdf & $\begin{array}{c}03 / 05 / 2017 \\
10: 04,05 \\
\end{array}$ & $\begin{array}{l}\text { Wilma Monteiro } \\
\text { Frésca }\end{array}$ & Aceilo \\
\hline Cronograma & Cronograma_Pesq_Isabela.polf & $\begin{array}{c}03 / 05 / 2017 \\
10: 03: 43 \\
\end{array}$ & $\begin{array}{l}\text { Wilma Monteiro } \\
\text { Frésca }\end{array}$ & Aceilo \\
\hline Orçamento & Orcamento_Pesq_isabela.pdf & $\begin{array}{c}03 / 05 / 2017 \\
10: 0324 \\
\end{array}$ & $\begin{array}{l}\text { Wilma Monteiro } \\
\text { Frésca }\end{array}$ & Aceilo \\
\hline Outros & CadastroHU_Pesq_isabela.pdf & $\begin{array}{c}03 / 05 / 2017 \\
10: 02.58 \\
\end{array}$ & $\begin{array}{l}\text { Wilma Monteiro } \\
\text { Frésca }\end{array}$ & Aceilo \\
\hline $\begin{array}{l}\text { Informaçoes Básicas } \\
\text { do Proleto }\end{array}$ & $\begin{array}{l}\text { PB_INFORMAÇOES_BASICAS_DO_P } \\
\text { ROJETO } 811069 . p d f\end{array}$ & $\begin{array}{c}26 / 04 / 2017 \\
13: 19: 58 \\
\end{array}$ & & Aceilo \\
\hline
\end{tabular}

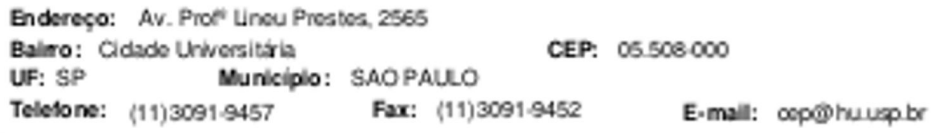




\section{USP - HOSPITAL \\ UNIVERSITÁRIO DA UNIVERSIDADE DE SÃO}

Coniruacio do Procor : 2072.531

\begin{tabular}{|c|c|c|c|c|}
\hline Outros & scan0003.polf & $\begin{array}{c}26 / 04 / 2017 \\
13: 18.56\end{array}$ & $\begin{array}{l}\text { ISABELA MART INS } \\
\text { ANGELO }\end{array}$ & Acelio \\
\hline Outros & scan0002.polf & $\begin{array}{c}26 / 04 / 2017 \\
13: 18: 15\end{array}$ & $\begin{array}{l}\text { ISABELA MART INS } \\
\text { ANGELO }\end{array}$ & Aceilo \\
\hline $\begin{array}{l}\text { Declaraçáa de } \\
\text { Insituiçăo e } \\
\text { Infraestrutura }\end{array}$ & scan0001.polf & $\begin{array}{c}26 / 04 / 2017 \\
13: 17: 39\end{array}$ & $\begin{array}{l}\text { ISABELA MART INS } \\
\text { ANGELO }\end{array}$ & Aceilo \\
\hline Folha de Rosio & scan.pdf & $\begin{array}{c}26 / 04 / 2017 \\
13: 16.55\end{array}$ & $\begin{array}{l}\text { ISABELA MART INS } \\
\text { ANGELO }\end{array}$ & Aceito \\
\hline Outros & AtestadodeMatriculacomdiscipinas poff & $\begin{array}{c}24 / 04 / 2017 \\
20: 3859\end{array}$ & $\begin{array}{l}\text { ISABELA MART INS } \\
\text { ANGELO }\end{array}$ & Aceito \\
\hline Outros & lattes polf & $\begin{array}{c}24 / 04 / 2017 \\
13: 44: 58 \\
\end{array}$ & $\begin{array}{l}\text { ISABELA MART INS } \\
\text { ANGELO }\end{array}$ & Aceilo \\
\hline Outros & $\begin{array}{l}\text { FOLHAGUIAPARADADOSDOTESTE.pd } \\
f\end{array}$ & $\begin{array}{c}24 / 04 / 2017 \\
13: 37: 16\end{array}$ & $\begin{array}{l}\text { ISABELA MART INS } \\
\text { ANGELO }\end{array}$ & Acelio \\
\hline $\begin{array}{l}\text { Projeto Detal hado / } \\
\text { Brochura } \\
\text { Investioador }\end{array}$ & ProjetodePesquisa.pdf & $\begin{array}{c}24 / 04 / 2017 \\
13: 32: 44\end{array}$ & $\begin{array}{l}\text { ISABELA MART INS } \\
\text { ANGELO }\end{array}$ & Acelio \\
\hline $\begin{array}{l}\text { TCLE / Termos de } \\
\text { Assentimento / } \\
\text { Justificativa de } \\
\text { Auskincia }\end{array}$ & TCLE.pdf & $\begin{array}{c}24 / 04 / 2017 \\
13: 32: 19\end{array}$ & $\begin{array}{l}\text { ISABELA MART INS } \\
\text { ANGELO }\end{array}$ & Acelio \\
\hline $\begin{array}{l}\text { TCLE / Termos de } \\
\text { Assentimento / } \\
\text { Justificativa de } \\
\text { AusAincia }\end{array}$ & TALE pdif & $\begin{array}{c}24 / 04 / 2017 \\
13: 31: 58\end{array}$ & $\begin{array}{l}\text { ISABELA MART INS } \\
\text { ANGELO }\end{array}$ & Aceito \\
\hline
\end{tabular}

Situaçäo do Parecer:

Aprovado

Necessita Apreciaçäo da CONEP:

Năo

SAO PAULO, 19 de Maio de 2017

\section{Assinado por: \\ Mauricio Seckler}

(Coordenador)

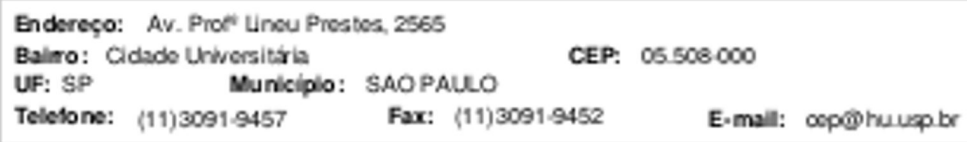




\section{A.2 Emenda 1}

USP - HOSPITAL
UNIVERSITÁRIO DA
UNIVERSIDADE DE SÃO

\section{PARECER CONSUBSTANCIADO DO CEP}

\section{DADOS DA EMENDA}

Titulo da Pesquisa: Afividades de programaçăo de computadơ com Crianças com Deficència Visual

Pesquisador: ISABELA MARTINS ANGELO

Área Temática:

Versăo: 2

CAAE: 67842917.7 .0000 .0076

Instituiçăo Proponente:UNIVERSIDADE DE SAO PAULO

Patrocinador Principal: FUND COORD DE APERFEICOAMENTO DE PESSOAL DE NIVEL SUP

\section{DADOS DO PARECER}

Número do Parecer: 2.226 .752

\section{Apresentaçăo do Projeto:}

Trata-se de uma emenda ao proje to, pois na execuçăo detectou-se grande dificuldade em captar participantes no formato original (crianças). Agora pretende-se incluir adultos. EXCERPTO: Alguns documentos e textos foram modificados em relaçăo aos participantes da pesquisa. O último envio considerava que os testes seriam feixos com crianças com e sem deficència visual. is to foi modifcado nesta emenda, passando a considerar como panicipantes crianças e também adulios videntes ou com deficiéncia visual devido à dificuldade da autora em agendar testes especticamente com crianças com defoüncia visual.

Objetivo da Pesquisa:

Alterado com inclusăo de aduitos.

Aval iaçắo dos Riscos e Beneficios:

Inaterados.

Comentários e Consider açóes sobre a Pesquisa:

Mantém-se de grande interesse.

Consideraçđes sobre os Termos de apresentaçăo obrigatór ia:

Semelhantes.

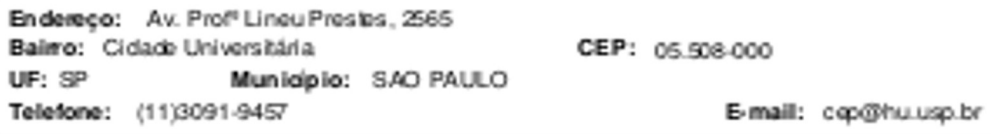




\section{USP - HOSPITAL \\ UNIVERSITÁRIO DA UNIVERSIDADE DE SÃO}

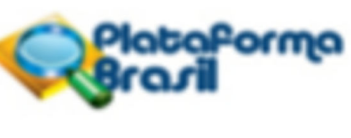

Coninucha da Paracar: 2223 is2

\section{Recomendaçes:}

Não existem.

Conclusdes ou Pendéncias e Lista de Inadequaçdes:

Não existem.

Consideraçdes Finais a critério do CEP:

Este parecer fol elaborado baseado nos documentos abaixo relacionados:

\begin{tabular}{|c|c|c|c|c|}
\hline Tipo Documento & Arquino & Postagem & Autor & Situaçăo \\
\hline $\begin{array}{l}\text { Intormaçðes Básicas } \\
\text { do Projeto }\end{array}$ & $\begin{array}{l}\text { PB_INFORMAÇOEES_BÁSICAS_972266 } \\
\text { E1.pdt }\end{array}$ & $\begin{array}{c}04,08 / 2017 \\
11: 27: 17 \\
\end{array}$ & & Aceito \\
\hline $\begin{array}{l}\text { Projeto Detalnado / } \\
\text { Brochura } \\
\text { hnestigador }\end{array}$ & Projeto_de_Pesquisapdít & $\begin{array}{c}04,08 / 2017 \\
11: 26.00\end{array}$ & $\begin{array}{l}\text { ISABELA MART INS } \\
\text { ANGELO }\end{array}$ & Aceto \\
\hline Outros & $\begin{array}{l}\text { FOLHA_GUIA_PARA_DADOS_DO_TE } \\
\text { STE_pdf }\end{array}$ & $\begin{array}{l}04,08 / 2017 \\
11: 25: 31\end{array}$ & $\begin{array}{l}\text { ISABELA MART INS } \\
\text { ANGELO }\end{array}$ & Aceto \\
\hline $\begin{array}{l}\text { TCLE / Termos de } \\
\text { Assentimento / } \\
\text { Justificativa de } \\
\text { Ausäncia }\end{array}$ & TCLE pdt & $\begin{array}{l}04,08 / 2017 \\
11: 19: 26\end{array}$ & $\begin{array}{l}\text { ISABELA MART INS } \\
\text { ANGELO }\end{array}$ & Aceto \\
\hline Cronograma & cronograma pdt & $\begin{array}{c}04,08 / 2017 \\
11: 18: 44 \\
\end{array}$ & $\begin{array}{l}\text { ISABELA MART INS } \\
\text { ANGELO }\end{array}$ & Aceito \\
\hline $\begin{array}{l}\text { Dedaraçăo de } \\
\text { Pesquisadores }\end{array}$ & Ded_Beneficios_Pesq_Isabelapdit & $\begin{array}{c}03,05 / 2017 \\
10.04: 24 \\
\end{array}$ & $\begin{array}{l}\text { Wilma Monteiro } \\
\text { Fréssca }\end{array}$ & Aceito \\
\hline $\begin{array}{l}\text { Declaraçao de } \\
\text { Pesquisadores }\end{array}$ & Ded_Compromisso_Pesq_isabela_pdt & $\begin{array}{c}03 / 05 / 2017 \\
10,04: 05\end{array}$ & $\begin{array}{l}\text { Wilma Monteiro } \\
\text { Frésca }\end{array}$ & Aceto \\
\hline Orçamento & Orcamento_Pesq_isabelapót & $\begin{array}{c}03 / 05 / 2017 \\
10.03: 24\end{array}$ & $\begin{array}{l}\text { Wilma Monveiro } \\
\text { Frésca }\end{array}$ & Aceto \\
\hline Outros & CadastroHU_Pesq_isabela pát & $\begin{array}{c}03,05 / 2017 \\
10.02 .58\end{array}$ & $\begin{array}{l}\text { Wilma Monteiro } \\
\text { Frésca }\end{array}$ & Aceto \\
\hline Outros & $\operatorname{scan} 0003 . p d$ & $\begin{array}{c}26 / 04 / 2017 \\
13: 18.56 \\
\end{array}$ & $\begin{array}{l}\text { ISABELA MART INS } \\
\text { ANGELO }\end{array}$ & Aceto \\
\hline Outros & $\operatorname{scan} 0002$.pdt & $\begin{array}{c}26,04 / 2017 \\
13: 18: 15 \\
\end{array}$ & $\begin{array}{l}\text { ISABELA MART INS } \\
\text { ANGELO }\end{array}$ & Aceto \\
\hline $\begin{array}{l}\text { Declaraçăo de } \\
\text { Instituiçăo e } \\
\text { Infraestrutura } \\
\end{array}$ & $\operatorname{scan} 0001 . p d t$ & $\begin{array}{c}26,04 / 2017 \\
13: 17: 39\end{array}$ & $\begin{array}{l}\text { ISABELA MART INS } \\
\text { ANGELO }\end{array}$ & Aceito \\
\hline Folina de Rosto & scanpdt & $\begin{array}{c}26,04 / 2017 \\
13: 16.55\end{array}$ & $\begin{array}{l}\text { ISABELA MART INS } \\
\text { ANGELO }\end{array}$ & Aceto \\
\hline Outros & lattes.pd & $\begin{array}{c}24: 04 / 2017 \\
13: 44.58\end{array}$ & $\begin{array}{l}\text { ISABELA MART INS } \\
\text { ANGELO }\end{array}$ & Aceto \\
\hline
\end{tabular}

Situaçăo do Parecer:

Endeçe: Av. Proe" Linou Preaka, 2665

Bairo: Cidad Universtalla

UF: SPP Munioiplo: SRO PAULO

CEP: 05.508000

Telesone: (11)9091-945

Email: coporu uspler 


\section{USP - HOSPITAL UNIVERSITÁRIO DA UNIVERSIDADE DE SÃO}

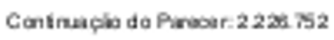

Aprovado

Necessita Apreciaçăo da CONEP:

Năo

SAO PAULO, 18 de Agosto de 2017

Assinado por:

Mauricio Seckler

(Coor denador)

Enderę̧: Av. Prof" Lineu Prestes, 2665

Bairro: Cidad Univorstarla

UF: SP Munidiolo: SRO PALLO

Telesone: (11) $9091-9457$
CEP: 05508000

Emall: cepohusepter 


\section{A.3 Emenda 2}

USP - HOSPITAL
UNIVERSITÁRIO DA
UNIVERSIDADE DE SÃO

\section{PARECER CONSUBSTANCIADO DO CEP}

\section{DADOS DO PROJETO DE PESQUISA}

Título da Pesquisa: Atividades de programação de computador com Crianças com Deficiência Visual

Pesquisador: ISABELA MARTINS ANGELO

Área Temática:

Versão: 3

CAAE: 67842917.7 .0000 .0076

Instituição Proponente: UNIVERSIDADE DE SAO PAULO

Patrocinador Principal: FUND COORD DE APERFEICOAMENTO DE PESSOAL DE NIVEL SUP

DADOS DA NOTIFICAÇÃO

Tipo de Notificação: Envio de Relatório Parcial

Detalhe:

Justificativa:

Data do Envio: 18/11/2017

Situação da Notificação: Parecer Consubstanciado Emitido

\section{DADOS DO PARECER}

Número do Parecer: 2.424.344

\section{Apresentação da Notificação:}

Notificação com a explicação detalhada da necessidade de revisão dos métodos da pesquisa.Também mostra artigo publicado em julho/2017 na revista CINTED/UFRGS

Objetivo da Notificação:

Participaram dos testes indiciais. ou seja,o teste da primeira versão do protótipo, quatro pessoas videntes e sem conhecimento prévio de programação. As idades eram14,9,8 e 7 anos. A criança de 7 anos não fez uso da venda.

A primeira atividade de identificação das peças foi completada sem dificuldade. Já a junção das peças apresentou razoável dificuldade. As de programação apresentaram grande dificuldade.

Avaliação dos Riscos e Benefícios:

Inalterados.

Endereço: Av. Prof $^{2}$ Lineu Prestes, 2565

Bairro: Cidade Universitária

UF: SP Município: SAO PAULO

CEP: $05.508-000$

Telefone: (11)3091-9457

E-mail: cep@hu.usp.br 


\section{USP - HOSPITAL \\ UNIVERSITÁRIO DA UNIVERSIDADE DE SÃO}

Continuação do Parecer: 2.424 .344

\section{Comentários e Considerações sobre a Notificação:}

De grande interesse, pois evidenciou necessidade de realinhamento de métodos. e já conseguiu gerar uma publicação com a revisão de artigos do método "scratch" de programação.

Considerações sobre os Termos de apresentação obrigatória:

Não se aplica.

Recomendações:

Não se aplica.

Conclusões ou Pendências e Lista de Inadequações:

Não se aplica.

Considerações Finais a critério do CEP:

O projeto foi apresentado e aprovado na reunião de hoje.Lembramos que cabe ao pesquisador elaborar e apresentar a este Comitê, relatórios parciais e final, de acordo com a Resolução n² 466/2012 do Conselho Nacional de Saúde, inciso XI.2, letra "d".

Este parecer foi elaborado baseado nos documentos abaixo relacionados:

\begin{tabular}{|l|l|c|l|c|}
\hline \multicolumn{1}{|c|}{ Tipo Documento } & \multicolumn{1}{|c|}{ Arquivo } & Postagem & Autor & Situação \\
\hline Envio de Relatório & rel_parc.pdf & $18 / 11 / 2017$ & ISABELA MARTINS & Postado \\
Parcial & & $20: 06: 07$ & ANGELO & \\
\hline Envio de Relatório & artigo.pdf & $18 / 11 / 2017$ & ISABELA MARTINS & Postado \\
Parcial & & $20: 07: 56$ & ANGELO & \\
\hline
\end{tabular}

\section{Situação do Parecer:}

Aprovado

Necessita Apreciação da CONEP:

Não

SAO PAULO, 08 de Dezembro de 2017

Assinado por:

Mauricio Seckler

(Coordenador)

Endereço: Av. Prof ${ }^{2}$ Lineu Prestes, 2565

Bairro: Cidade Universitária

UF: SP

Município: SAO PAULO

CEP: $\quad 05.508-000$

Telefone: (11)3091-9457

E-mail: cep@hu.usp.br 